Prepared for the U.S. Department of Energy

Under Contract DE-AC05-76RL01830

\title{
ImSET 3.1: Impact of Sector Energy Technologies Model Description and User's Guide
}
MJ Scott
JM Roop
OV Livingston
PJ Balducci
RW Schultz

May 2009 


\title{
DISCLAIMER
}

This report was prepared as an account of work sponsored by an agency of the United States Government. Neither the United States Government nor any agency thereof, nor Battelle Memorial Institute, nor any of their employees, makes any warranty, express or implied, or assumes any legal liability or responsibility for the accuracy, completeness, or usefulness of any information, apparatus, product, or process disclosed, or represents that its use would not infringe privately owned rights. Reference herein to any specific commercial product, process, or service by trade name, trademark, manufacturer, or otherwise does not necessarily constitute or imply its endorsement, recommendation, or favoring by the United States Government or any agency thereof, or Battelle Memorial Institute. The views and opinions of authors expressed herein do not necessarily state or reflect those of the United States Government or any agency thereof.

\author{
PACIFIC NORTHWEST NATIONAL LABORATORY \\ operated by \\ BATTELLE \\ for the \\ UNITED STATES DEPARTMENT OF ENERGY \\ under Contract DE-AC05-76RL01830
}

Printed in the United States of America

Available to DOE and DOE contractors from the

Office of Scientific and Technical Information,

P.O. Box 62, Oak Ridge, TN 37831-0062;

ph: (865) 576-8401

fax: (865) 576-5728

email: reports@adonis.osti.gov

\author{
Available to the public from the National Technical Information Service, \\ U.S. Department of Commerce, 5285 Port Royal Rd., Springfield, VA 22161 \\ ph: (800) 553-6847 \\ fax: (703) 605-6900 \\ email: orders@ntis.fedworld.gov \\ online ordering: http://www.ntis.gov/ordering.htm
}

This document was printed on recycled paper.

$(9 / 2003)$ 


\title{
ImSET 3.1: Impact of Sector Energy Technologies Model Description and User's Guide
}

\author{
MJ Scott \\ JM Roop \\ OV Livingston \\ RW Schultz \\ PJ Balducci
}

May 2009

Prepared for

the U.S. Department of Energy

under Contract DE-AC05-76RL01830

Pacific Northwest National Laboratory

Richland, Washington 99352 


\section{Executive Summary}

As part of measuring the impact of government programs in improving energy efficiency within the nation's infrastructure, the U.S. Department of Energy's Office of Energy Efficiency and Renewable Energy (EERE) is interested in assessing the economic impacts of these programs, specifically as they relate to national employment and wage income. As a consequence, EERE funded Pacific Northwest National Laboratory (PNNL) to develop a simple-to-use method for in-house estimation of economic impacts of individual programs.

This 3.1 version of the Impact of Sector Energy Technologies (ImSET) model represents the next generation of the ImSET model (previous version ImSET 2.0). ImSET was developed in 2005 to estimate the macroeconomic impacts of energy-efficient technology in buildings. In essence, ImSET is a specialpurpose version of the National Benchmark Input-Output (I-O) model that has been modified specifically to estimate the national employment and income effects of the deployment of energy-saving technologies developed by the Office of Energy Efficiency and Renewable Energy (EERE). This version of ImSET uses the U.S. Bureau of Economic Analysis 2002 national input-output table, which is the latest version available. The model has also been moved from the FORTRAN legacy operating environment to a modern $\mathrm{C}++$ code.

ImSET incorporates information developed by each of the EERE offices as part of the requirements of the Government Performance and Results Act. While it does not include the ability to model certain dynamic features of markets for labor and other factors of production featured in the more complex models, for most purposes these excluded features are not critical. ImSET is also easier to use than these extant macroeconomic simulation models. The simplified (I-O) approach embedded in ImSET is credible as long as the assumption holds that relative prices in the economy would not be substantially affected by energy efficiency investments. In most cases, the expected scale of these investments is small enough that neither labor markets nor production cost relationships should seriously affect national prices as the investments are made. The exact timing of impacts on gross product, employment, and national wage income from energy efficiency investments is not well-enough understood that much special insight can be gained from the additional dynamic sophistication of a macroeconomic simulation model. Thus, we believe that this version of ImSET is a cost-effective method for estimating the economic impacts of the development of energy-efficient technologies. 


\section{Acronyms and Abbreviations}

$\begin{array}{ll}\text { BEAR } & \text { Berkeley Energy and Resources } \\ \text { BT } & \text { Building Technologies (Program) } \\ \text { CGE } & \text { computable general equilibrium } \\ \text { DEEPER } & \text { Dynamic Energy Efficiency Policy Evaluation Routine } \\ \text { DOE } & \text { U.S. Department of Energy } \\ \text { EERE } & \text { DOE's Office of Energy Efficiency and Renewable Energy } \\ \text { FTE } & \text { full-time equivalent } \\ \text { GDP } & \text { gross domestic product } \\ \text { GPRA } & \text { Government Performance and Results Act of 1993 } \\ \text { IHP } & \text { integrated heat pump } \\ \text { IMPLAN } & \text { Impact Analysis for Planning (I/O model) } \\ \text { ImSET } & \text { Impact of Sector Energy Technologies } \\ \text { I-O } & \text { input-output } \\ \text { NAICS } & \text { North American Industry Classification System } \\ \text { O\&M } & \text { operations and maintenance } \\ \text { PNNL } & \text { Pacific Northwest National Laboratory } \\ \text { PIRG } & \text { public interest research group } \\ \text { R\&D } & \text { research and development } \\ \text { SAM } & \text { social accounting matrix } \\ \text { TVMI } & \text { Technology Validation and Market Introduction } \\ \text { ZEH } & \text { zero-energy house }\end{array}$





\section{Contents}

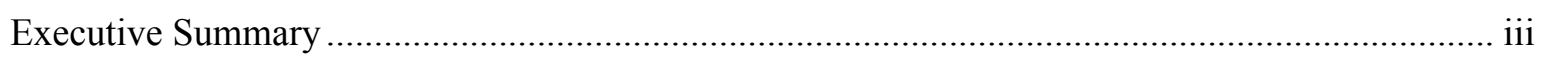

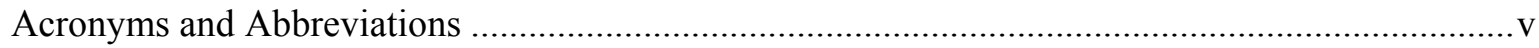

1.0 Introduction: A Method for Assessing Economic Impacts of Energy-Efficient Technologies1.1

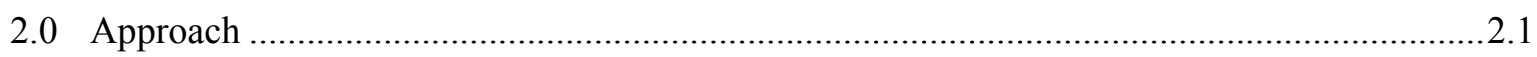

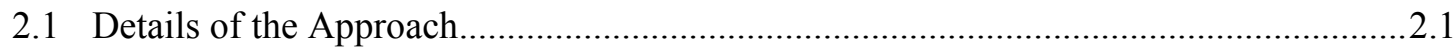

2.2 Components of Impacts: A Once-Only Investment …..................................................

3.0 ImSET 3 Model Results for Sample EERE Programs............................................................ 3.1

3.1 Comparison of Capital and Operating Cost Scenarios for Sample Technologies............ 3.1

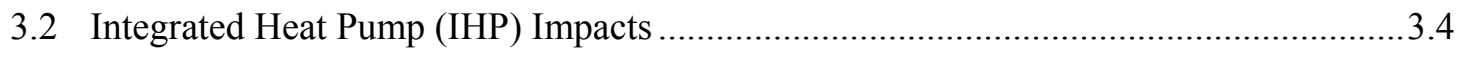

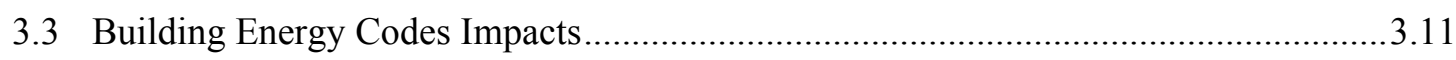

4.0 Comparison with Other Studies: An Update .................................................................... 4.1

4.1 Comparisons of the ImSET Approach to Other Studies .............................................. 4.1

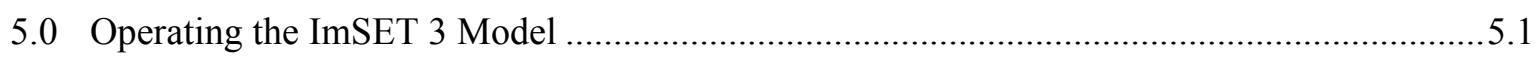

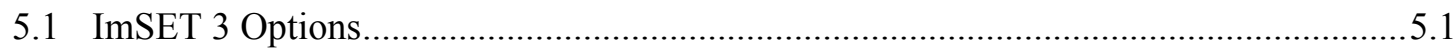

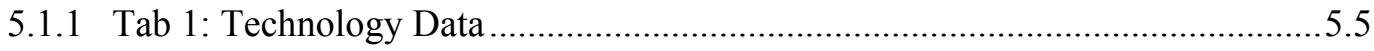

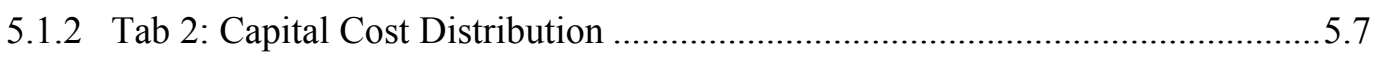

5.1.3 Tab 3: Source of Investment Funds.............................................................. 5.8

5.1.4 Tab 4: Energy and Water Savings Distribution.............................................5.10

5.1.5 Tab 5: Operating and Maintenance Savings Distribution .................................5.11

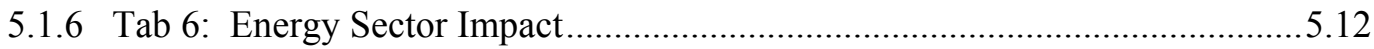

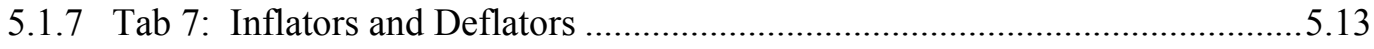

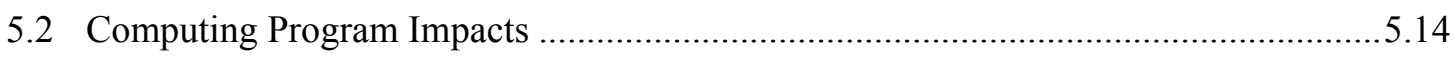

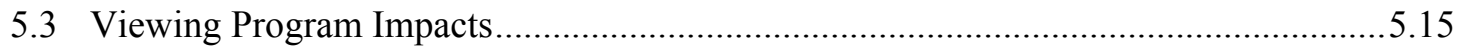

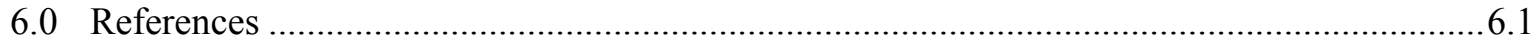

Appendix A Base Cases for Energy-efficiency Technologies ..................................................... 1

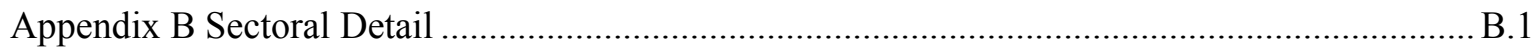

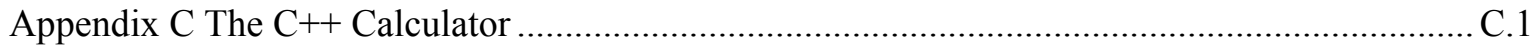




\section{Figures}

Figure 2-1. Process for Analyzing Economic Impact of Energy-efficiency Programs...................2.2

Figure 2-2. Detailed Calculations of the ImSET Model ...........................................................2.4

Figure 2-3. Impact on National Employment of a Hypothetical Once-Only Investment in Appliance Efficiency

Figure 3-1. Incremental Capital Costs by Year for GPRA Metrics Market Scenarios of Integrated

Heat Pump and Building Energy Codes ......................................................................... 3.1

Figure 3-2. Value of Energy Savings by Year Relative to Baseline for GPRA Metrics Market

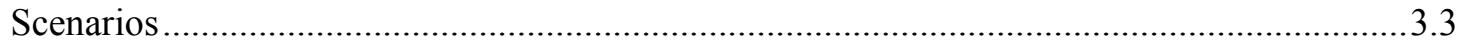

Figure 3-3. Employment Impacts of Investment in Integrated Heat Pumps ................................... 3.5

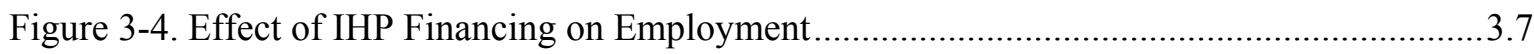

Figure 3-5. Impact of IHP Investment Financing on National Wage Income .................................. 3.9

Figure 3-6. Sensitivity of Impacts on National Wage Income to IHP Investments ........................10

Figure 3-7. Impact on National Employment of Building Energy Codes......................................12

Figure 3-8. Impact of Building Energy Codes Energy Savings on National Wage Income...........3.13

Figure 3-9. Effect of Buildings Energy Codes Financing on Employment Levels........................3.14

Figure 3-10. Effect of Buildings Energy Codes Financing on National Wage Income.................3.15

Figure 5-1. ImSET 3 “Run Selection” Screen ........................................................................... 5.1

Figure 5-2. Run Selection Screen Showing File Menu............................................................. 5.2

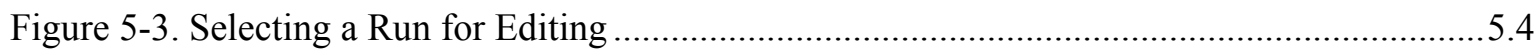

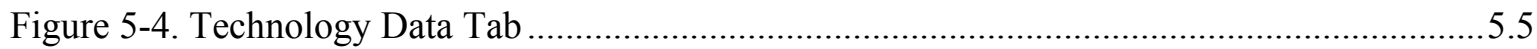

Figure 5-5. Adding to the Technology Options .......................................................................... 5.7

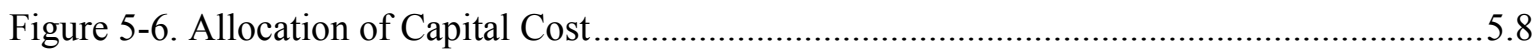

Figure 5-7. Opportunity Cost of Investment Funds ........................................................................

Figure 5-8. Energy/Water Cost Savings Distribution Among Sectors........................................5.11

Figure 5-9. Operations and Maintenance Cost Savings for Residential and Commercial Sector..5.12

Figure 5-10. Impact of Energy Savings on Energy Sector Investments and Released Funds .......5.13

Figure 5-11. Assigning Inflators and Deflators.........................................................................

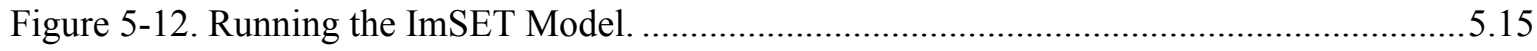

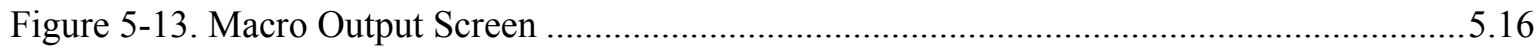

Figure 5-14. Industry Output Screen (Gross Product Impact by Sector) .....................................5.17 


\section{Tables}

Table 2.1. Employment Impact of Hypothetical Once-Only Investment (Thousands)

Table 3.1. Incremental Capital Costs by Year for Integrated Heat Pump and Building Energy Codes (Millions of 2005\$)

Table 3.2. Value of Energy Savings by Year Relative to Baseline for Integrated Heat Pumps and Building Energy Codes (Millions of 2005\$)

Table 3.3. Employment Impacts of Investment in Integrated Heat Pumps (Thousands of

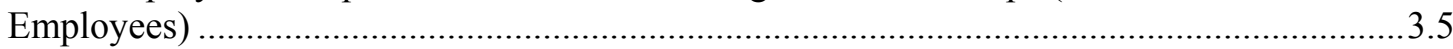

Table 3.4. Effects of IHP Investment Financing on Employment (Thousands of Employees) ........3.7

Table 3.5. Impact of IHP Investment Financing on National Wage Income (Million 2007\$) .........3.9

Table 3.6. Sensitivity of Impacts on National Wage Income to IHP Investments (Million 2007\$).

Table 3.7. Impact on National Employment of Building Energy Codes (Thousands of Employees)

Table 3.8. Impact of Building Energy Codes Energy Savings on National Wage Income (Million $2007 \$)$

Table 3.9. Effect of Buildings Energy Codes Financing on Employment Levels (Thousands of Employees)

Table 3.10. Effect of Buildings Energy Codes Financing on National Wage Income (Million $2007 \$)$

Table 4.1. Employment Multipliers, Nayak, and Selected ImSET 3 Industries (Jobs per Million Dollars of Final Demand)

Table 4.2. Summary of Selected Past Energy-Efficiency Studies 


\subsection{Introduction: A Method for Assessing Economic Impacts of Energy-Efficient Technologies}

As part of measuring the impact of government programs in improving energy efficiency within the nation's infrastructure, the U.S. Department of Energy's (DOE) Office of Energy Efficiency and Renewable Energy (EERE) is interested in assessing the economic impacts of these programs. Therefore, EERE funded Pacific Northwest National Laboratory (PNNL) to develop a simple-to-use method for inhouse estimation of economic impacts of individual programs. After surveying three fundamental methods available to estimate employment and wage income impacts for selected energy-efficiency improvements in the U.S. economy (multipliers, input-output [I-O] models, and macroeconomic simulation models), the I-O approach was selected as the best overall approach (for an overview of each of these approaches, see the original documentation in Scott et al. 1998, 2002). The current 3.1 version of the ImSET model also has features that assess impacts of technologies designed to reduce energy use in industrial processes, transportation, and electric power generation.

Version 3.1 of ImSET uses essentially the same methodology as the previous version (see Roop et al. 2005), but has redefined several sectors of the economy to match the 2002 national I-O table. The major updates to ImSET are as follows:

- The I-O structure is based on the Bureau of Economic Analysis benchmark I-O accounts of the U.S. economy for 2002 (Stewart et al. 2007), specially aggregated for this project to 187 sectors.

- Associated FORTRAN programs have been rewritten in $\mathrm{C}++$.

- The model now automatically generates gross output by sector, used to drive estimates of the demand for capital stock and investment (in monetary terms, and selectively, in physical terms).

The model is a static I-O model, but it allows ample flexibility regarding the types of energyefficiency effects that can be accommodated. For example, ImSET accesses the detailed effects of certain inter-industry purchases. Some energy-efficiency investments will not only reduce the quantities of energy required but also the requirements for labor and other goods and services. In the language of economics, ImSET both accounts for investment-specific increases in productivity and value-added ${ }^{1}$, and the changes to the I-O structure brought about by increased energy efficiency. The improvement in productivity is a desired effect at the core of many investment decisions. Savings in the energy, labor, materials, and services from improved productivity are the source of subsequent rounds of investment and economic growth.

ImSET can be used to estimate the impact of changes in overall efficiency and productivity in the economic sectors that make energy-efficiency investments. As an example, ImSET could apply to an investment by a paper mill in more energy-efficient equipment, the investment by an electric utility in a more efficient plant, or improvements in transportation infrastructure. ImSET also can keep track of the potential increases in value added that result from the improvement in efficiency and can-with

\footnotetext{
${ }^{1}$ Value added is the difference between the value of the output of a sector and the costs of the purchased goods and services that go into the sector. It is mainly composed of labor and proprietor income, retained earnings of corporations, rents, and taxes.
} 
appropriate assumptions - calculate the macroeconomic effects associated with spending of this increased income.

The current version of ImSET has retained its capabilities and its ease of use from previous versions, along the advantage that it provides more theoretically plausible and comprehensive results than alternative models.

The chief drawback of this, or any conventional I-O model, are that 1) they do not provide information on the timing of impacts (e.g., the models do not predict how long an investment in efficiency will take to work its way through the economy); and 2) because no prices or explicit behavioral adjustment mechanisms are typically found in I-O models, no internal market features are present, such as increasing prices for factors of production that automatically limit the size of impacts. In an I-O model, it is assumed that inputs needed for production in each sector are available without limits in constant proportions at constant unit cost. Therefore, when analyzed in an I-O framework, even very large-scale investments that increase the scale of an industry several times over would not encounter either labor or material shortages and associated price increases. In the real world, price increases would dampen the economic response.

While the authors of this report acknowledge the drawbacks to this (I-O model) approach, the scale of most energy-efficiency improvements relative to the overall economy is generally small enough to make the drawbacks inconsequential in their effects. To analyze larger-scale efficiency improvements or investments, a macroeconomic simulation model would be more appropriate because it would account for changes in relative prices that could be expected from very large investment cases. 


\subsection{Approach}

The macroeconomic impacts of EERE programs can be analyzed using the following four-step process, as shown in Figure 2-1. The first three steps are conducted as part of an established analytical process to estimate the benefits of EERE as proposed in the annual Presidential Budget Request. PNNL conducts this analysis of costs and energy savings associated with the Building Technologies Program (BTP) efforts as part of EERE's implementation of the Government Performance and Results Act (GPRA). For more information on this estimation process, see "Projected Benefits of Federal Energy Efficiency and Renewable Energy Programs FY 2008 Budget Request (see especially Appendix G on the Building Technology Program)," which can be found at:

http://www1.eere.energy.gov/ba/pba/program_benefits.html

The fourth step (calculating the economic impacts) has been integrated with the GPRA analysis and has been automated in ImSET. The goal of the model-building process was to create a computerized tool that required only knowledge of ImSET technologies to operate. The national I-O model is a 187 by 187 -sector version of the detailed 430 by 430 benchmark in the U.S. economy I-O table for 2002 (Stewart et al. 2007). The 187 sectors are those deemed most important for analyzing economic impacts of EERE technologies; this structure is sufficiently comprehensive to cover all energy-efficient technologies produced within EERE.

\subsection{Details of the Approach}

The four individual steps are described below.

\section{Step 1. Identify Program Economic Characteristics}

To analyze existing EERE programs, a set of assumptions must be developed concerning the effects in the marketplace when, in the future, more efficient technologies are developed or adopted as a result of current program activities. Relevant program information includes the size of the incremental investment in the technology over time compared with the conventional technology it replaces, corresponding extra energy savings by fuel type in physical and monetary terms (may include additional use of some fuels when one type of fuel replaces another), and non-energy operations savings (if any) in comparison with current (conventional) technology. ${ }^{1}$ Sufficient information of this type currently exists for many EERE technology development and deployment projects as a result of the GPRA metrics process. Two technologies are used as examples in this report; they were chosen to demonstrate different types of programs, as well as some related macroeconomic issues.

- Integrated Heat Pump. The purpose of this DOE program is to develop an air-to-air integrated heat pump (IHP) system that can meet the air heating, cooling, dehumidifying, ventilating, and water heating requirements of a tight-envelope, mechanically ventilated near-zero-energy house (ZEH).

\footnotetext{
${ }^{1}$ Some EERE programs also save water, and there is increased interest in calculating the economic consequences of these savings. ImSet 3.1 allows the user to analyze the impacts of water savings. However, the PNNL development team notes that in the 2002 national I-O table (Stewart et al. 2007), water utilities (which are estimated to be highly capital-intensive) are grouped with solid waste management (a much more labor-intensive industry). The two sectors cannot be separated at this time at the 430 industry level; therefore, calculated water savings impacts on employment may be misleading.
} 
- Building Energy Codes. The DOE program helps define the minimum requirements for new construction (as well as additions and alterations to existing buildings) that are published by national building code organizations. Building energy codes set minimum requirements for building thermal envelope performance, building mechanical system performance, and building lighting and power system performance (commercial buildings only). The DOE program also seeks to accelerate the adoption and improve the compliance of building energy codes by state and local governments.

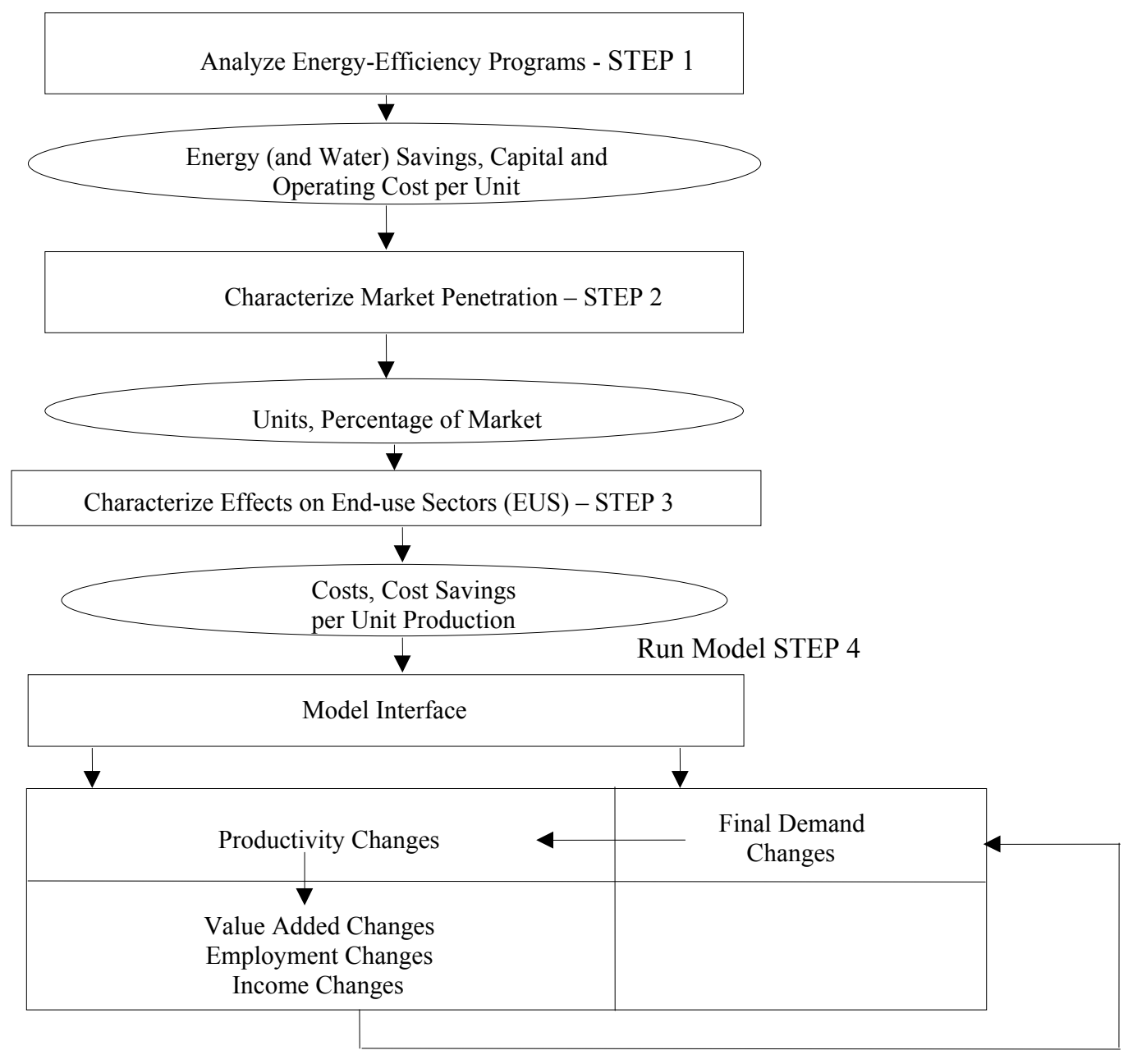

Figure 2-1. Process for Analyzing Economic Impact of Energy-efficiency Programs

These examples demonstrate the impact of programs aimed at both residential technology development and commercial technology development.

\section{Step 2. Characterize Market Penetration of the New Technologies}

Existing research on the size and characteristics of the market (s) being addressed by the EERE technologies or programs is used to estimate market penetration of the new technologies or programs (see Elliott et al. 2004, Elliott et al. 2008). In the GPRA metrics effort, analyst judgment is combined with 
available market information to construct the penetration functions used to model technology or project impacts. The market analyses within the GPRA metrics effort distinguish between technologies or programs that primarily accelerate the adoption of technologies and those programs that would not have been developed or implemented at all in the absence of government funding.

\section{Step 3. Characterize Effects of the EERE Programs on End-Use Sectors (Residential, and Commercial Buildings, Industrial, Transportation and Power Production Sectors)}

The effects of the program on the end-use sectors, using the technology or results of the program, are characterized in Step 3. This step combines analysis from Steps 1 and 2. The model interface is used to match buildings and equipment investments in end-use sectors (e.g., classes of commercial buildings) to the economic sectors that construct, operate or occupy these buildings. This process is necessary because although the EERE programs are organized around the principal energy-consuming sectors of the economy and their end uses, I-O models use economic sectors organized according to North American Industry Classification System (NAICS) codes (these have supplanted the former U.S. Standard Industrial Classification System since 1997). For purposes of the empirical analysis in this report, economic sectors occupying commercial buildings are assumed to experience savings in proportion to their baseline expenditures on energy and goods and services for building maintenance.

\section{Step 4. Calculate Economic Impacts}

Using the data developed in Steps 1 through 3, the ImSET model then calculates the impacts of energy-efficiency programs on employment in the following three sub-steps.

\section{Initial Investment Impacts}

First, the model calculates the gross output, income, and employment effects of initial spending on energy-efficiency investments. (These impacts include the initial spending on plant and equipment by businesses and households that adopt the new energy-efficient equipment and practices. The impact of spending by the EERE programs on services provided in government, universities, and other contractors typically is not computed.) In an I-O model, this impact is estimated by changing expenditure levels in the government, household consumption, and business investment columns of final demand and in the productivity changes box of Figure 2-1. The left-hand side of Figure 2-2 illustrates the necessary calculations in more detail. The residential and commercial buildings investments are estimated, based on Step 2, and then allocated to business sectors through the bridging calculations. This calculation is done directly in the business sector for commercial businesses, industrial processes, transportation, and power production.

An important finding of this project is that the size and algebraic sign of the national employment impacts of the initial investment process can depend critically on project financing. The investment typically must be financed by diverting resources from elsewhere in the economy. Therefore, the net employment impact of these energy-saving investments depends not only on the labor intensity of the investment process itself, but also on the relative labor intensities of those investment and consumption processes from which the necessary investment resources are diverted. For example, as will be shown in Section 3.1, the positive impact of the initial capital investment is dampened considerably and may be reversed after the opportunity cost of the investment funds is taken into account. 


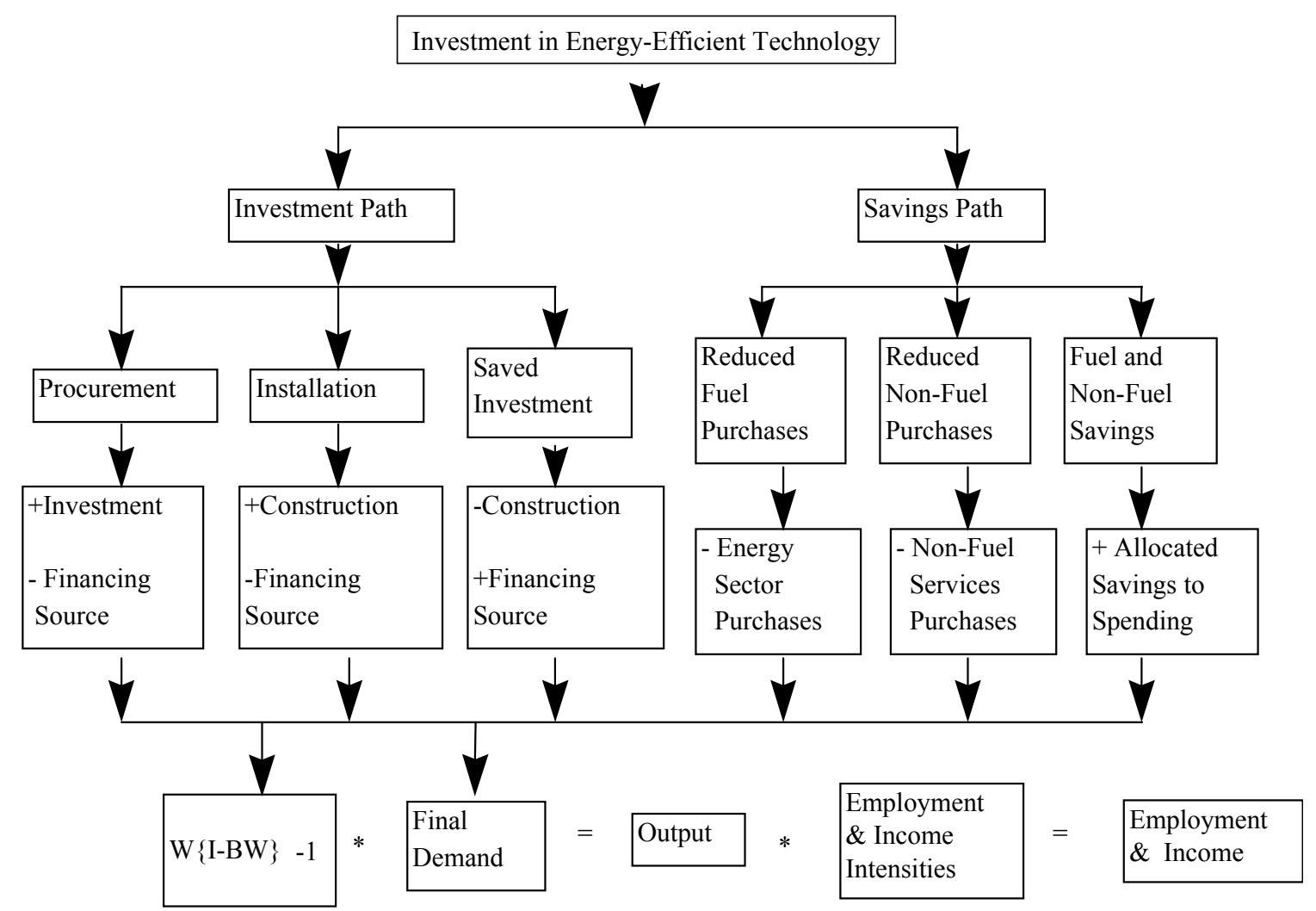

Figure 2-2. Detailed Calculations of the ImSET Model

\section{Calculate Impact of Energy Savings on Value Added and Residential Savings}

ImSET calculates economic savings (see Figure 2-2) associated with changes in the use of energy, labor, and materials with the improved technologies and practices. In the case of residential buildings and private transportation applications, this is relatively straightforward because residential and private transportation savings are assumed to be recycled into final demand. ${ }^{2}$ For commercial buildings, commercial transportation, industry, and power production applications, the process is more complicated because the inter-industry relationships between specific sectors are affected, not just final demand. For example, if the commercial building saves electricity, the business sectors operating and occupying these buildings would have lower purchases from the electric utility industry per dollar of output; thus, the coefficients in the utility industry row of the I-O structure of the economy must be reduced. Results from Step 3 are inserted into the ImSET model in the inter-industry portion of the I-O table (shown as "Productivity Changes" in the bottom portion of Figure 2-1); then, the model is run with the automatically recomputed table. Because the energy and maintenance intensity of the commercial sector changes at

\footnotetext{
${ }^{2}$ Final demand is an input-output modeling term that refers to purchases of goods and services, excluding those purchases of inputs for intermediate production. BEA sometimes now refers to this concept as "final use." Value added refers to the difference between an industry's output and the cost of its intermediate inputs. It is equal to compensation of employees, taxes on production and imports less subsidies, and gross operating surplus. For these and other I-O concepts see Horowitz and Planting (2006).
} 
each annual time step, the coefficients of the I-O structure are automatically recalculated at each annual time step.

The financial impacts of energy and non-energy savings in the commercial building, commercial transportation, industry, and power production sectors (for example, savings in building maintenance) are computed by the model. These savings are regarded as an increase in value added that is available to be saved or invested by the sector collecting the income.

The energy and non-energy savings do not affect employment in the national economy until they are reinvested or spent. For purposes of the analysis conducted for this report, the increments to value added (savings) are assumed to be allocated to final demand as with all other value added in each sector. That is, the additional income of these sectors is assumed to be spent on final demand. These increments to value added increase the gross domestic product (GDP), so the increments are accumulated and are used to modify the vector of final demands (in equal proportions) so that the sum of value added and GDP are again in balance. Thus, an energy savings that occurs for industry, transportation, or commercial activity is assumed to contribute to value added and thus increase the overall GDP, however slightly. ${ }^{3}$

\section{Calculate Economic Impact of Value Added and Residential Savings}

ImSET accumulates the energy and non-energy savings in the residential buildings and personal transportation sector and the value-added changes associated with energy and non-energy savings within the commercial buildings, industrial, power production, or commercial transportation sectors. The model then calculates spending impacts associated with these savings by proportionately increasing final demand across relevant economic sectors as noted, while at the same time reducing final demand in the sectors that supplied the saved resources. This step accounts for the spending associated with the monetary savings and improvements in technological efficiency and for the associated shift from energy to non-energy spending. It also accounts for changes in the patterns of economic activity within the economy because of technological changes caused by the EERE programs (e.g., in retail trade, less electricity is used per dollar of output because of more efficient lighting). ${ }^{4}$ This calculation is shown in the last row of Figure 2-2 (the first box represents the recalculation of the direct and indirect requirements matrix as these technological changes occur [Lawson et al. 2002]).

\footnotetext{
${ }^{3}$ In terms of the U.S. National Income and Product Accounts, the additional income can be thought of as increases in corporate profits and proprietors' income. The assumption here is that some of this income will be spent on investment (e.g., via retained earnings by corporations) and some on consumption goods (funded by corporate dividends to households and a portion of proprietors' income). (Some increase in government spending is also assumed as tax revenue increases on this profit-type income.) This formulation is based upon an I-O structure with fixed output prices. An alternative formulation would be for the economic sectors to pass along the cost savings in energy as lower output prices. The alternative formulation would increase the complexity of the model substantially (requiring an explicit sub-model for prices) and would require further assumptions about what constitutes a final equilibrium of the economy after the efficiency investment is made.

${ }^{4}$ ImSET does not account for all long-run impacts of technological change. The change in energy-using capital in the commercial sector, for example, could alter the productivity and marginal value of factors of production other than energy (including labor and capital) and could induce a rearrangement of capital and labor that ultimately results in an increase in output and in final demand. The authors of this report show part of this effect - that of the initial spending associated with the savings, but not the effect of increased capital stock that would be created by the investment portion of the spending. Most economic models, including many dynamic simulation models, do not completely reflect the effect of capital accumulation and growth in capacity on final output and employment.
} 
ImSET collects the estimates of the initial investments, energy and non-energy savings, and economic activity associated with spending of the savings (increases in final demand in personal consumption, business investment, and government spending), and provides overall estimates of the change in national output for each NAICS sector using the adjusted I-O matrix. Finally, the model applies estimates of employment and wage income per dollar of economic output for each sector and calculates impacts on national employment and wage income.

When finished, the results of ImSET model runs can be saved by running an imbedded dialog designed for this purpose.

\subsection{Components of Impacts: A Once-Only Investment}

Energy conservation technology affects the activity level of the U.S. economy through three primary mechanisms. First, if the incremental capital costs of the new technology per installed unit are different (either more or less) than those of the conventional technology it replaces, changes in final demand will occur in the sectors involved in manufacturing, distribution, and installation for both technologies, changing the level of overall economic activity. ${ }^{5}$ Second, depending on how the efficiency investment is financed, it may "crowd out" other potential domestic business investments and consumer spending, which somewhat reduces overall economic activity. Third, energy and some non-energy expenditures are reduced; however, this reduction lowers final demand in the electric and gas utility sectors, as well as the trade and services sectors that provide maintenance, parts, and services. It increases net disposable income of households and businesses and increases general consumer and business spending in all sectors (including some increases in expenditures for electric and gas utility services and retail trade and services).

Figure 2-3 illustrates how these mechanisms work in the ImSET model by showing the effect of a hypothetical once-only investment in residential energy conservation technology. Four cases are presented. For all four cases, it is assumed consumers spend a premium of $\$ 100$ million beyond what they otherwise would have spent on more-efficient residential heating and cooling appliances in the year 2008 and will each year thereafter save $\$ 15$ million in electricity costs, \$30 million in natural gas, and \$5 million in building maintenance expenditures, for an annual savings of $\$ 50$ million. This $\$ 50$ million dollar annual savings yields a simple payback period of 2 years. The net employment impacts are presented in Figure 2-3 and Table 2.1.

\footnotetext{
${ }^{5}$ Frequently, a premium is present in the cost of purchase and installation of a new technology, over and above the cost of an alternative conventional system. The authors of this report assumed the premium attached to the new technology is caused entirely by the differential cost of manufacturing the equipment. Distributor markups and dealer costs are assumed to be unaffected. The share of the premium from incremental installation costs, if any, may be assigned to the construction sector or some other sector performing the installation, as appropriate.
} 


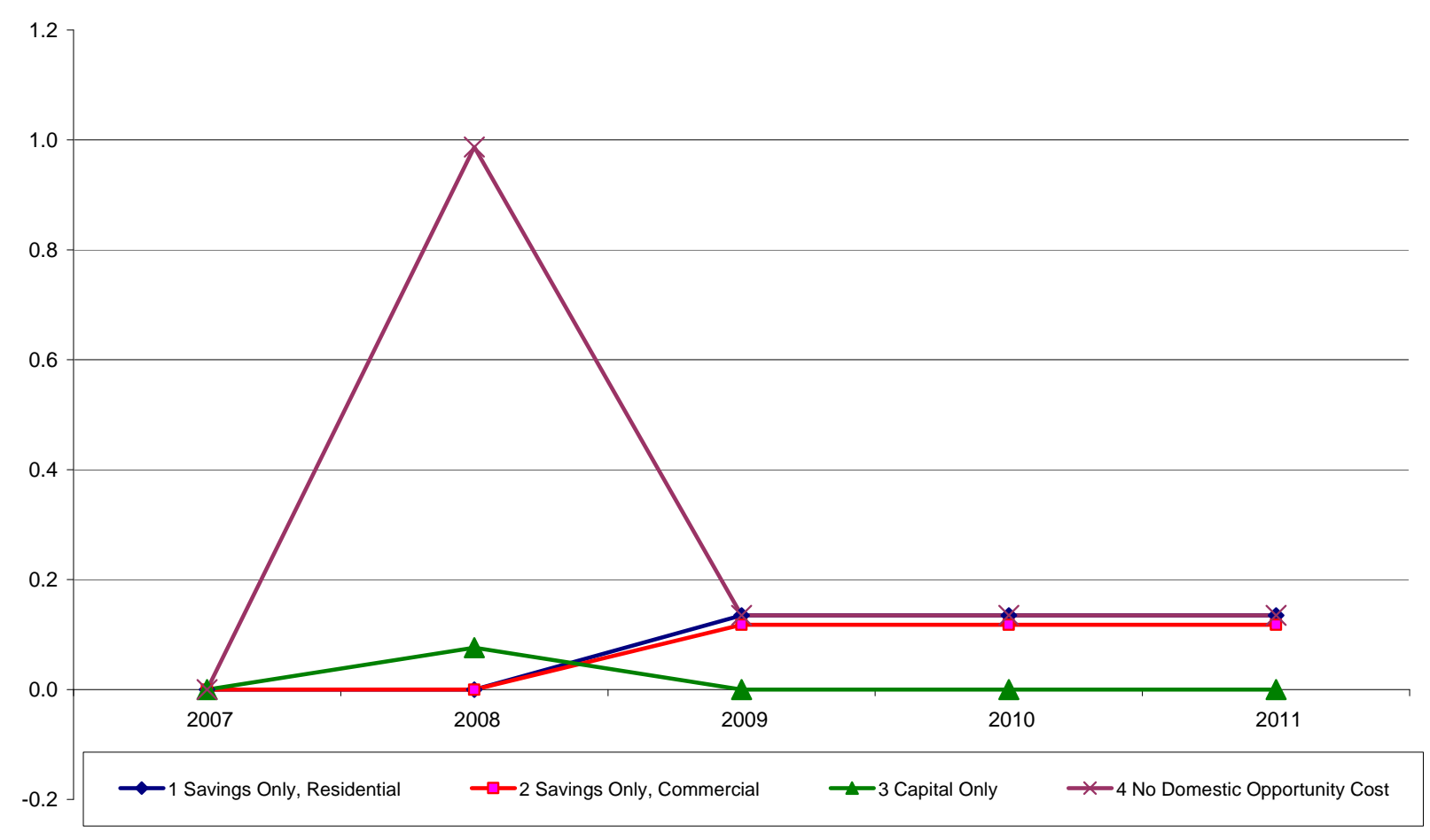

Figure 2-3. Impact on National Employment of a Hypothetical Once-Only Investment in Appliance Efficiency

Table 2.1. Employment Impact of Hypothetical Once-Only Investment (Thousands)

\begin{tabular}{llllllll}
\hline Case\# & \multicolumn{1}{c}{ Run Title } & \multicolumn{1}{c}{$\begin{array}{c}\text { End-Use } \\
\text { Sector }\end{array}$} & $\mathbf{2 0 0 7}$ & $\mathbf{2 0 0 8}$ & $\mathbf{2 0 0 9}$ & $\mathbf{2 0 1 0}$ & $\mathbf{2 0 1 1}$ \\
\hline 1 & $\begin{array}{l}\text { Savings only } \\
\text { Residential }\end{array}$ & Residential & - & - & 0.135 & 0.135 & 0.135 \\
2 & $\begin{array}{l}\text { Savings only } \\
\text { Commercial }\end{array}$ & Commercial & - & - & 0.118 & 0.118 & 0.118 \\
3 & $\begin{array}{l}\text { Capital only } \\
\text { Residential }\end{array}$ & Residential & - & 0.076 & - & - & - \\
4 & $\begin{array}{l}\text { No Domestic } \\
\text { Opportunity Cost }\end{array}$ & Residential & - & 0.987 & 0.135 & 0.135 & 0.135 \\
\hline
\end{tabular}

Cases 1 and 2 in Figure 2-3 show the employment effects of the $\$ 50$ million savings only. In Case 1, the savings are experienced by consumers occupying the residential buildings, and the savings are assumed to be recycled in the economy as consumer final demand, spent on the usual mix of consumer goods and services. Case 2 shows that the impacts would change if these energy savings had instead been realized in the commercial buildings, where the savings are initially experienced as reductions in intermediate energy expenditures of commercial businesses (ImSET sectors 140 and 150-185). These reductions in business costs are assumed to be shared by the firms' workers as compensation, by the companies as profits and by government as additional taxes. These monies are then assumed to be 
recycled in the economy as spending by workers, spending by companies, and spending by the government experiencing increases in tax collections for their usual respective mixes of goods and services. In Case 1 shown in Figure 2-3 and Table 2.1, the energy savings in the residential sector of \$50 million have a net impact on the U.S. economy of about 135 jobs. The impact in Case 2 is somewhat smaller (118 jobs) because the energy savings occur in the commercial sector and the employment intensity of the spending mix of businesses, their workers, and government associated with commercial savings is slightly lower than employment intensity of the spending mix of consumers.

Figure 2-3 (and Table 2.1) includes a third and fourth case to show the employment impacts of the $\$ 100$ million investment premium spent on advanced heat pumps. Case 3 shows the impact of the investment premium (no savings, only capital cost entered) under the assumption that national saving is not affected so that (as is normally the case) investments made in any particular sector are financed by someone, somewhere else in the economy, not obtaining a loan or having to reduce spending. The investment is assigned to the air conditioning, refrigeration, and forced air heating sector (IMSET sector 88 ), which is assumed to make the more-efficient appliances. In this case, although additional investment in the technology itself generates employment, the short-run net employment impact is quite small (76 jobs) because the investment has an opportunity cost - the goods and services (and as a result, the jobs) that it would have produced elsewhere in the U.S. economy if expenditures had not been on moreefficient appliances. By coincidence, this displaced activity is almost exactly as labor intensive as the specific manufacturing sector (ImSET sector 88) that makes the more-efficient appliances, so jobs gained in sector 88 and its supplying industries are offset by job losses elsewhere. ${ }^{6}$

Typically, energy efficiency programs are thought by casual observers to be relatively labor intensive, but this is not always the case. Heating and air conditioning manufacturing, for example, has a direct and indirect labor intensity that is very similar to the overall economy, while some other sectors producing advanced energy technologies are much less labor intensive. Air conditioning, refrigeration, and forced air heating sector, which would make advanced heat pumps, has an employment multiplier of about 11.5 jobs per million dollars of sales, while the average employment multiplier for the economy as a whole is also about 11.5. By contrast, the employment multiplier for electric bulb and lamp manufacture (ImSET sector 110), which would manufacture advanced lighting, is only 8.9.

The strength and direction of the net investment effect on employment depends on the size of the investment premium and its combined domestic U.S. direct and indirect labor intensity, relative to that of other domestic spending (the opportunity cost of the investment). For the employment impact of the investment to be positive, the sectors supplying the new technology must on average create more domestic jobs per dollar of spending than other domestic spending. An extreme form of this positive investment effect would occur if the investment were financed internationally (i.e., no domestic opportunity cost is included). This is shown in Case 4, which shows a short-run jobs impact of 987 jobs, with an employment impact as a result of the energy savings unchanged from Case 1. Case 4 also corresponds, at the national level, to the assumption made in many regional analyses of energy conservation impacts, where the investment funds are assumed to come from somewhere else and have no opportunity cost in the region.

\footnotetext{
${ }^{6}$ Strictly speaking, the labor intensity that counts is the employment, direct and indirect, that is created by each dollar of spending. Thus, it is theoretically possible for a capital-intensive industry to buy lots of labor-intensive inputs from other industries and the total effect to be labor intensive as a result. See Section 3.2 for further discussion.
} 


\subsection{ImSET 3 Model Results for Sample EERE Programs}

This section provides the results obtained by using the ImSET model to calculate the employment and income consequences of two specific building programs as they are introduced into the U.S. residential and commercial sectors. The two programs were chosen because they represent the diversity of EERE programs, are likely to affect the economy in different ways, and illustrate a number of issues concerning the economic impact of energy-efficient end-use technologies.

\subsection{Comparison of Capital and Operating Cost Scenarios for Sample Technologies}

The impact of EERE technologies on the national economy depends on the market penetration of these technologies and their associated investments and operating costs. This analysis is tied to the scenarios for market conditions, costs, and energy consumption of specific technologies and programs from the EERE GPRA metrics, a product of significant work on technology performance, costs, and markets. This section describes the programs and summarizes their costs and savings. Appendix A shows the detailed values of these savings and expenditures for the specific scenarios of market penetration. Figure 3.1 shows the premium in capital costs (measured in 2005 dollars) for the GPRA metrics market penetration scenarios associated with two Building Technologies (BT) programs in the fiscal year 2009 EERE Budget Request to Congress: Space Conditioning Research and Development (R\&D) on integrated heat pump and Technology Validation and Market Introduction (TVMI) on building energy codes. These choices illustrate two basic types of EERE programs: an equipment R\&D program (focused on the residential sector) and building energy codes program (focused on the residential and commercial sector). Descriptions of these programs follow.

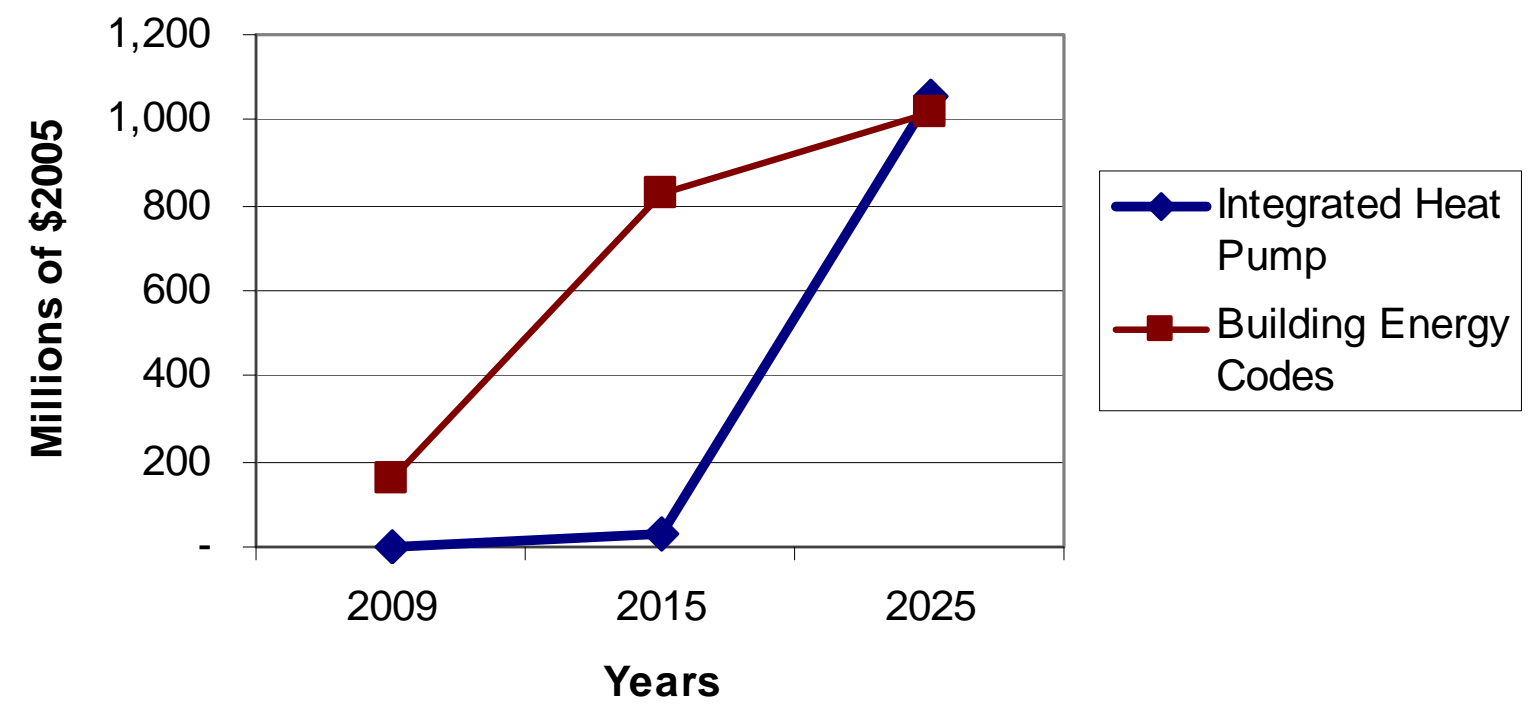

Figure 3-1. Incremental Capital Costs by Year for GPRA Metrics Market Scenarios of Integrated Heat Pump and Building Energy Codes 
Table 3.1. Incremental Capital Costs by Year for Integrated Heat Pump and Building Energy Codes (Millions of 2005\$)

\begin{tabular}{|c|c|c|c|c|c|}
\hline & Run Title & $\begin{array}{l}\text { End-Use } \\
\text { Sector }\end{array}$ & 2009 & 2015 & 2025 \\
\hline 1 & $\begin{array}{l}\text { Integrated Heat } \\
\text { Pump }\end{array}$ & Residential & 0.00 & 29.9 & 1059.4 \\
\hline 2 & $\begin{array}{l}\text { Building Energy } \\
\text { Codes }\end{array}$ & $\begin{array}{l}\text { Residential/ } \\
\text { Commercial }\end{array}$ & 160.0 & 826.4 & 1014.2 \\
\hline
\end{tabular}

Integrated Heat Pump. The first program is an integrated heat pump design concept within heating, ventilation, and air conditioning and water heating R\&D. The program objective is to develop an air-toair integrated heat pump (IHP) system that can meet the air heating, cooling, dehumidifying, ventilating, and water heating requirements of a tight-envelope, mechanically ventilated, near-zero-energy house (ZEH). The unit is designed to have about one ton of cooling capacity $(12,000 \mathrm{Btu} / \mathrm{hr})$, which is projected to be the remaining space conditioning load after the building shell (windows, walls, roof, and basement) and air tightness goals have been met. Target energy savings is 50 percent relative to ZEH with an appropriate suite of benchmark equipment meeting the same needs ${ }^{1}$.

Achieving the ZEH goal will require the development of space cooling and heating equipment that reduces energy consumption by 50 percent relative to the Building America 2004 Benchmark by 2010 . Similarly, water heating equipment that reduces energy consumption between 50 and 80 percent relative to the benchmark must also be developed. Substantial improvements in appliance energy efficiency will greatly enhance the viability of ZEH.

TVMI Building Energy Codes. The second program is a component of the Technology Validation and Market Introduction (TVMI) program that advances building energy codes. The DOE program facilitates the development, adoption, and enforcement of more energy efficient (stringent) building codes (and standards). These codes define the minimum requirements for new construction, as well as additions and alterations to existing buildings. Building energy codes set minimum requirements for building thermal envelope performance and building lighting and power system performance, and in the case of commercial buildings, building mechanical system performance. Commercial building requirements for mechanical equipment also are the starting point for BT's equipment standards rulemaking.

Capital expenditures shown in Figure 3.1 represent the estimated premium of investment cost over the money that otherwise would have been spent to equip the same residential and commercial building stock with baseline technologies. The costs shown are dependent not only on the cost per unit of the new technology but also on the costs of the technology with which it is assumed to compete.

\footnotetext{
${ }^{1}$ BT FY 2009 Annual Operating Plan (AOP) Pre-Proposal. According to EERE guidance, the AOP will identify the program mission and functions, which support the overall mission and functions of the higher-level organizations, program strategic objectives, FY tasks planned under each strategic objective, and the personnel and fiscal resources assigned for task accomplishment. The AOP will also identify responsibilities, planned milestones, controls for program execution, and interfaces and interrelationships with other organizations.
} 
Figure 3-2 shows the associated energy and non-energy savings (reduction in operating costs) compared with conventional technologies. All cost premiums and savings are measured in 2005 dollars relative to baseline conditions by the GPRA metrics program. These figures represent total increases or decreases in cash outlays in the year shown and not the annualized savings or costs. ${ }^{2}$ Cash outlays vary not only because of the characteristics of the technologies themselves, but also because the market penetration of each technology is expected to change over time as a result of EERE program success.

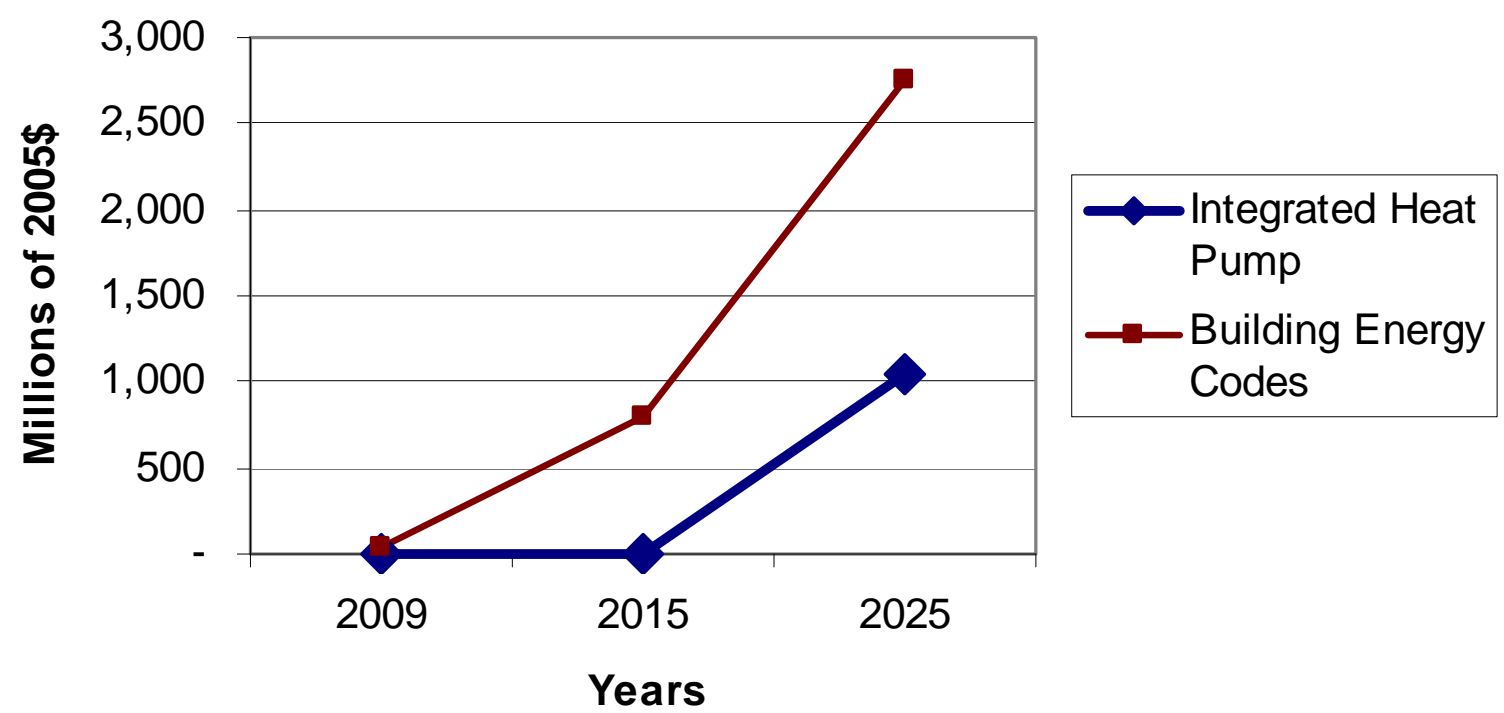

Figure 3-2. Value of Energy Savings by Year Relative to Baseline for GPRA Metrics Market Scenarios

Table 3.2. Value of Energy Savings by Year Relative to Baseline for Integrated Heat Pumps and Building Energy Codes (Millions of 2005\$)

\begin{tabular}{rllccc}
\hline & Run Title & \multicolumn{1}{c}{$\begin{array}{c}\text { End-Use } \\
\text { Sector }\end{array}$} & $\mathbf{2 0 0 9}$ & $\mathbf{2 0 1 5}$ & $\mathbf{2 0 2 5}$ \\
\hline 1 & $\begin{array}{l}\text { Integrated Heat } \\
\text { Pump }\end{array}$ & Residential & - & 7.6 & $1,046.7$ \\
2 & $\begin{array}{l}\text { Building Energy } \\
\text { Codes }\end{array}$ & $\begin{array}{l}\text { Residential/ } \\
\text { Commercial }\end{array}$ & 32.0 & 796.7 & 2759.44
\end{tabular}

\footnotetext{
${ }^{2}$ The authors of this report show these figures in this manner because economic impacts, such as employment, will occur when the money is actually being spent, not when the economic entities incur the costs associated with the spending. Thus, for purposes of this analysis, if an investment is made in the year 2009, the jobs created are the same whether the money to pay the workers is accumulated cash or borrowed funds. The impact of the opportunity cost is more of a question because financing theoretically could change the time distribution of the impact on the cost side. Shown is the impact as if it all occurred in the same year as the investment in energy efficiency.
} 
Both programs show significant energy cost savings in Figure 3-2 - over \$1 billion annually for IHP by 2025 , and almost $\$ 2.8$ billion annually for Building Energy Codes. These cost savings depend on the cumulative number of units installed compared with the same market developed with more conventional technology, the relative amount of energy used or saved, and any additional non-energy costs or savings.

The values used as inputs to ImSET sometimes have been derived from program assessments that are treated in isolation from each other. That is, each of the programs assumes that it has no impact on any other program. Ignoring interactions may possibly overstate the total benefits when all technologies are aggregated. In the examples shown in this report, the input data were corrected for potential program interactions.

\subsection{Integrated Heat Pump (IHP) Impacts}

Figure 3-3 and Table 3.3 show the employment impacts associated with variations of the GPRA metrics IHP scenario. An essential feature throughout all scenarios is the ever-increasing investment in the IHP throughout the forecast period out to 2025, with a high and still-growing level of new investments ( $\$ 1.1$ billion) in the last year. The net result is that for any time period, the economy is experiencing a mix of consequences from energy cost savings offset by additional new energy efficiency investments, with the prospect that increased investment consequences could dominate and thereby depress employment. For example, by 2025 energy cost savings in residential natural gas and oil purchase from the replacement of conventional heating systems with IHPs (approximately $\$ 1.4$ billion per year) exceed the increased cost of the additional electricity needed to operate the IHPs that replace them ( $\$ 350$ million), for a net savings of consumer energy cost of $\$ 1.0$ billion. The savings-only case demonstrates that the net employment effect of the $\$ 1$ billion savings on employment is slight (only about 50 jobs). This is because the negative impacts of lower energy sales on the energy industry and its supplying industries are about $-12,500$ jobs and the positive impacts of consumers' spending of the saved funds also are about $+12,500$ jobs.

At the same time, a substantial investment is required to produce these net energy cost savings, which means that in any particular time period, the economy is experiencing a mix of consequences from energy savings and the required new energy-efficiency investments. The investment in heat pumps produces a net positive impact on jobs because spending is transferred from less labor-intensive to more laborintensive sectors of the economy, as discussed for a simpler case in Section 2.2. The Base Case in Figure 3-3 includes the positive net impact on jobs from the investment in heat pumps. Because the investment cost in 2025 ( $\$ 1.1$ billion) is larger than the net value of energy savings ( $\$ 1.0$ billion) and has a relatively stronger net (positive) impact on job creation, the positive impact of the investment on jobs reinforces the small positive impact of energy savings. Thus, the Base Case lies above the Savings-Only Case in Figure 3-3. 


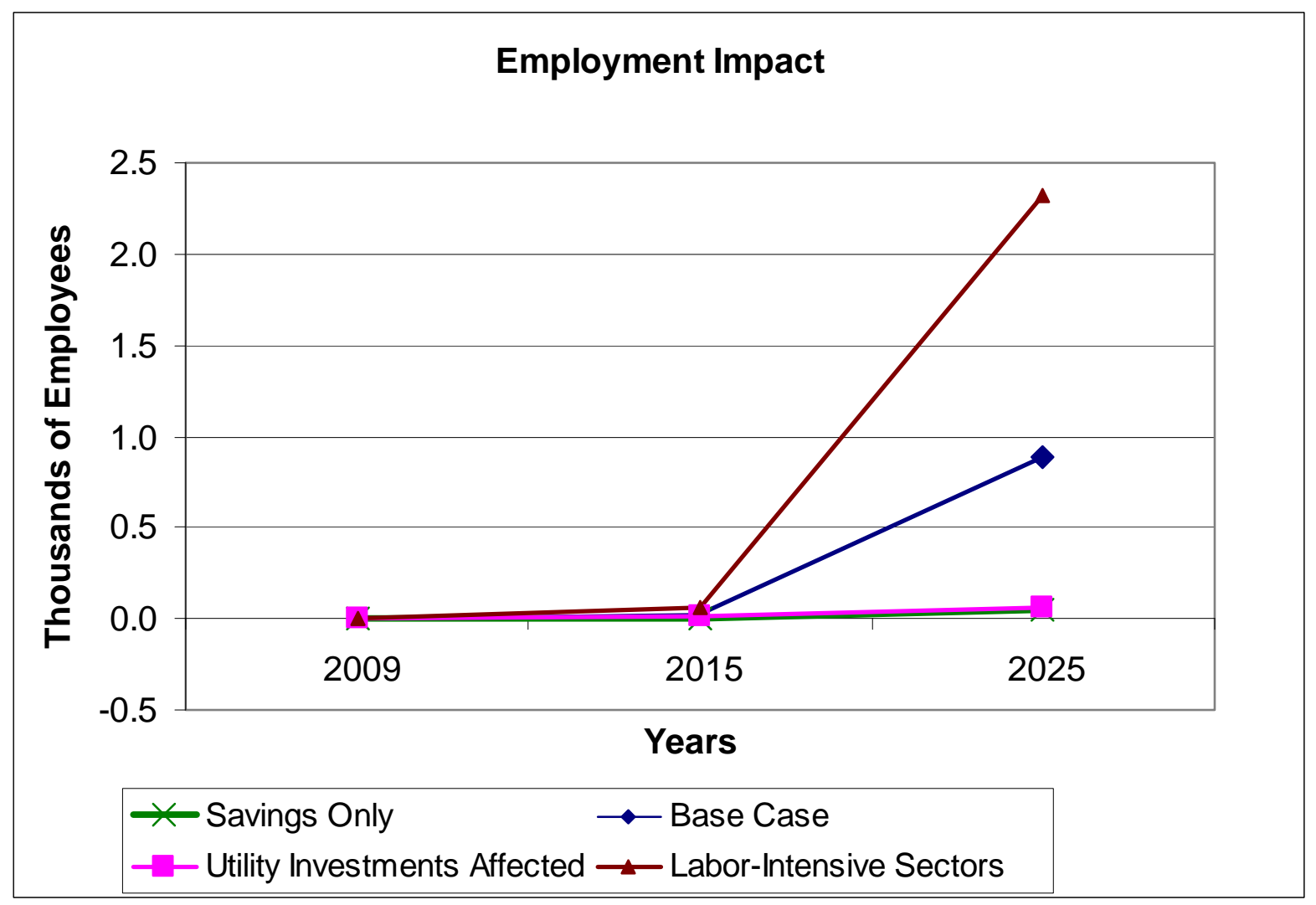

Figure 3-3. Employment Impacts of Investment in Integrated Heat Pumps

Table 3.3. Employment Impacts of Investment in Integrated Heat Pumps (Thousands of Employees)

\begin{tabular}{|c|c|c|c|c|c|}
\hline $\begin{array}{c}\text { Case } \\
\text { No. }\end{array}$ & Run Title & $\begin{array}{l}\text { End-Use } \\
\text { Sector }\end{array}$ & 2009 & 2015 & 2025 \\
\hline 1 & Savings Only & Residential & 0.000 & -0.00 & 0.05 \\
\hline 2 & Base Case & Residential & 0.000 & 0.02 & 0.89 \\
\hline 3 & $\begin{array}{l}\text { Utility Investments } \\
\text { Affected }\end{array}$ & Residential & 0.00 & 0.02 & 0.07 \\
\hline 4 & $\begin{array}{l}\text { Labor-Intensive } \\
\text { Sectors }\end{array}$ & Residential & 0.00 & 0.06 & 2.32 \\
\hline
\end{tabular}

Next, we consider the effect of energy conservation on investment in capital by electric utilities and gas utilities. If energy consumption decreases, it may be possible for utilities to defer investments they otherwise would make in plant and equipment. To analyze this question, it was assumed that each reduction of 1 trillion Btu of annual electrical energy demand saves $\$ 32.9$ million of electric utility investment (about $\$ 590$ per kW of capacity) and every trillion Btu of natural gas saved in annual demand 
saves $\$ 5.29$ million of gas utility investment. ${ }^{3}$ Reduced investment by gas utilities releases $\$ 654$ million in investment demand from the gas utility construction to the economy as a whole, which is slightly less labor intensive, partially offset by an increase in electricity investment demand (\$432 million), with labor intensity similar to gas utility construction. The net effect in comparison with the base case is a decrease of 820 jobs (the net employment impact is about +70 in this case as compared with the base case of +890 ). Thus, avoided utility investment, to the extent it occurs, has a negative impact on employment. ${ }^{4}$

So far, this analysis has assumed that the cost premium for an integrated heat pump derives entirely from their manufacture. The Labor-Intensive Sectors Case in Figure 3-3 is a sensitivity case that shows that if the more labor-intensive appliance distribution sectors of the economy were also affected by the initial investment (not just appliance manufacturing), the net employment effects of the investment premium would be higher, and the overall net effects could be above those of the energy savings alone. ${ }^{5}$

However, there is no reason to assume that wholesale and retail trade percentage markups would be levied on top of the incremental higher manufacturing costs. It is more likely that distribution, marketing, and installation costs would be about the same for the IHP and the competitor unit.

Figure 3-4 and Table 3.4 present four financing scenarios. The source of financing affects the size of the projected net employment effect because the labor intensity of displaced spending varies across the sectors of the economy. The net effect depends on the market penetration scenario (i.e., how fast and at what cost the technologies enter the market) and what activity in the U.S. economy is impacted by investments in IHP manufacture instead of other spending. Employment impacts are estimated for the IHP market penetration of the GPRA metrics scenarios under differing scenarios concerning the financing of substantial upfront investments. For example, in the Base Case, which is the same as the base case in Figure 3-3, the funds necessary to finance the water heater investment are drawn proportionately from all sectors of the economy. The Base Case could also be labeled "all sectors affected." 6 The Free Financing Case in Figure 3-4, assumes that the investment does not impinge on U.S. economic activity, and thus the entire incremental investment adds to U.S. final demand and domestic product. A number of reasons exist why this could happen. From a macroeconomic perspective, two plausible reasons are that consumers

\footnotetext{
${ }^{3}$ For this report, we estimated electric power plant construction savings at about $\$ 590 / \mathrm{kW}$ of delivered electric energy, based on data in EIA (2008). The equivalent value for natural gas is about $\$ 1.20$ per cubic foot per day capacity, based on EIA (1996).

${ }^{4}$ This analysis assumes that saved utility investment funds would be recycled in the economy in proportion to the all spending in final demand. If these funds instead were used to make foreign investments, for example, the negative impact would be much greater: $-1,670$ jobs instead of +70 . If the freed-up funds were entirely concentrated on business investment across the economy instead of being distributed to all sectors, the impact would be slightly more positive than as shown in the figure: +220 jobs instead of +70 .

${ }^{5}$ The differential employment impact of the IHP investment arises because the appliance manufacturing sector and its suppliers are slightly less capital intensive as a group than the economy as a whole. Thus, diverting investment funds from the rest of the economy to appliance manufacturing tends to increase employment slightly. If the investment cost premiums were spread amongst more labor-intensive sectors - such as wholesale and retail tradethe average employment intensity of the IHP investment would be significantly above the national average. For the sensitivity case in Figure 3.3, it was assumed that manufacturing took $46 \%$ of the investment premium; wholesale and retail trade, $37 \%$; and construction, $17 \%$. These proportions assume that the investment premium is spread among installers and trade markups in addition to the manufacturing sector.

${ }^{6}$ Based the average percentages for the U.S. economy from 2002-2008, personal (household) consumption is assumed to represent $66.9 \%$ of spending; gross private fixed investment, $14.8 \%$; federal defense spending, $4.5 \%$; federal nondefense spending, $2.4 \%$; and state and local government spending, about $11.6 \%$.
} 
decide to spend previously accumulated savings, or alternatively, the investment funds come from overseas.

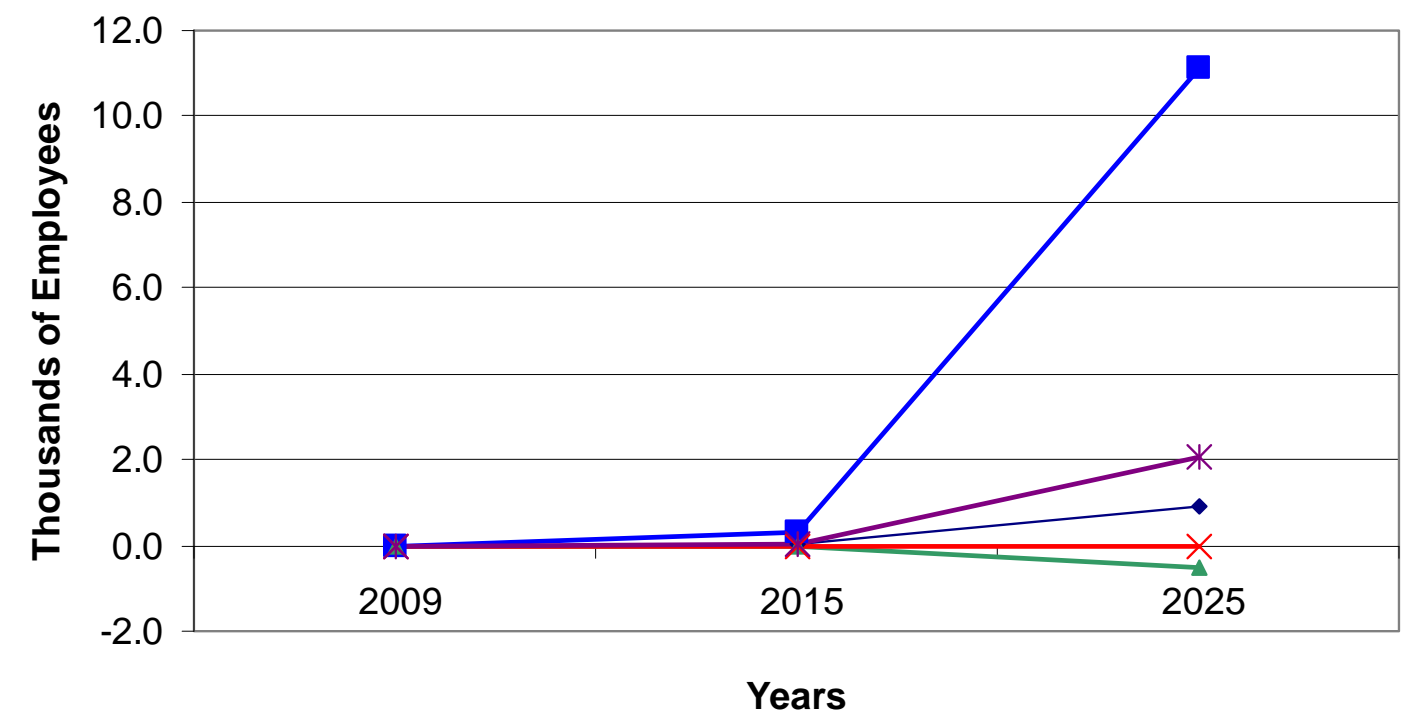

\begin{tabular}{ll}
$\rightarrow-$ Base Case & $\rightarrow$ Free Financing \\
$*$ Investment Affected & $*$ Consumption Affected \\
\hline
\end{tabular}

Figure 3-4. Effect of IHP Financing on Employment

Table 3.4. Effects of IHP Investment Financing on Employment (Thousands of Employees)

\begin{tabular}{|c|c|c|c|c|c|}
\hline $\begin{array}{l}\text { Case } \\
\text { No. }\end{array}$ & Run Title & $\begin{array}{l}\text { End-Use } \\
\text { Sector }\end{array}$ & 2009 & 2015 & 2025 \\
\hline 1 & Base Case & Residential & 0.00 & 0.02 & 0.89 \\
\hline 2 & Free Financing & Residential & 0.00 & 0.31 & 11.10 \\
\hline 3 & $\begin{array}{l}\text { Consumption } \\
\text { Affected }\end{array}$ & Residential & 0.00 & -0.02 & -0.50 \\
\hline 4 & Investment Affected & Residential & 0.00 & -0.00 & 0.00 \\
\hline 5 & $\begin{array}{l}\text { Government } \\
\text { Affected }\end{array}$ & Residential & 0.00 & 0.05 & 2.04 \\
\hline
\end{tabular}

When increased investment in the energy efficiency industry does not cause investment to be reduced elsewhere, the positive impact on U.S. employment is maximized. . This impact is large enough to dominate other macroeconomic effects of the technology's energy savings in some years.

The other cases in Figure 3-4 (Consumption Affected, Investment Affected, and State and Local Government Affected) demonstrate, to varying degrees, the temporary employment impact when the new incremental investment in IHPs displaces consumer spending business investment, or state and local 
government spending. ${ }^{7}$ Because the amount of funds needed for investment in integrated heat pumps is the same in each scenario in Figure 3-4, the level of the offsetting impact depends on the relative employment intensity of economic activity in the various sectors of the domestic economy from which the investment funds come. The figure shows that although consumer spending is usually thought of as purchasing products and services that are relatively labor-intensive, the resulting differences in employment impacts among the different domestic financing options for IHP investments are very small.

Jobs are not the only metric by which we can measure the macroeconomic impact of energy-efficiency programs. Because different industries pay different wages on average, it is theoretically possible to create a number of low-paying jobs while reducing the number of well-paying jobs and overall income. Thus, it is worth examining the impact on earnings as well as employment. Figure 3-5 and Table 3.5 illustrate the effects on national earned income of the various scenarios, previously shown in Figure 3-4, with their different sources of investment capital.

Figure 3-5 illustrates the effects on national earned income (wages), as opposed to employment levels, using the same scenarios, shown previously. Figure 3-5 illustrates that the impact of the heat pump investments and energy savings on national wage income. The effects on wage income are positive for four cases (Free Financing, Base Case, Consumption Affected, and Investment Affected) and negative in one case (State Local Government Affected). The impacts are most positive when the investment does not crowd out domestic spending and investment (Free Financing). With the investment funds being the drawn proportionately from the entire economy (the Base Case, which is the same case as in Figure 3-4), the net impact on national income is still positive, but smaller. The impact on wage income is generally reduced (but not negative) if normal domestic investments are foreclosed by heat pump investments. The impact is more positive than the Base Case if the relatively low-wage activity, supported by consumer spending, is displaced by IHP investments (Consumption Affected). Conversely, the impact is lower than the Base Case if a relatively high-wage activity is displaced (Investment Affected). If state and local government investment is displaced (State and Local Government Affected), the overall impact on national wage income is slightly negative, since on balance wage-intensive activity is supported by state and local government spending.

\footnotetext{
${ }^{7}$ The financing effects could be viewed in the following ways. If consumer spending is the only sector affected, it might be because consumers reduce their purchases of consumer durables like washing machines (or buy less expensive ones) to afford the additional heat pump investments. Business investments could be reduced instead because lenders provide loans to households to pay for heat pumps instead of loans to businesses to buy plants and equipment. Finally, state and local government spending could be reduced because tax credits are allowed on state and local income taxes for investments of this type.
} 

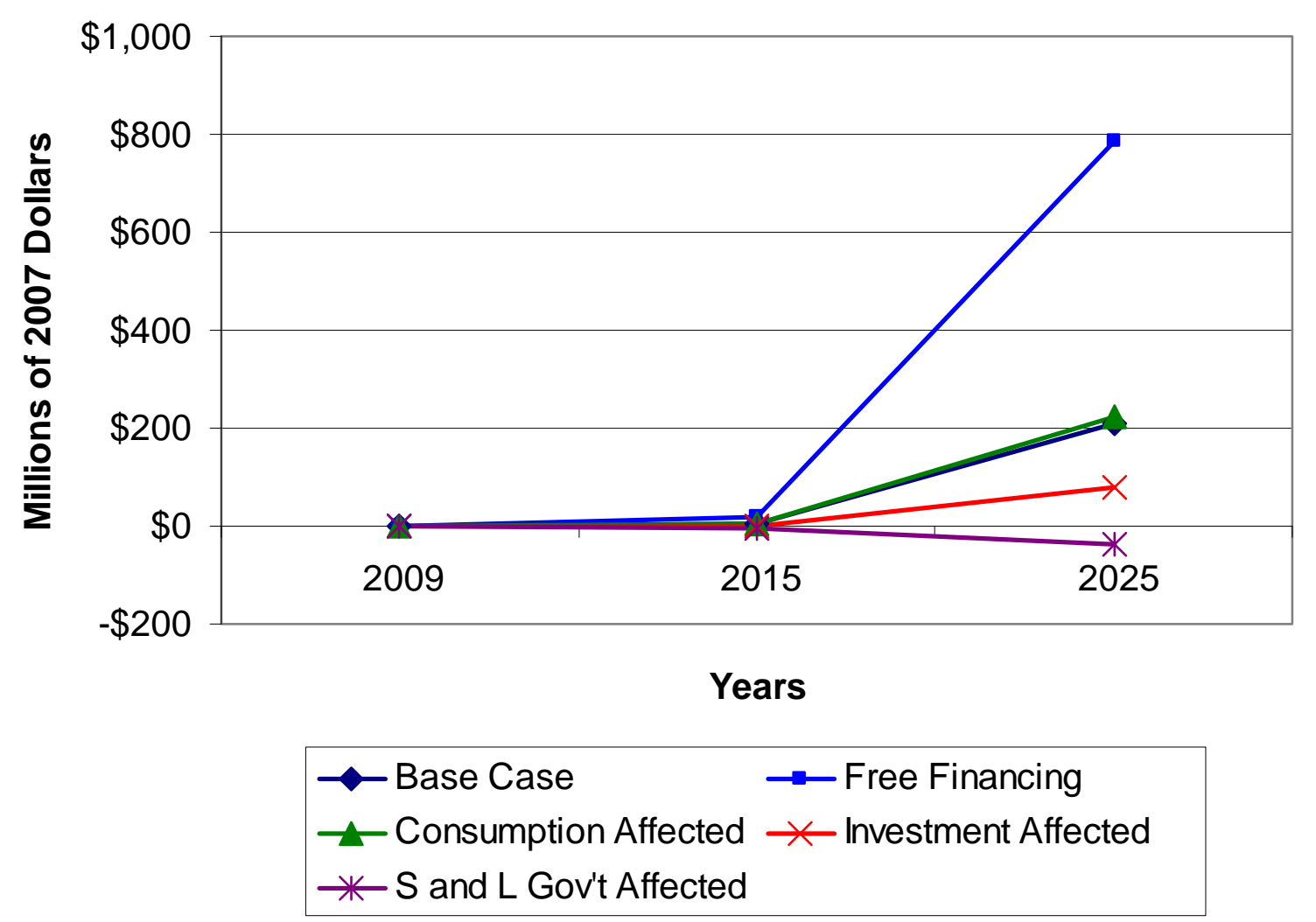

Figure 3-5. Impact of IHP Investment Financing on National Wage Income

Table 3.5. Impact of IHP Investment Financing on National Wage Income (Million 2007\$)

\begin{tabular}{|c|c|c|c|c|c|}
\hline $\begin{array}{l}\text { Case } \\
\text { No. }\end{array}$ & Run Title & $\begin{array}{l}\text { End-Use } \\
\text { Sector }\end{array}$ & 2009 & 2015 & 2025 \\
\hline 1 & Base Case & Residential & 0 & 3 & 209 \\
\hline 2 & Free Financing & Residential & 0 & 19 & 787 \\
\hline 3 & $\begin{array}{l}\text { Consumption } \\
\text { Affected }\end{array}$ & Residential & 0 & 3 & 221 \\
\hline 4 & Investment Affected & Residential & 0 & -1 & 79 \\
\hline 5 & $\begin{array}{l}\text { State and Local } \\
\text { Government } \\
\text { Affected }\end{array}$ & Residential & 0 & -4 & -39 \\
\hline
\end{tabular}

Figure 3-6 is the wage income equivalent of Figure 3-3. As shown in the Savings-Only Case in Figure 3.6, and in the accompanying Table 3.6, the residential sector consumer savings, when spent in the economy, have a positive impact on wage income. The Base Case shows that the initial investment in itself increases national wage income (the Base Case curve lies above the Savings-Only Case curve). This difference occurs mostly because the initial investment occurs in a high-wage, slightly capital-intensive sector. Although IHP manufacturing and its supplying industries employ slightly more workers per dollar 
of activity than the national average economic activity, they generate significantly more-than-average income. As was noted in the discussion of Figure 3-3, energy savings, if they are large enough, also could reduce utility investment in new plants and equipment (which is mostly construction activity). Should this occur, the Utility Investment Affected Case in Figure 3-6 shows that the reduced construction activity frees up dollars that tend to have a slightly less positive impact on national wage income than if spent on utility construction. ${ }^{8}$ Thus, the net impact on national wage income in the Utility Impact Affected Case is a slight decrease relative to the Base Case,

Finally, the Labor-Intensive Sectors Case in Figure 3-6 shows that if the investment in IHPs were distributed across more labor-intensive industries rather than just appliance manufacturing, there would be a slightly smaller net increase in national wage income than in the Base Case because the altered investment pattern would then represent a diversion of investment dollars into labor-intensive but relatively low-wage retail and wholesale distribution, as well as into high-wage construction and capitalintensive manufacturing. ${ }^{9}$ However, it is likely that majority of the cost premium, at least in most cases, would be as a result of the additional cost of manufacturing.
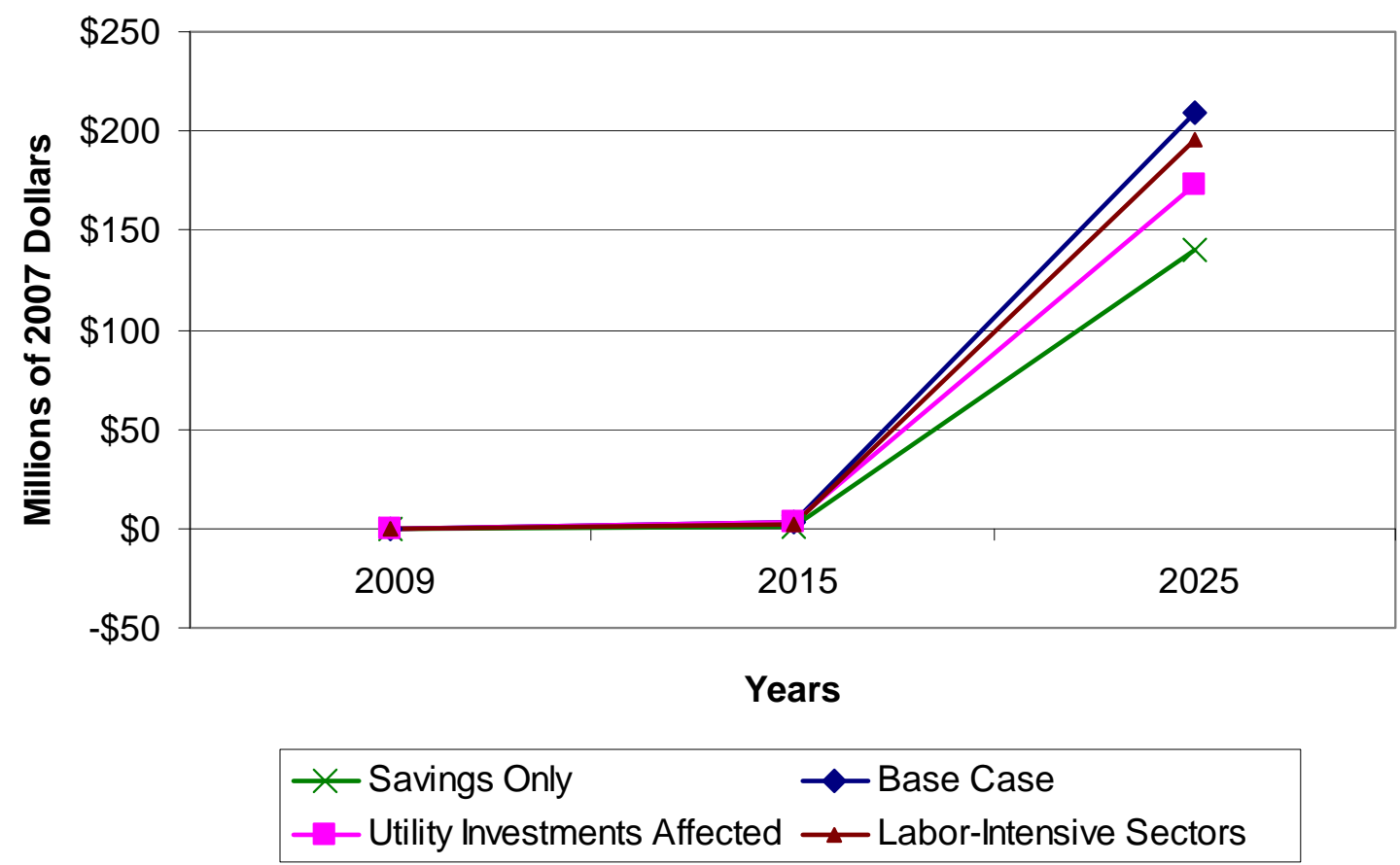

Figure 3-6. Sensitivity of Impacts on National Wage Income to IHP Investments

\footnotetext{
${ }^{8}$ In the case analyzed, the net effect is small and could be of either sign depending on exactly which sectors are affected. When relatively capital-intensive sectors spend the released investment funds, the effect is negative for both employment and income; when labor-intensive sectors spend the money, the net effect is positive for both. The illustrated case involves a mix of sectors.

${ }^{9}$ In this case, the investment premium was distributed $46 \%$ to air conditioning, and forced air and heating; $19 \%$ to the wholesale; $18 \%$ to retail trade; $12 \%$ to residential new construction; and $5 \%$ to residential remodeling construction sectors for installation.
} 
Table 3.6. Sensitivity of Impacts on National Wage Income to IHP Investments (Million 2007\$)

\begin{tabular}{llllll}
\hline $\begin{array}{c}\text { Case } \\
\text { No. }\end{array}$ & \multicolumn{1}{c}{ Run Title } & \multicolumn{1}{c}{$\begin{array}{c}\text { End-Use } \\
\text { Sector }\end{array}$} & $\mathbf{2 0 0 9}$ & $\mathbf{2 0 1 5}$ & $\mathbf{2 0 2 5}$ \\
\hline 1 & Savings only & Residential & 0 & 3 & 209 \\
2 & Base Case & Residential & 0 & 1 & 140 \\
3 & Utility Investments & Residential & 0 & 3 & 173 \\
& Affected & Residential & 0 & 3 & 196 \\
\hline
\end{tabular}

\subsection{Building Energy Codes Impacts}

Building energy codes (and standards) set minimum requirements for building thermal envelope performance, building mechanical system performance (commercial buildings only), and building lighting and power system performance. Adherence to the new codes is expected to require an incremental investment to builders and owners, both residential and commercial. This is an important distinction from the IHP, which is for the most part a residential product (though with small commercial potential). The IHP and building energy codes scenarios differ because building energy codes span both residential and commercial buildings. From a macroeconomic point of view, this difference is important because the ultimate pathway for expenditures that develops as a result of the energy and non-energy operational savings in the commercial sector is not obvious. Potentially, energy savings would increase the profitability of firms with new buildings that comply with more stringent energy codes. Alternatively, the additional value-added per dollar of output could be shared with the work force (in the form of higher wages resulting from higher productivity) and with the government (in the form of additional tax collections). With respect to business profits, it is not clear how much would be spent or invested, or how much would be saved.

However, even if a particular business had no immediate investment plans for the funds provided by energy savings, the economy as a whole would have abundant investment and consumption options available and the capital markets could readily absorb any savings. Therefore, it is assumed that energy savings by commercial businesses are proportionately allocated to labor earnings, business profits, and taxes (in the shares they comprise of value-added for each industry), and then are immediately recycled in the economy as consumer spending, business investments, and government spending, respectively. The impact on national employment is shown for the savings alone in the Savings Only case in Figure 3-7 and Table 3.7. The Base Case in the figure additionally accounts for the impacts of the investments required to achieve these savings. ${ }^{10}$ As in previous scenarios, Utility Investments Affected case in Figure 3-7 illustrates that if the energy savings allow for the deferral of labor-intensive electric and gas utility

\footnotetext{
${ }^{10}$ Capital spending estimates were $\$ 160$ million in 2009, $\$ 826$ million in 2015, and $\$ 1.1$ billion in 2025 . The distribution of capital spending among sectors was assumed to be as follows: commercial building construction, 7.5 percent; new residential construction, 10 percent; commercial remodeling construction, 7.5 percent; residential remodeling construction, 5 percent; flat glass manufacturing, 10 percent; glass and glass products manufacturing, 10 percent; air conditioning, refrigeration, and forced air heating manufacturing, 22.5 percent; air purification equipment manufacturing, 7.5 percent; electronic components manufacturing, 10 percent; electric lamp bulb and parts manufacturing, 5 percent; and electric lighting fixtures manufacturing, 5 percent. The labor intensity of the displaced activity is slightly less than that of the activity supported by the investment, so there is a small positive impact on employment from the investment required to deploy the building codes.
} 
infrastructure investments (and allowance is made for the recycling of this money into the economy), there is a negative impact on overall employment for the same reasons as in Figure 3-3. If the some portion of the cost savings were not re-spent inside the U.S. economy (e.g., business energy cost savings were invested in telecommunications in Asia), that portion of the energy savings would have no positive effect on the domestic economy. This is illustrated in Figure 3-7 as the No Commercial Recycle Case, where the only residential savings are recycled in the domestic economy.
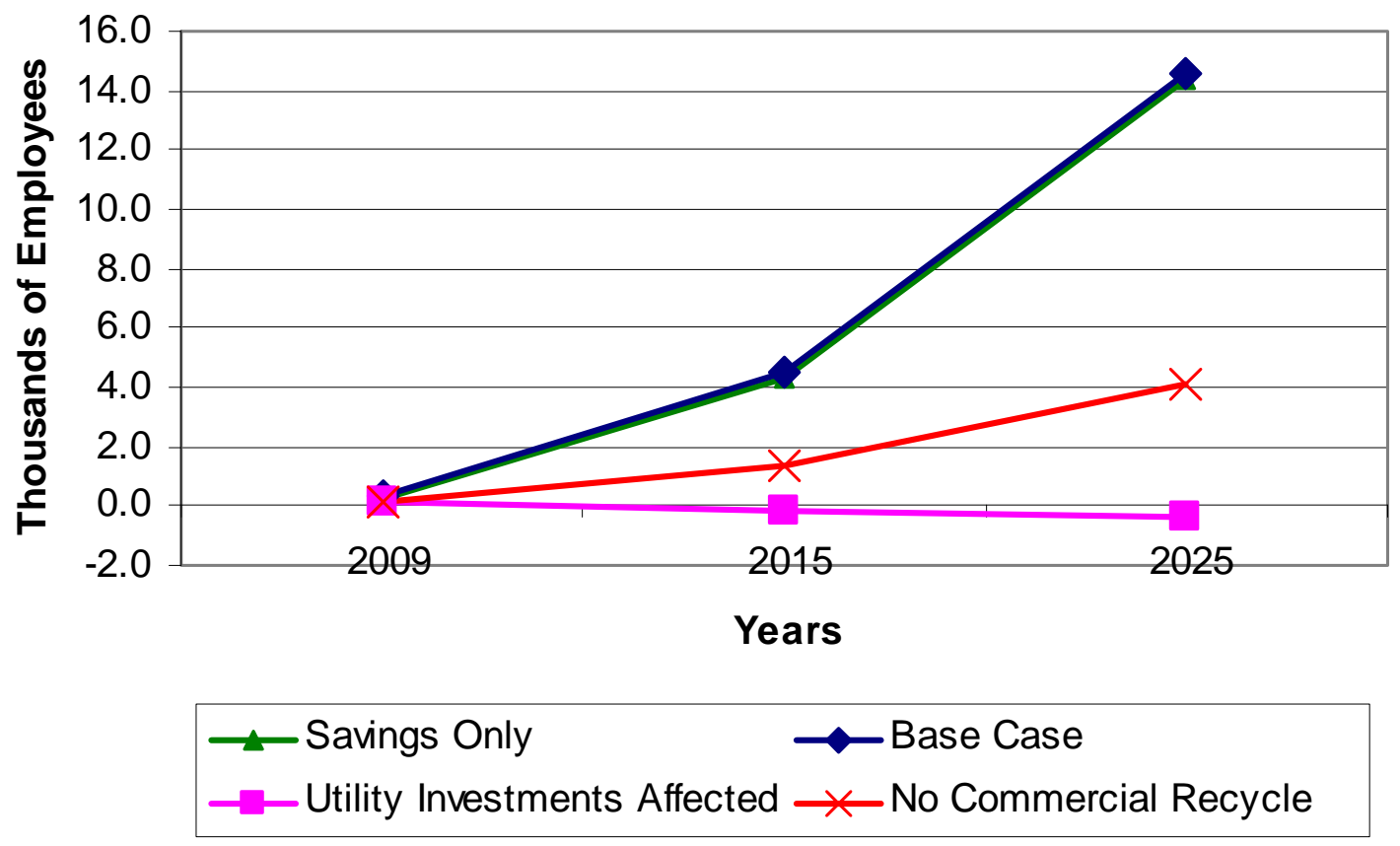

Figure 3-7. Impact on National Employment of Building Energy Codes

Table 3.7. Impact on National Employment of Building Energy Codes (Thousands of Employees)

\begin{tabular}{|c|c|c|c|c|c|}
\hline $\begin{array}{l}\text { Case } \\
\text { No. }\end{array}$ & Run Title & End-Use Sector & 2009 & 2015 & 2025 \\
\hline 1 & Savings Only & Residential/Commercial & 0.27 & 4.35 & 14.42 \\
\hline 2 & Base Case & Residential/Commercial & 0.30 & 4.50 & 14.60 \\
\hline 3 & $\begin{array}{l}\text { Utility Investments } \\
\text { Affected }\end{array}$ & Residential/Commercial & 0.10 & -0.17 & -0.39 \\
\hline 4 & $\begin{array}{l}\text { No Commercial } \\
\text { Recycle }\end{array}$ & Residential/Commercial & 0.17 & 1.33 & 4.12 \\
\hline
\end{tabular}

Figure 3-8 and accompanying Table 3.8 show national wage income impacts of the same cases discussed in Figure 3-7. The net impact of the cases Savings Only, Base Case, Utility Investments Affected, and the No Commercial Recycle cases appear in the same order relative to each other as in 
Figure 3-7. The impact on national wage income is significant and positive, except for when utility investment is affected. The reasoning for the order of cases is the same as in Figure 3-7.

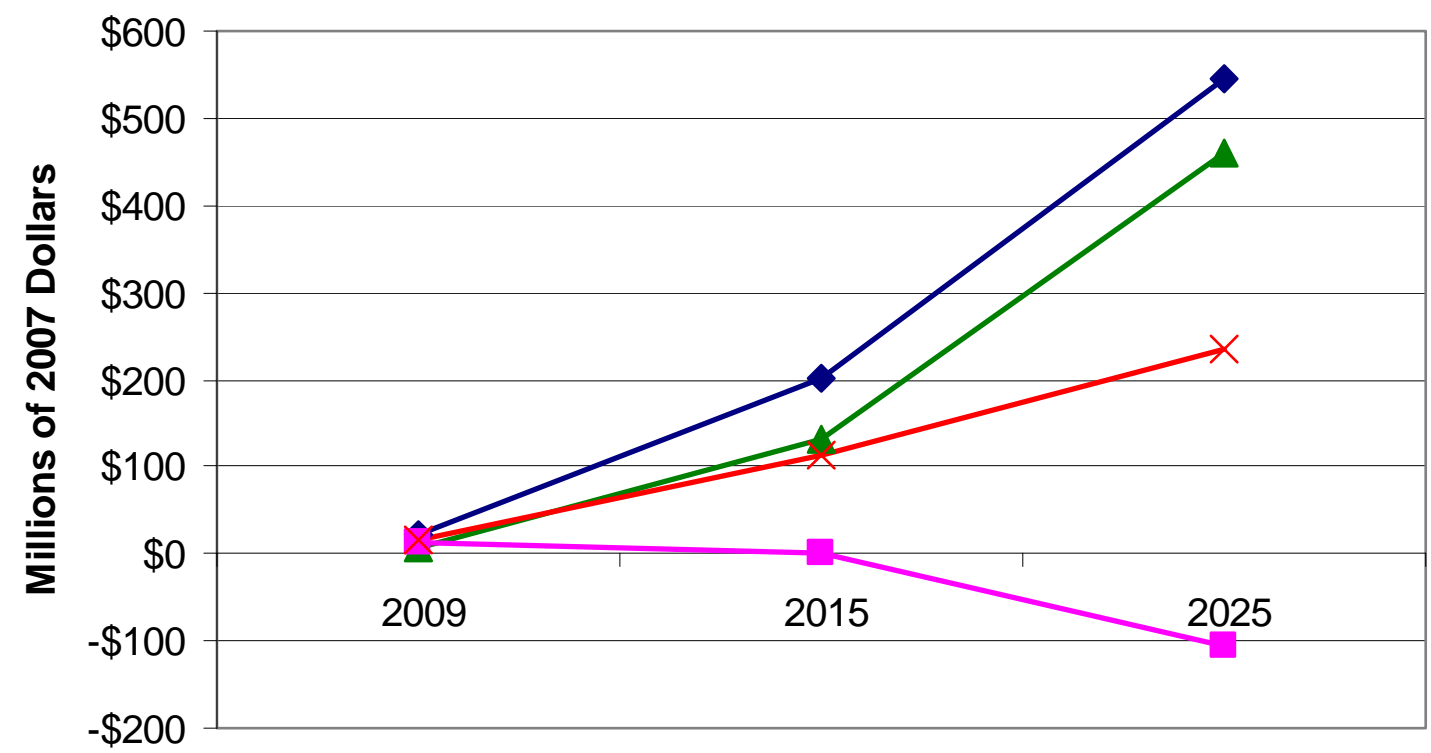

\section{Years}

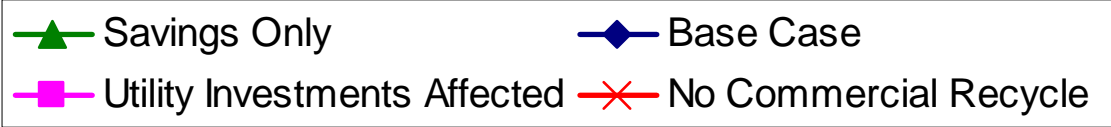

Figure 3-8. Impact of Building Energy Codes Energy Savings on National Wage Income

Table 3.8. Impact of Building Energy Codes Energy Savings on National Wage Income (Million 2007\$)

\begin{tabular}{|c|c|c|c|c|c|}
\hline $\begin{array}{l}\text { Case } \\
\text { No. }\end{array}$ & Run Title & End-Use Sector & 2009 & 2015 & 2025 \\
\hline 1 & Savings Only & Residential/Commercial & 7 & 133 & 460 \\
\hline 2 & Base Case & Residential/Commercial & 21 & 203 & 545 \\
\hline 3 & $\begin{array}{l}\text { Utility Investments } \\
\text { Affected }\end{array}$ & Residential/Commercial & 12 & -0 & -107 \\
\hline 4 & $\begin{array}{l}\text { No Commercial } \\
\text { Recycle }\end{array}$ & Residential/Commercial & 17 & 112 & 236 \\
\hline
\end{tabular}

Figure 3-9 and accompanying Table 3.9 show the net impact of buildings energy code investments on employment levels when different financing scenarios are considered. The impacts of the financing cases on jobs are all positive, similar to those in the analysis performed for IHP in Figure 3-5. The impacts in the Free Financing case are again the largest, because the economy enjoys the positive impacts of the investment program to deploy the building energy codes without having to reduce other spending (investment) to pay for it. Since the investment program for building energy code deployment includes purchases in a variety of sectors with varying degrees of labor intensity, the spending pattern of the 
building energy codes investment has about the same labor intensity as the rest of the economy. Thus, the remaining three cases (Base Case, Consumption Affected, Investment Affected, and State and Local Government Affected) all have impacts very similar to each other, all of which are dominated by the impacts of the energy savings rather than the investments required to produce them.

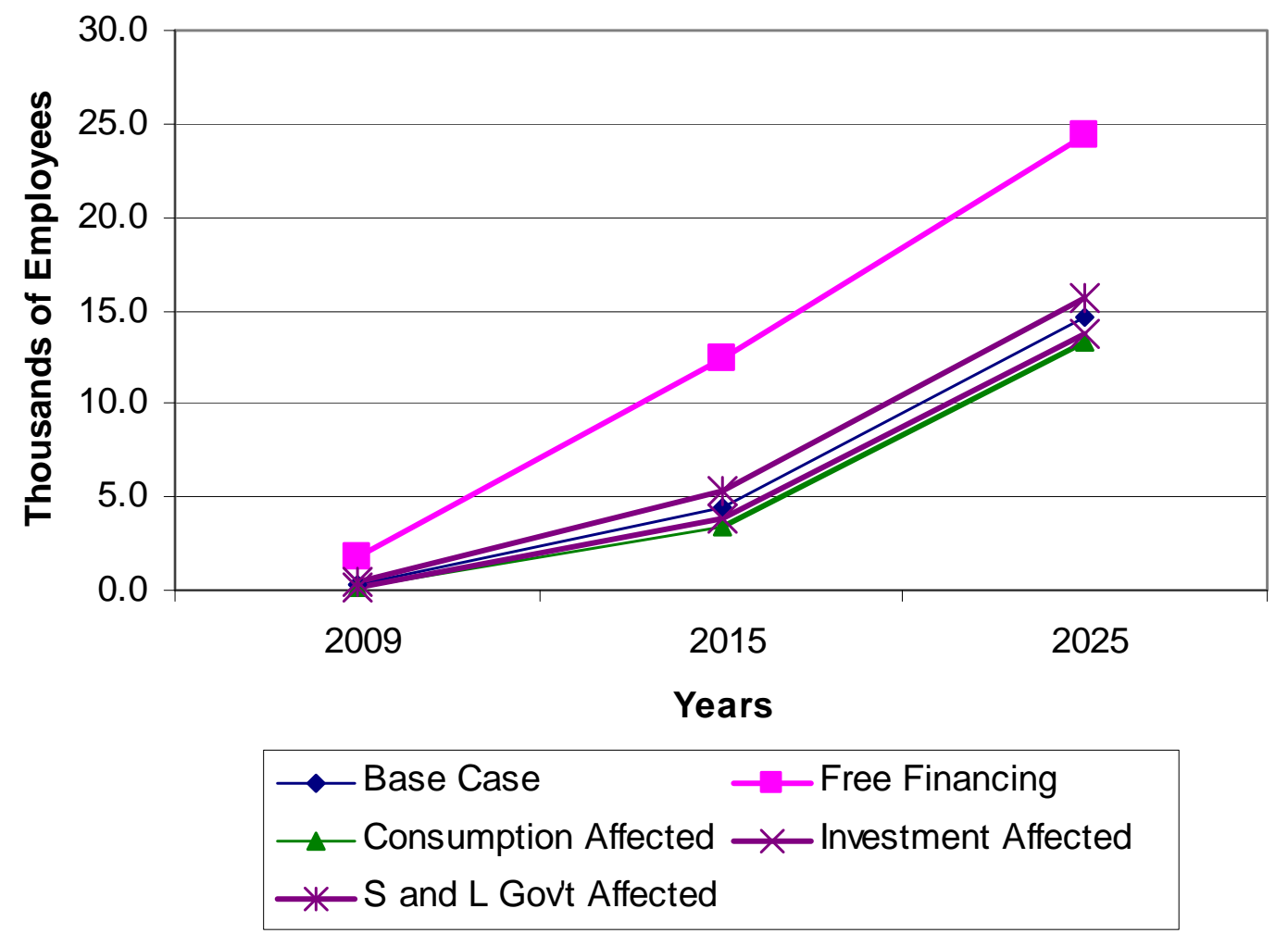

Figure 3-9. Effect of Buildings Energy Codes Financing on Employment Levels

Table 3.9. Effect of Buildings Energy Codes Financing on Employment Levels (Thousands of Employees)

\begin{tabular}{|c|c|c|c|c|c|}
\hline $\begin{array}{l}\text { Case } \\
\text { No. }\end{array}$ & Run Title & End-Use Sector & 2009 & 2015 & 2025 \\
\hline 1 & Base Case & Residential/Commercial & 0.30 & 4.50 & 14.60 \\
\hline 2 & Free Financing & Residential/Commercial & 1.84 & 12.46 & 24.37 \\
\hline 3 & $\begin{array}{l}\text { Consumption } \\
\text { Affected }\end{array}$ & Residential/Commercial & 0.09 & 3.42 & 13.27 \\
\hline 4 & Investment Affected & Residential/Commercial & 0.16 & 3.81 & 13.75 \\
\hline 5 & $\begin{array}{l}\text { Government } \\
\text { Affected }\end{array}$ & Residential/Commercial & 0.47 & 5.39 & 15.70 \\
\hline
\end{tabular}

Figure 3-10 and the accompanying Table 3.10 show the net impact of building energy code financing on the wage income in the economy. As in the comparable analysis of the IHP financing cases in Figure 
3-5, the national wage income is the highest in the Free Financing Case both because of the positive impacts of the energy cost savings (common to all of the cases in the figure) and because there is assumed to be no domestic financing cost of the investment required to deploy the building energy codes. Also, as before, the Base Case (financed by a proportional reduction in other domestic economic activity) shows a positive net impact of the savings program on national wage income because the impacts of the energy cost savings are positive and because the investments required to bring them about are in relatively highwage sectors compared with the rest of the economy. Consumption Affected lies above the Base Case, because the forgone consumption is in sectors that generally have lower wage rates than the average U.S. economic activity forgone in the Base Case. The Investment Affected Case lies below the Base Case because its package of forgone activity is relatively high-wage activity. As also was the case in Figure 3-5, the forgone economic activity associated with state and local government spending in the State and Local Government Affected case has the largest labor intensity and highest wage intensity of all.

Therefore, it has the least positive effects on national wage income of the all of the cases in the Figure. Unlike the comparable IHP case, however, the impacts of the energy cost savings area large enough to keep the net impacts of this case in positive territory.
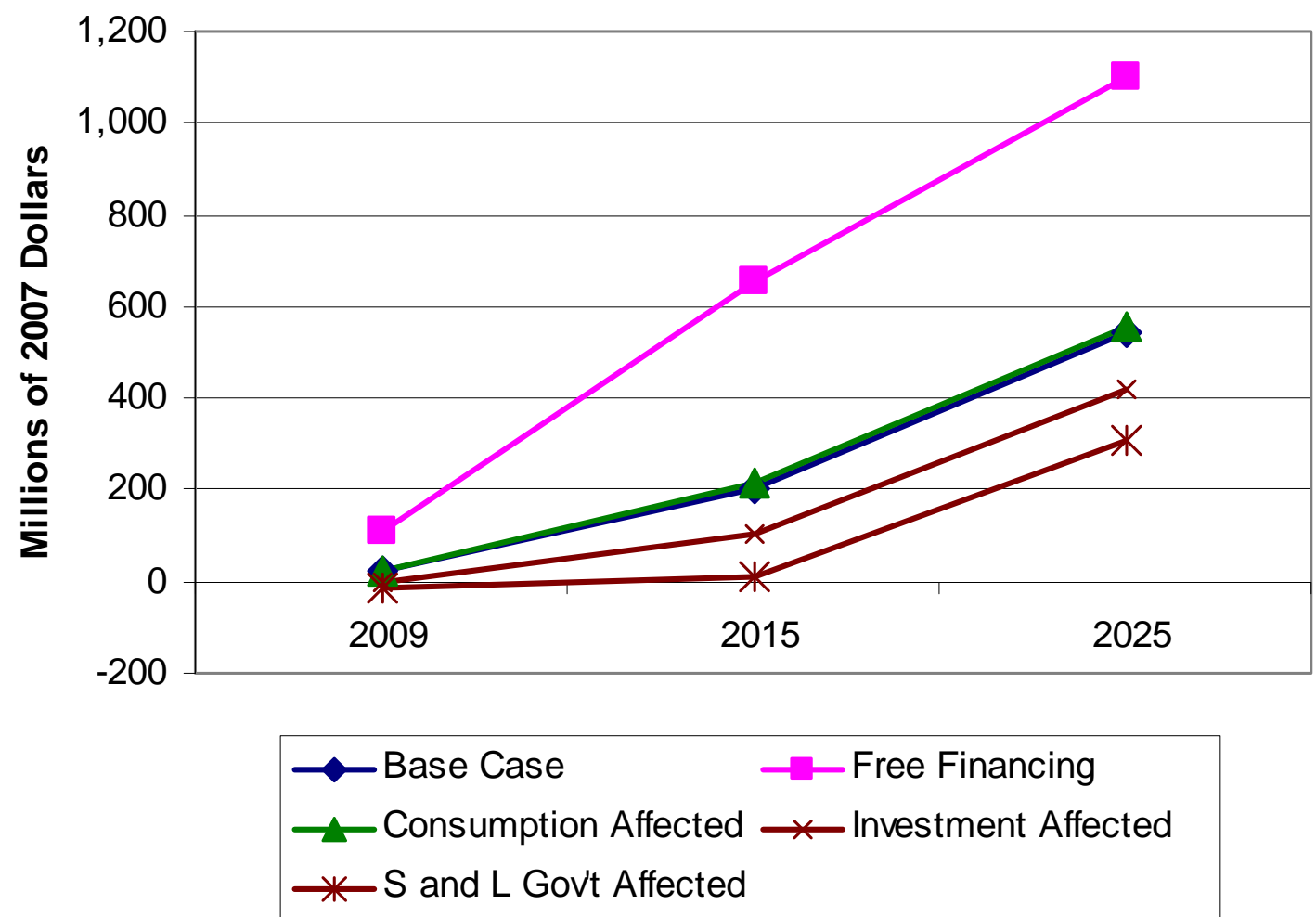

Figure 3-10. Effect of Buildings Energy Codes Financing on National Wage Income 
Table 3.10. Effect of Buildings Energy Codes Financing on National Wage Income (Million 2007\$)

\begin{tabular}{lllccc}
\hline $\begin{array}{c}\text { Case } \\
\text { No. }\end{array}$ & \multicolumn{1}{c}{ Run Title } & End-Use Sector & $\mathbf{2 0 0 9}$ & $\mathbf{2 0 1 5}$ & $\mathbf{2 0 2 5}$ \\
\hline 1 & Base Case & Residential/Commercial & 21 & 203 & 545 \\
2 & Free Financing & Residential/Commercial & 108 & 654 & 1099 \\
3 & Consumption & Residential/Commercial & 23 & 213 & 557 \\
4 & $\begin{array}{l}\text { Affected } \\
\text { Investment Affected }\end{array}$ & Residential/Commercial & 1 & 102 & 421 \\
5 & $\begin{array}{l}\text { State and Local } \\
\text { Government } \\
\text { Affected }\end{array}$ & Residential/Commercial & -17 & 10 & 308 \\
\hline
\end{tabular}




\subsection{Comparison with Other Studies: An Update}

A number of studies have been completed in recent years examining the impact of energy efficiency programs on employment and national income. Where possible, we attempted to reproduce and compare the results of those studies using Version 3.1 of ImSET. This exercise is similar to ones conducted for previous versions of the ImSET model (see, for example, Roop et al. 2005). Our conclusions generally remain the same. Where we have been able to conduct direct comparisons to other models using the same inputs, ImSET's results are quite similar compared to those of the other models that we reviewed. Where there are differences in results from this other work, these differences are in large measure due to differences in sector aggregation as well as to differences in a few critical assumptions among the authors of the various papers.

\subsection{Comparisons of the ImSET Approach to Other Studies}

As a framework for differentiating between different approaches to estimating impacts on macroeconomic variables such as employment or income, Berck and Hoffmann (2002) provide a taxonomy of five approaches. In order of increasing complexity, the approaches are as follows:

1. Supply and demand analysis of the affected industry

2. Partial equilibrium analysis of multiple markets

3. Fixed-price general equilibrium simulations

4. Nonlinear computable general equilibrium (CGE) simulations models

5. Econometric estimation of the adjustment process.

Included in the third approach are both I-O and social accounting matrix (SAM) models, into which ImSET 3 falls. Berck and Hoffmann (2002) note on their page 135 that I-O, SAM, and CGE represent a continuum of approaches, with I-O and SAM models providing an upper bound to the employment impacts because factor substitution (e.g. between labor and capital) does not occur. ${ }^{1}$ In a classical CGE model, which operates with a fully employed labor force, factor substitution would be complete, and there would be no net employment impacts in the economy, although there might be income impacts as a result of the migration of labor from one industry to another. Berck and Hoffmann (2002) apply the I-O/SAM approach to estimating the employment impacts of a decline in redwood timber sales from Del Norte and Humboldt counties in northern California. (See Xie [2000] for an application of SAM to environmental policy in China.) In pointing out the limitations of the third approach (fixed-price general equilibrium), Berck and Hoffmann (2002) note that

\footnotetext{
${ }^{1}$ Factor substitution does not occur in I-O models because each economic sector is assumed to always use the same ratio of capital, land, labor, and other inputs in fixed proportions regardless of the scale of the sector. These resources are also assumed to exist in whatever amounts are needed at constant relative prices, so there is no reason to substitute one relatively scarce and expensive input for another.
} 
“... with policies that do not affect relative prices, linear models are more likely to provide good approximations of actual changes than in situations where the policy impact is large enough to affect relative prices." (p. 145)

Earlier, the case was made that the technology changes examined in ImSET 3 are usually so small relative to the size of the economy and the economic sectors affected, that relative prices are unlikely to be affected. Therefore, the I-O approach will provide reasonably good estimates of the impacts of the penetration of DOE technologies into the economy.

Kaiser and Pulsipher (2003) and Kaiser et al. (2004) used a similar approach to estimate the impact of establishing a Louisiana Public Benefit Fund (proposed, but not enacted), which would levy a $1 \mathrm{mill} / \mathrm{kWh}$ $(\$ 0.001 / \mathrm{kWh})$ surcharge on all electricity sales; these funds would then be leveraged with other public and private funds to provide low-income energy bill assistance, low-income weatherization assistance programs, and residential and commercial energy conservation programs. ${ }^{2}$ Kaiser and Pulsipher (2003) and Kaiser et al. (2004) used the Impact Analysis for Planning (IMPLAN) model's I-O table for Louisiana provided by the company MIG, Inc., to estimate the economic impacts of the Public Benefit Fund. Their expected outcome would provide over 32,000 residential homes with insulation, nearly 19,000 commercial buildings improved with energy savings of $\$ 26.6$ million and a benefit/cost ratio of 1.7. Their expectation is there would be almost 1700 jobs created, additional tax revenues to the state of $\$ 8.3$ million, and a net economic benefit of $\$ 345.9$ million.

This approach is similar to ImSET 3 but does not modify the use matrix in the I-O framework to show the impact of adopted technologies on expenditures by commercial and industrial firms (see Section 2.1). Our interpretation of the Kaiser et al. (2004) results suggest that a distribution of benefits and costs $\left(30^{\text {th }}, 50^{\text {th }}\right.$, and $80^{\text {th }}$ percentiles) were estimated using multipliers from the IMPLAN model to determine output, value added, and through these output changes, employment changes to the Louisiana economy. Specific discussion of the financing of the investments is absent, suggesting the treatment is as if the costs and benefits are on an annualized life-cycle cost basis or on a net present value basis.

Nayak (2005) (a description of the model was provided in Economic Research Associates [2005]) examined the economic and consumer benefits of clean energy policies. The I-O model used in Nayak's study is very similar in approach to that used in the Geller et al. (1992) study. The national model has 15 sectors, analyzing the impact of reduced expenditures on energy over a period of 10 years. The payback period for any energy-efficiency project is assumed to be 4 years; the financing of the project would be at 80 percent of the cost, at 8 percent interest; and ad hoc adjustments for increased productivity and energy prices are factored into the analysis. ${ }^{3}$ Over the 10-year time period, labor productivity changes would occur and these would reduce jobs per unit of output in all but the energy savings sector. In one example, energy prices changes during the forecast period were assumed to have no effect on the cost of initial building improvements or the energy sector's lost revenues (these are fixed outside of the model), but the

\footnotetext{
${ }^{2}$ The Kaiser, et al. (2005) paper uses the approach to measure the impact of the (enacted) Louisiana Energy Fund, a public/private cooperative, effort partially funded by tax-exempt state bonds, to fund energy and water conservation projects.

${ }^{3}$ Exactly how this is done is not explained. It is clear from the example in the Nayak report that these effects are multiplicative: the table on p. 4 shows what effect labor productivity, price effects, and interest rate changes have on final demand, but the derivation of the prices and interest rate changes is not explained. With a 4-year payback, the 10 -year energy saving would be $\$ 2.5$ million. Presumably the productivity impacts are derived from Bureau of Labor Statistics estimates, as explained in the first paragraph on p. 6 of the Nayak report.
} 
increasing real energy prices would increase the impact of physical energy savings on final demand in the economy by 8 percent. Meanwhile, the impact of reduced utility revenues on final demand would reduce final demand by 6 percent. Interest rate changes would increase final demand by 2 percent in the buildings improvement sector and would increase the revenue impacts, but would have no impact on energy savings or utility revenues. A number of state models were derived from the national model and were designed to allow for specific effects, as requested by the U.S. Public Interest Research Groups (PIRG) Education Fund. ${ }^{4}$

The Nayak study was designed to examine the impact of two major policy changes to a federal government energy strategy proposal that they call the 2004 Federal Energy Package: 1) shifting \$35 billion in government expenditures from subsidizing fossil and nuclear industries under the 2004 Federal Energy Package to instead spending the $\$ 35$ billion on renewable energy and energy efficiency; and 2) enacting a 20 percent national renewable energy portfolio standard (the $20 \%$ Renewable Energy Standard), which would require that the United States generate 20 percent of its electricity from clean energy by 2020. Nayak (2005) shows impacts on jobs and GDP for three scenarios:1) the 2004 Energy Package; 2) the 20 percent Renewable Energy Standard; and 3) the Clean Energy Package, which is which is a combination of both the 20 Percent Renewable Standard and the $\$ 35$ billion shift in government expenditures. The net impact going from the first to the third scenario in 2020 is an increase of about 130,000 jobs, $\$ 5.1$ billion in wages $(2001 \$)$ and an increase of nearly $\$ 4.5$ billion in GDP.

While direct comparisons between ImSET 3 and the model used by the U.S. PIRG Educational Fund are not possible, it is possible to roughly compare employment impact multipliers, as seen in Table 4.1. The term "roughly" is used because the authors of this report have taken a simple average of the set of industries represented by the sectors reported in Nayak (2005) rather than aggregating and properly weighting the impacts by output measures. While these averages are only indicative, it is fair to report that the ImSET 3 employment impact multipliers based on the 2002 U.S. I-O table and Bureau of Labor Statistics' sectoral employment intenstities are generally smaller than those reported by Nayak (2005). Nayak's employment intensities were based on the ImPLAN 2001 database (in turn based on the 1997 U.S. I-O table and 2001 prices and labor intensities). The values for ImSET 2.0 were very close to those in Nayak (2005) where the in the sectors where the sector definitions were very similar-e.g., coal mining, electricity utilities, construction, wholesale and retail trade, and finance (Roop et al 2005). However, in comparing ImSET 2.0 and ImSET 3, we have noticed that sectoral employment intensities per dollar of output dropped significantly (perhaps 20 percent) between the 1997 and 2002 U.S. I-O tables, so the fact that ImSET 3 shows lower employment multipliers than we observe in Nayak (2005) is not surprising.

\footnotetext{
${ }^{4}$ Again, neither the number of state models nor the specific states are identified. It is not clear whether these are composite state models derived from the national model or specific state models constructed from IMPLAN data files.
} 
Table 4.1. Employment Multipliers, Nayak, and Selected ImSET 3 Industries (Jobs per Million Dollars of Final Demand)

\begin{tabular}{|c|c|c|}
\hline Sector & $\begin{array}{c}\text { Employment Multipliers, } \\
\text { Nayak (2005) }\end{array}$ & $\begin{array}{c}\text { ImSET } 3 \text { Employment } \\
\text { Multipliers }\end{array}$ \\
\hline Agriculture & 24.2 & 12.08 \\
\hline Oil and gas extraction & 9.1 & 8.75 \\
\hline Coal mining & 9.9 & 7.04 \\
\hline Other mining & 11.1 & 7.15 \\
\hline Electric utilities & 6.1 & 3.87 \\
\hline Natural gas distribution & 7.1 & 10.06 \\
\hline Construction & 18.3 & 10.98 \\
\hline Manufacturing & 11.6 & 10.65 \\
\hline Wholesale trade & 11.5 & 9.67 \\
\hline Transport and utilities & 15.9 & 19.55 \\
\hline Retail trade & 25.0 & 19.08 \\
\hline Services & 15.4 & 13.09 \\
\hline Finance & 11.1 & 7.27 \\
\hline Source: Nayak (2005). & Nayak (2005), p. 20 & ImSET 3, selected industries \\
\hline \multicolumn{3}{|c|}{$\begin{array}{l}\text { Laitner and McKinney (2008) examined } 48 \text { reports that document the economic impacts associated } \\
\text { with energy-efficiency investments, mostly at the level of individual states. A summary of the results of } \\
\text { these studies is reported in Table } 4.2 \text {. In terms of study time horizons, the period of analysis averaged } 12 \\
\text { years in the reviewed studies, with a low of } 5 \text { years and a high of } 26 \text { years. The average in terms of energy } \\
\text { savings over a reference case in the } 48 \text { studies was } 23 \text { percent, with savings (generally savings in the } \\
\text { energy bill rather than physical energy) ranging from } 6 \text { to } 33 \text { percent. All programs examined within the } \\
48 \text { studies reported benefits exceeding costs, with benefit-cost ratios ranging from } 1.1 \text { to } 4.8 \text {. Further, } \\
\text { each program generated positive net jobs. The net impact on GDP was positive in nearly all cases, with an } \\
\text { average impact of } 0.15 \text { percent and a high of } 0.6 \text { percent. The increase in GDP among programs was } \\
\text { attributed to the following: 1) the net benefits of energy efficiency exceeded the investment costs, and } 2 \text { ) } \\
\text { there was a shift in business activity away from energy-producing sectors, which are less labor-intensive } \\
\text { and tend to provide a smaller value-added contribution to the overall economy relative to other sectors. } \\
\text { These conclusions support those drawn in this report based on analysis of ImSET model output. }\end{array}$} \\
\hline
\end{tabular}


Table 4.2. Summary of Selected Past Energy-Efficiency Studies

\begin{tabular}{|c|c|c|c|}
\hline Key Indicator & Low & High & Average \\
\hline Period of analysis (years) & 5 & 26 & 12 \\
\hline $\begin{array}{l}\text { Efficiency potential (savings over reference } \\
\text { case) }\end{array}$ & $6 \%$ & $33 \%$ & $23 \%$ \\
\hline Benefit-cost ratio of policy scenario & 1.10 & 4.80 & 1.95 \\
\hline $\begin{array}{l}\text { Net jobs gained per trillion Btu of efficiency } \\
\text { gains }\end{array}$ & 9 & 95 & 49 \\
\hline $\begin{array}{l}\text { Net impact on GDP (as percent change in } \\
\text { reference case) }\end{array}$ & $-0.1 \%$ & $+0.6 \%$ & $+0.15 \%$ \\
\hline
\end{tabular}

Source: Laitner and McKinney (2008).

Laitner and McKinney (2008) went further to use the comparable data from 24 of the studies to estimate national economic impacts associated with energy-efficiency investments. The authors found that the economic impact of efficiency programs was a function of the magnitude of the energy-efficiency savings and the economic efficiency of the programs, as measured through benefit-cost analysis. ${ }^{5}$ Through careful examination of the data supporting the aforementioned 24 studies, a matrix correlating benefit-cost ratios and energy-efficiency gains to employment effects was constructed. The results of the analysis suggest that at the national level, investments resulting in energy-efficiency savings of 20 percent and a benefit-cost ratio of 2.0 would create 838,000 jobs in 2030 . Investments resulting in energyefficiency gains of 25 percent with benefit-cost ratios of 3.0 would result in an increase in employment of 1.5 million. However, no direct comparison with ImSET results can be conducted because the Laitner and McKinney (2008) study does not explicitly mention the level of investments required to achieve suggested energy savings.

Roland-Holst (2008) examines the economic impact of existing and proposed future energyefficiency policies in California. In so doing, the goal of the analysis was to assess the economic impact of the state's drive toward reducing greenhouse gas emissions and associated impacts on global warming. These goals include those outlined in California Executive Order \#S-3-05, which calls for a 30 percent reduction in greenhouse gas emissions by 2020 and an 80 percent reduction below 1990 levels by 2050 .

Detailed I-O tables were constructed for the United States and California, which were used to examine the historical impact of California's energy-efficiency policies inside a general computable equilibrium model of the California economy named the Berkeley Energy and Resources (BEAR) model. These I-O tables comprised value added, inter-industry flows, and final demand for 500 activity and commodity categories. The data covered the 1972 through 2006 time period, and were aggregated up to a 50-sector framework. The I-O model was then used to compare two cases: 1) a baseline where no

\footnotetext{
${ }^{5}$ Regardless of whether an investment is cost effective or not, the results always show GDP and net job impacts because it is the size and distribution of expenditures that affects GDP and employment, not whether there are any net benefits at all. An extreme example of a project with no economic benefit that has positive GDP and employment impacts is a make-work project that hires two teams of workers: one team to bury rocks, and a second team to dig them up. Cost-effectiveness of the investment requires a separate calculation.
} 
efficiency gains were made, and 2) a scenario that considers the impact of the programs that allow California per-capita energy demand to fall 40 percent below the national average. The study found the energy-efficiency gains experienced between 1972 and 2006 had enabled California households to divert $\$ 56$ billion from energy expenditures towards other goods and services. The economic effects of the reduced energy costs included the expansion of employment by 1.5 million full-time equivalent jobs and an increase in payroll by $\$ 45$ million.

BEAR, used to examine historical energy-efficiency gains in California, has some similarities to ImSET inasmuch as it contains an I-O model that accounts for inter-industry flows, value added, final demand, and multiplier (indirect and induced) effects. However, it does not appear to take into account the effects of financing the technologies required to achieve the energy-efficiency gains. Nor does BEAR appear to account for the capital costs associated with investment in new technologies (Roland-Holst 2008). For comparison purposes, ImSET was run to assess the impacts of savings in California in isolation, but with our assumptions, the net annual job growth in ImSET was only 8100 jobs, and the net income increase was approximately $\$ 240$ million. ${ }^{6}$ We cannot however directly compare our results with Roland-Holst (2008) as the ImSET model requires more detailed information than could be found in the documentation of the BEAR model results.

Sedano et al. (2005) examines the economic impact of energy-efficiency programs and renewable energy investments in New England. More specifically, the study used the IMPLAN I-O model to estimate the direct, indirect, and induced effects of three distinct programs: 1) energy efficiency-oriented programs beginning in 2000 with planned funding levels extended through 2010;2) renewable energy deployments since 2000; and, 3) the two previous scenarios with additional investments required to meet existing renewable portfolio standards requirements. Sedano et al. account for the tradeoffs between reduced electricity prices, enhanced business profitability, increased consumer purchasing power, and enhanced spending on efficiency-related goods and services relative to fuel and operating expenses for power plants. Their projected result of the energy-efficiency programs in New England includes a net increase in economic output of $\$ 2$ billion, employment of almost 15,000 job-years $(15,000$ cumulative years of employment over the study period), and about $\$ 700$ million in cumulative income over the 2000 2010 time period. Similar analysis in ImSET shows a job increase of 28 thousand job years and $\$ 1.8$ billion in cumulative income over the 2000-2010 time period. $^{7}$

As noted previously, Sedano et al. (2005) uses the IMPLAN model to estimate the economic impacts of energy scenarios. In so doing, the model traces the flows of income, goods and services, and employment among various sectors of the economy. IMPLAN, as employed in Sedano et al. (2005), is very similar to ImSET in that it considered energy cost savings, increased costs associated with investments in technologies, and a shift away from business activity in the generation of power, all in a static manner. The Sedano et al. (2005) estimate was for a regional economy. Using the same assumptions, ImSET, which is a national model, should show (and does show) a larger impact because it

\footnotetext{
${ }^{6}$ The savings-only case was computed with $\$ 160$ million of annual savings assigned to residential oil expenditures, $\$ 571$ million to residential natural gas expenditures, and \$869 million to residential electricity expenditures.

Reduction of the investment in electric utilities and natural gas distribution as a result of natural gas and electricity savings was also considered.

${ }^{7}$ The ImSET analysis assumed free financing and included the transitory impacts of the efficiency investment. The input data set was developed based on Tables 2.12 and 2.13 in Sedano (2008). Energy-efficiency impact was adjusted to account for reduction of investment in utilities as a result of electricity savings.
} 
incorporates economic impacts that ordinarily would be part of the "leakage out of regional economy such as New England's" (Sedano et al. 2005). However, it is not entirely clear from available documentation whether there is complete equivalency of assumptions.

Eldridge et al. (2008) examines the energy and economic impacts associated with a suite of policy proposals aimed at enhancing energy efficiency in Maryland. In modeling the macroeconomic effects of the energy-efficiency gains associated with the proposed energy policies, Eldridge et al. (2008) used American Council for an Energy-Efficient Economy's Dynamic Energy Efficiency Policy Evaluation Routine (DEEPER) model. Inputs used by the model include annual program spending, electricity savings resulting from energy-efficiency investments, and the capital and operating, including financing, costs associated with those investments. The DEEPER model is described as a quasi-dynamic input-output model with six key modules:

1. Global data (economic time series data, key model coefficients, and parameters needed to generate final model results)

2. Macroeconomic model (input-output relationships based on IMPLAN data)

3. Investment, expenditures, and energy savings

4. Price dynamics

5. Final demand

6. Results.

The macroeconomic modeling procedures used in DEEPER, which includes I-O matrices, are similar to those in ImSET. Further, like ImSET, DEEPER considers the impact of investment financing costs. Unlike ImSET, DEEPER also includes modules designed to explore the impact of reduced energy consumption on wholesale electricity prices.

Policies evaluated by Eldridge et al. include implementation of federal and state appliance standards, more stringent residential and commercial building codes, policies designed to encourage investment in combined heat and power systems, and expanded utility demand response programs. The impacts of these policies were estimated to result in 15 percent savings in energy consumption compared to the reference forecast, producing $\$ 861$ million in consumer energy cost savings in 2015 and $\$ 2.6$ billion by 2025. On average, households in Maryland are forecast to save $\$ 8$ on their monthly electricity bill in 2015 with an additional $\$ 2$ in savings resulting from the impact of declining demand on wholesale energy prices. These energy savings are forecast to result in positive net employment effects of 8067 jobs in 2015 and 12,241 jobs in 2025. Wages are forecast to increase by a net $\$ 462$ million in 2015 and $\$ 780$ million in 2025.

Assuming a savings-only case with savings split equally between residential and commercial sectors, the results of ImSET calculations for the same level of savings show a net job increase of 5930 jobs in year 2015 and 17,930 in 2025. The net earnings increase is \$156 million in 2015 and $\$ 470$ million in 2025. While the models are different and the documentation available in the Eldridge et al. (2008) report did not allow exact duplication of assumptions for ImSET, it appears that both models obtained impact results of roughly the same order of magnitude. 


\subsection{Operating the ImSET 3 Model}

ImSET 3 runs on the Windows ${ }^{\circledR}$ operating system. It requires installation of the software using SETUP.EXE program provided. Prior to installing ImSET 3, all previous versions need to be uninstalled. This will ensure that all components of the model are installed properly. Once ImSET 3 is installed, the user starts the program using normal Windows interface methods. On startup, the ImSET 3 program displays the main "Run specifications" screen (see Figure 5-1). The user uses this screen to add records to represent specific program assumptions.

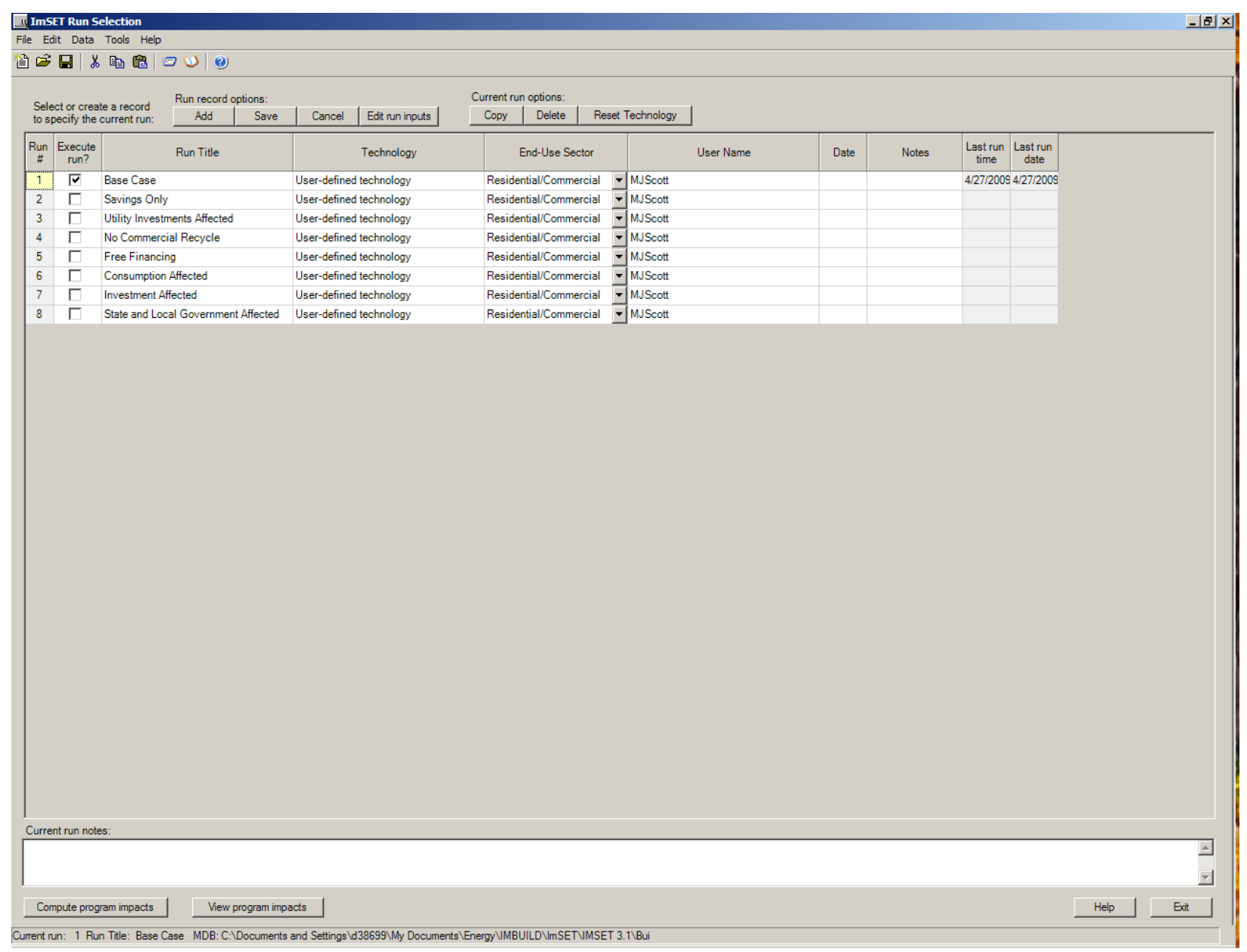

Figure 5-1. ImSET 3 "Run Selection” Screen

\subsection{ImSET 3 Options}

The "ImSET Run Selection" screen is used to specify unique program scenarios. Each input record signifies a unique program scenario. Users can add as many records as there are unique scenarios to be 
compared. However, only the records that have "Execute run" checkbox checked will be executed (see Figure 5-1). By specifying "run records," the user creates a new "run database", which is a Microsoft Access Database (.mdb) file. The user can create, save, or open scenario files using the menu options under the "File" menu (see Figure 5-2). The run database will hold all information and results specific to the scenarios established and specified. Thus, a user can make any number of run databases for specifying unique scenarios.

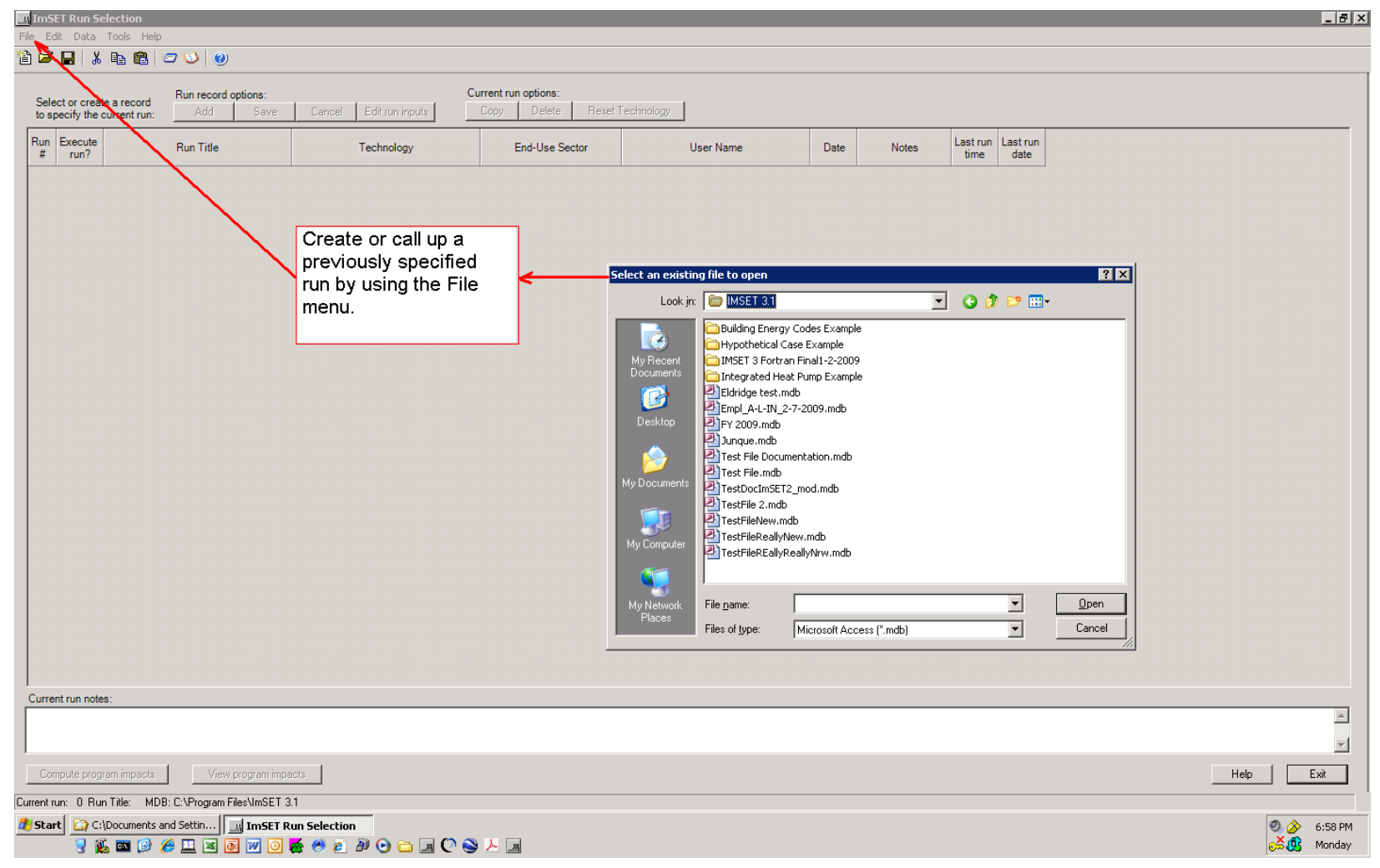

Figure 5-2. Run Selection Screen Showing File Menu

\section{Screen Functionality}

- Add Adds a run record to the run database.

- Save Saves the run records currently listed on the screen to the currently open run database.

- Cancel - Cancels any unsaved changes to a run record and refreshes the display.

- Edit run inputs - Displays a screen of detailed "run inputs" that can be edited by the user.

- Copy - Copies the currently selected run record and adds a duplicate to the bottom of the current database (the currently selected record is indicated by yellow marker in column furthest left and/or in status bar at the bottom of the screen). To select an existing run record, point the cursor at its title and left click, or use the keyboard up and down arrows. 
- Delete - Removes the currently selected run record from the screen and the run database. A "Confirmation request" is displayed to verify the request. The "Confirmation request" can be "turned off" for future deletions by checking the appropriate check box in the "Confirmation request" screen.

- Compute program impacts - Computations of program/technology impacts are run on all run records that have the "Execute run" column checked. After computations are done, the results screen is displayed.

- View program impacts - Displays the results screen without running computations. Results are displayed for the last computed impacts.

- Help Displays the help file.

- Exit - Exits the ImSET program.

"Run specification" columns (Figure 5-3) are described in the following:

- Run \# - A unique identifier for a run record. This is a non-editable column and is determined programmatically.

- Run title - User provides description of the specified run record.

- Technology - The technology/program is assigned to the specified run record. When a run record is added, the technology list is displayed as a drop-down list containing all default technologies/programs. Select the appropriate choice.

- Note: The user cannot change the technology choice after it is saved using the run record. However, after saving the record, the user can edit the technology description and edit its underlying data and/or copy the edited technology to another run record.

- End-use sector - Identifies the appropriate energy end-use sector for the run record. The selection determines what energy use sectors the user will have access to in the "Run inputs" screen. The energy end-use sectors in ImSET are the residential, commercial, industrial, and transportation sectors. Depending on the end-use sector selected, different subsets of ImSET's 187 economic sectors experience energy savings. ${ }^{1}$

- User name - User provides name for reference purposes only.

\footnotetext{
${ }^{1}$ ImSET economic sectors that are benefitted by commercial energy end-use savings are sectors $12,13,14,140$ and 150 - 175 and government enterprises in sectors 177-178, 180-181 and 184-185; sectors that benefit from industrial end-use also include agricultural, mining, and construction sectors and comprise sectors 1 through 139 (except for 12-14); transportation end-use savings benefit sectors 141 through 149 and 179. Household enterprises (176), owner-occupied housing, and rest-of-world (186-187) cover the rest of the economic sectors. They are not affected by energy and water savings. Residential end-use savings are treated separately and automatically by ImSET and benefit almost all sectors through consumer spending.
} 
- Date - User provides date for reference purposes only.

- Notes - Place available to enter brief explanatory notes on the run record. Save the notes after entering by using the Save button under Run Record Options on the screen.

- Last run time - Indicates the time the record impacts were last evaluated.

- Last run date - Indicates the date the record impacts were last evaluated.

If a new run database has been newly created, it will appear without any run records. Click the Add button to add a new record and then fill in the cells. Run Title, Technology, and End-Use Sector must be specified. Select Save to save any new run records or changes to existing run records.

To access the underlying economic and technical data of the run record, select the Edit run inputs button and review/edit the data as needed.

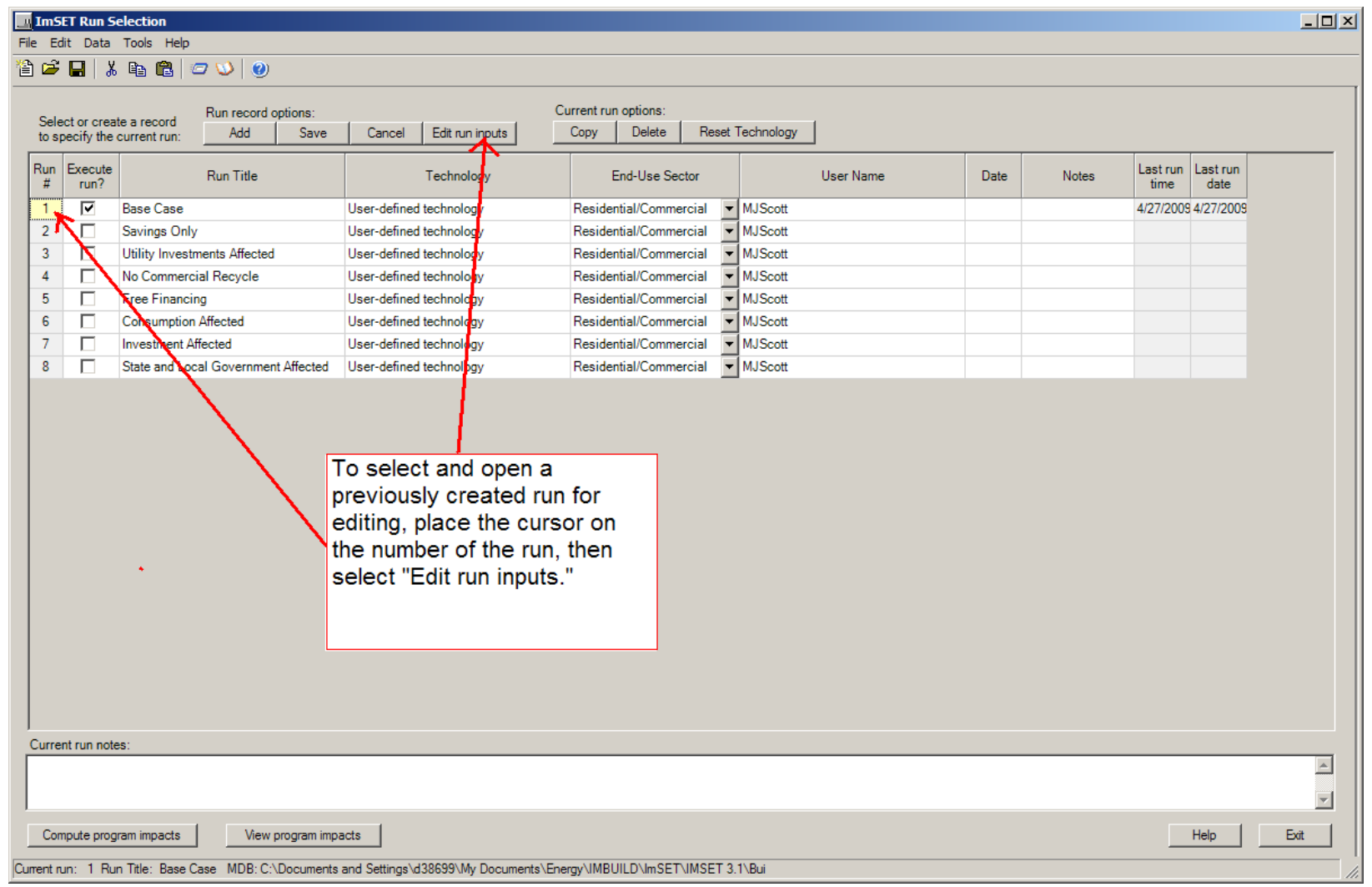

Figure 5-3. Selecting a Run for Editing

When all data have been specified, the user can select Compute program impacts to perform the actual calculations and display results. Note that only those run records that have "Execute run" checked will be included in the calculation process and displayed in the results screen. If there are no changes since the last calculations were run and the user simply wants to review the results, select the 
View program impacts button.

\subsubsection{Tab 1: Technology Data}

The Technology Data tab (see Figure 5-4) is used to enter and edit the model user's assumptions concerning incremental programmatic impacts on capital cost, installation cost, energy or resource cost, O\&M cost, and energy or resource savings for a single run record. The appropriate units for each variable are displayed in the row headings. Note that all data are specific to the run record described in the dropdown list at the top of the screen. Furthermore, the rows that are displayed in the screen are dependent on the "End-use sector" (residential, commercial, industrial, or transportation) that is selected for the run record. To view the technology data for a different run record, select a different run record at the top of the screen.

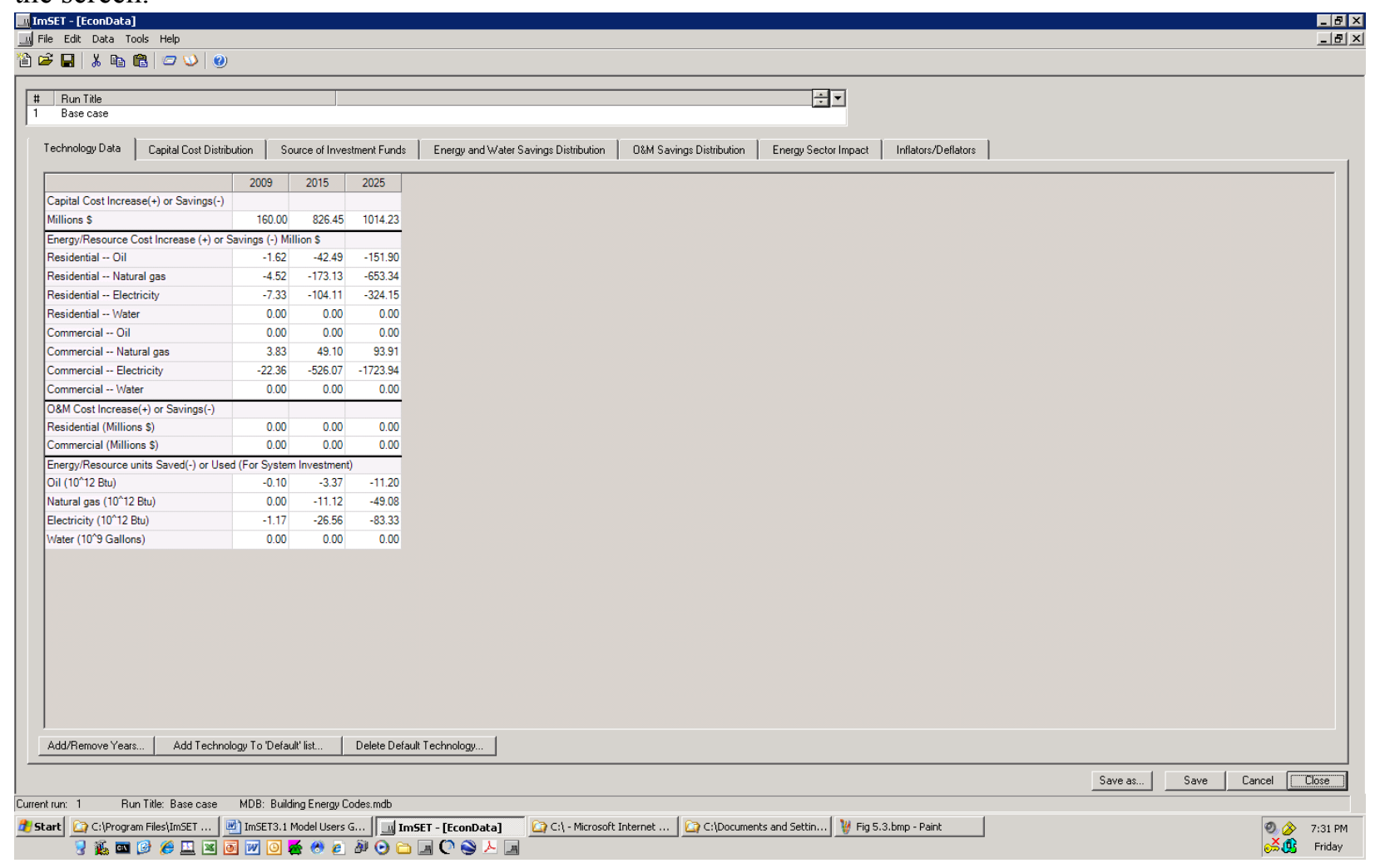

Figure 5-4. Technology Data Tab

Values on the Technology Data tab can be imputed or edited by hand. However, this requires an understanding of the total market impacts (e.g., energy savings, cost savings, investment costs) of the technology; which would usually be derived from another model or analytical framework. For example, PNNL uses the BEAMS model (Elliott et al. 2004; Elliott et al. 2008) to develop many of these estimates. Years covered by the scenario can also be changed.

Note that all costs or savings values are considered to be differences from the conventional competing technology. In the example shown in Figure 5-4, the adoption of the energy-efficiency technology results in $\$ 160$ million in additional investments during the year 2009. As shown in Figure 5-4, this investment yields the following annual expenditure impacts: $\$ 7.33$ million saved in residential electricity, \$22.36 
million in commercial electricity, \$4.52 million in residential natural gas, and \$1.62 million in residential oil, with no change in water expenditures, and no change in non-energy operating costs. In this example, the cost of consumption of commercial natural gas increases by $\$ 3.83$ million. The energy, water, and operating cost savings are differentials between some base case and that produced by the new technology. The costs are expressed in annual savings for the year shown even though those savings (entered as negative values) depend on cumulative investments. The capital costs are the cash investments in the year shown (entered as positive values). This accounting is required by the input-output model's structure with requires an annual cash flow.

\section{Technology Data Tab key functions:}

\section{Advanced technology options - Two buttons (Add Technology to 'Default' list... and}

Delete Default Technology... ) enable the user to add a technology to the "Default" technology list and/or delete technologies from the "Default" technology list. This feature allows the user to establish customized versions of a technology that can then be used repeatedly when adding new run records.

Add/remove years Enables the user to add and/or remove years from the currently displayed run record

Note: Choices made on the Technology Data tab only affect the currently displayed run record. Before run records in a run dataset can be processed by the model to calculate impacts, all run records in the run dataset must have the same set of years.

\section{Changing the Default Technology Options}

Add Technology to 'Default' list... - Enables the user to add a technology to the "Default" technology list (see Figure 5.5). This feature allows the user to establish customized versions of a technology that can then be used repeatedly when adding new run records to a run dataset. More specifically, the user may have a particular set of technology data and years that are not currently represented in the "Default" technology list. To create a new "Default" technology, simply select an existing run record (which can be an existing "Default" technology or a "User-defined technology"), edit it if desired, save any changes, and then select the Add Technology to 'Default list...' button on the Technology Data Tab..The user will see a new "Add technology" screen appear (Figure 5-5), in which a unique technology name can be entered where requested, then select Save and Close. At this point, the user can return to the "Run Selection" screen. 


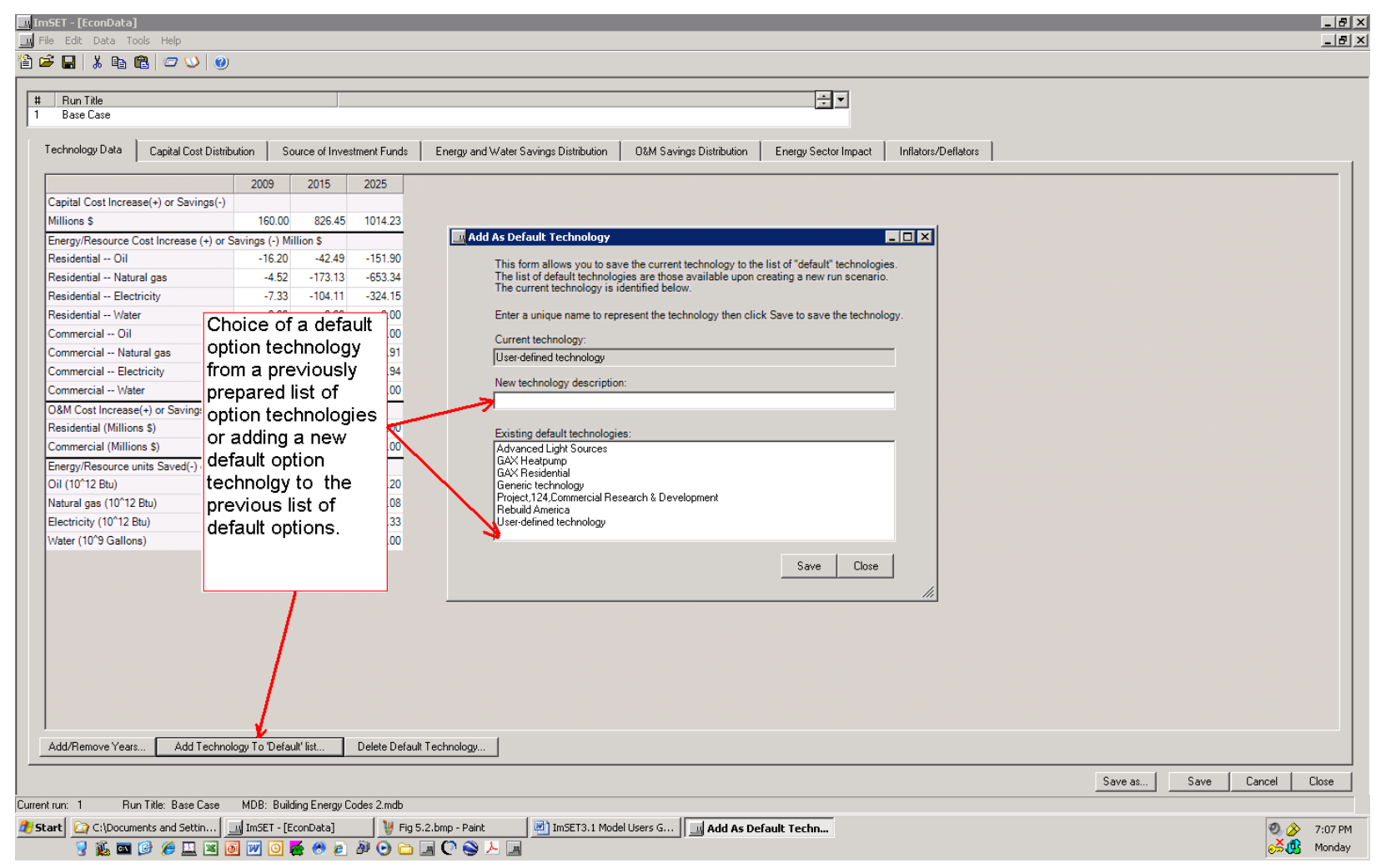

Figure 5-5. Adding to the Technology Options

If the user adds new run records, the newly created technology will appear in the drop-down list of "Default" technologies.

Delete Default Technology... - Enables the user to delete technologies from the "Default" technology list. Note: deletion of a technology only affects the "Default" technology list and in no way deletes records from the user database file.

\subsubsection{Tab 2: Capital Cost Distribution}

Enter the percentage values (enter " 50 percent" as " 50 ") that represent the distribution of capital cost premiums for the applicable sectors. The total of all values ordinarily must equal $100 .^{2}$ In the example shown in Figure 5-6, the capital cost premium is spread across several sectors to equal $100 \%$. Completing this table requires some understanding of both the nature of the technology as well as the structure of the economy that will need to produce that technology. When finished entering values in the table, enter Save and Close. Each time a value is entered by hitting "enter," the "Total \%" cell will update, showing

\footnotetext{
${ }^{2}$ The user may want to account for investments that have a large import component. The authors of this report recommend the user record the portion of the investment that is domestic in the technology data tab, allocate that domestic portion to equal 100\% (as shown in Figure5.6), and then under the source of funds tab (discussed in Section 5.2.5), record the domestic opportunity cost of funds as more than $100 \%$ to account for both the domestic and imported portions of the investment; e.g., if $50 \%$ of a $\$ 100$ million cost were domestic, the user would record $\$ 50$ million, allocate $100 \%$ of that, and then ensure the source of funds summed to $200 \%$ (of the $\$ 50$ million).
} 
the sum of the values entered (if all values are zero, the cell will be 0 ). The current system default is zero for all values in the table. The Reset all to 0 button sets all of the values in the table to zero.

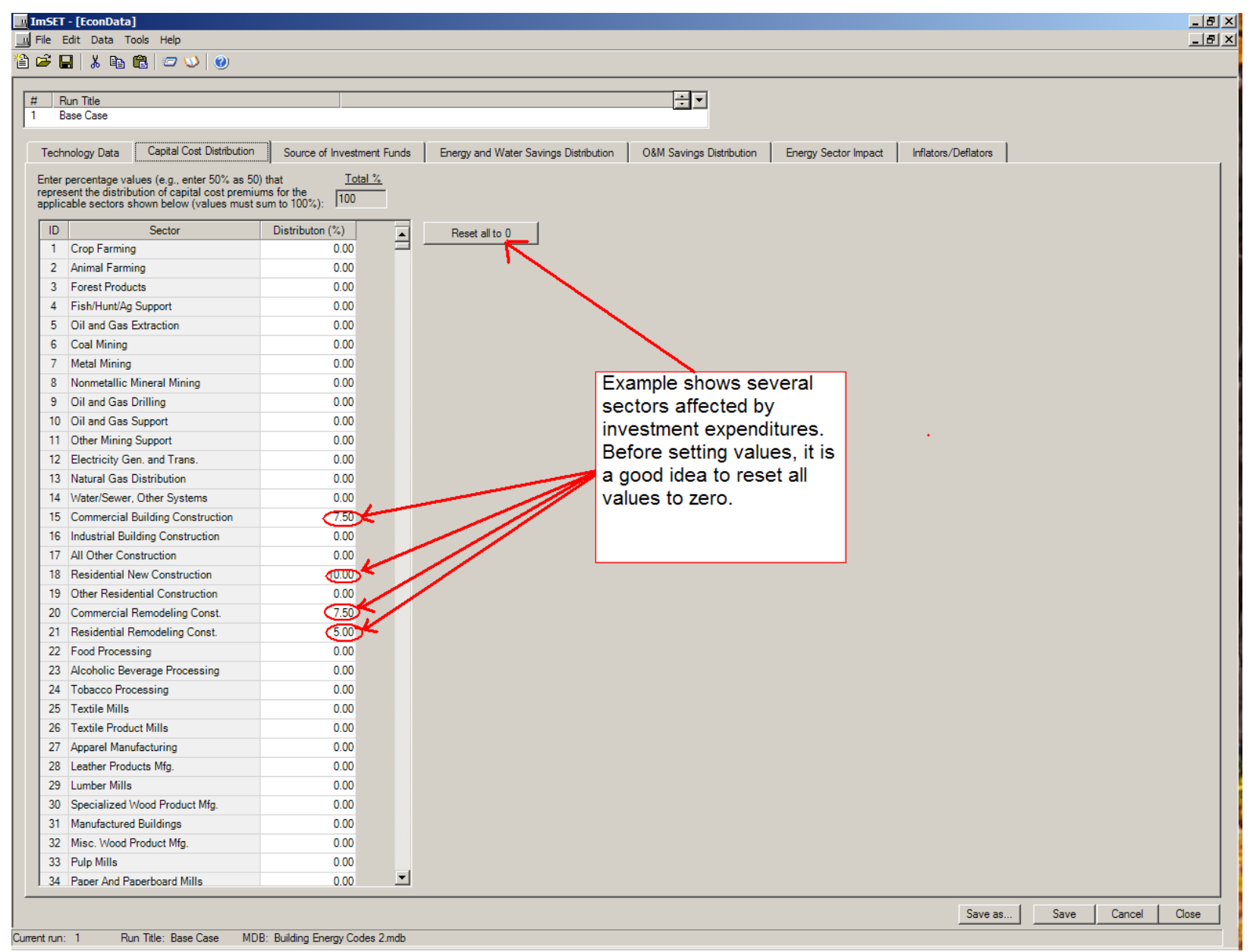

Figure 5-6. Allocation of Capital Cost

\subsubsection{Tab 3: Source of Investment Funds}

Investment funds spent on energy-efficient equipment have an opportunity cost; that is, they would have been spent somewhere else in the domestic economy or overseas if they were not spent on energyefficient equipment. This tab allows the user to specify the source of the funds used for investment. Enter the percentage values (e.g., enter "50 percent" as "50") that represent the share of the energy-efficient investment funding provided by each applicable source in the economy (personal consumption expenditures or PCE, investment, etc). The most common assumption is that investment funds will come proportionately from all domestic spending.

There are occasions when the user may not want to consider the opportunity cost of some or all the funds used for investment. For example, if only the impacts on a local region were being considered and 
the funds came from the national financial markets, the local area might see the positive impact of the investment as well as any energy savings, but would not experience costs to the national economy. These costs would be felt elsewhere. Another reason might be if a substantial part of the displaced spending were somewhere else in the world and only the domestic impact was important.

The sum of the sector allocations does not need to equal 100 percent, but if it does not, the model will proportionately allocate the remaining percentage to sum to 100 percent $^{3}$ unless it is overwritten. The overwrite check box allows some or all of the opportunity cost of invested funds to not be counted against domestic final demand. If opportunity cost of the investment funds is irrelevant to the analysis, then all values can be set to 0 . To do this, set all of the sectors to 0 , check the check box, and then enter 0 in the "Share to allocate" box to 0 as well. However, note that even if all explicit shares in the Distribution \% box are set to 0 , each sector will have its spending reduced by the proportion it represents of all final demand unless the overwrite check box is checked.

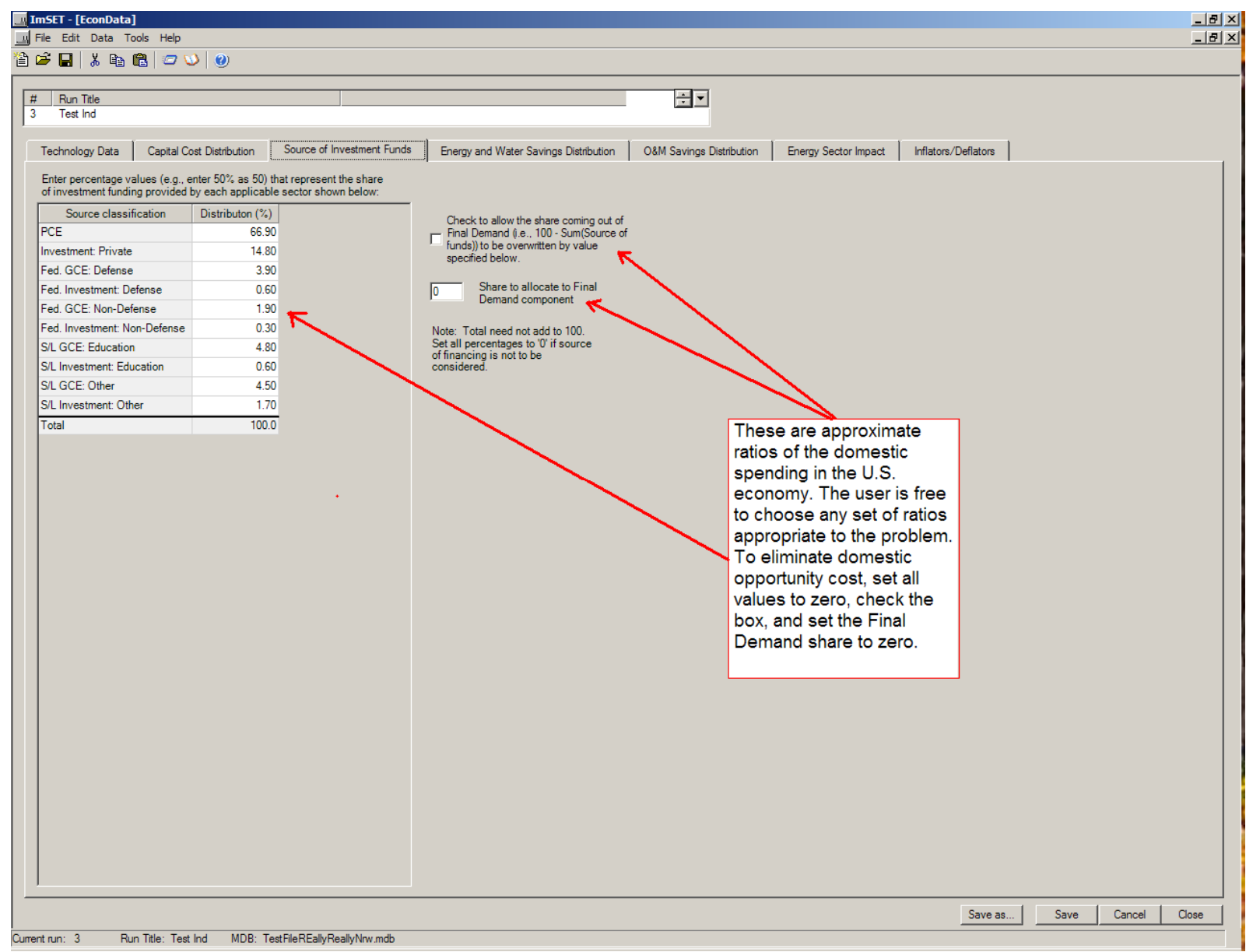

Figure 5-7. Opportunity Cost of Investment Funds

\footnotetext{
${ }^{3}$ The model allocate spending reductions within the remainder (unallocated) percentage using the average proportions that consumption, investment, etc comprise in all final demand in the 2002 economy. To see how this works, note that the actual shares in the 2002 economy were $70.2 \%$, for PCE and $15.1 \%$ for investment. Thus, if the sum of the explicit values in the "Distribution \%" column were $90 \%$, the remaining $10 \%$ of the opportunity cost would be allocated proportionately as $7 \%(70.2 \% \times 10 \%)$ to PCE, $1.5 \%$ to investment $(15.1 \% \times 10 \%)$, etc.
} 


\subsubsection{Tab 4: Energy and Water Savings Distribution}

Enter the percentage values (enter " 50 percent" as " 50 ") that represent the distribution of energy and water cost savings for the applicable sectors (see Figure 5-8). The total of all values must equal 100. Note the sectors shown will depend on the end-use sector targeted by the technology or program. For example, commercial end-use energy cost savings can be felt in sectors 12-14, 140, 150-175, 177-178, 180-181, and 184-185; industrial end-use energy cost savings (including agriculture, mining, and construction) can be felt in sectors 1-139 (except for sectors 12-14) and 182-183; and transportation energy cost savings can be felt in sectors 141-149, and 179 (State and local passenger transit). Each sector experiencing savings is assumed to experience these savings as value-added in the sector (Personal compensation, retained earnings, or indirect business taxes) and is assumed to be spent in the same manner (personal consumption, investment, or government spending). Federal government defense services (sector 183) are assumed to be relatively large energy users and are grouped with "industrial" users. Government enterprises and government services in sectors 177-178, 180-181, and 184-185 are treated as "commercial" for purposes of energy savings distributions. The remaining handful of sectors include household enterprises (176) and accounting conventions (186-187), which are not treated as beneficiaries of end-use energy savings. Residential end-use technology and program cost savings will impact all final demand; thus, there will be no specific industry sectors directly affected. Residential energy savings are allocated to final demand. The spending of residential savings is allocated across industries in the same proportions as all other residential final demand.

Energy savings in commercial buildings by default are allocated to each commercial sector in proportion to fuel likely purchased for each sector; e.g., if sector 140 (wholesale trade) purchased 4.57 percent of baseline electricity purchased in commercial buildings, then sector 140 would likely have accumulated 4.57 percent of the savings as well. The user is free to change these proportions. On the other hand, if a particular program were focused only on electricity used by hospitals, it would make sense to make sector 169 (Hospitals and Residential Care) the sole beneficiary of the energy savings for that program and allocate $100 \%$ of electricity savings to that sector. The model also includes water cost savings; this is important for water-using equipment, such as laundry equipment. 


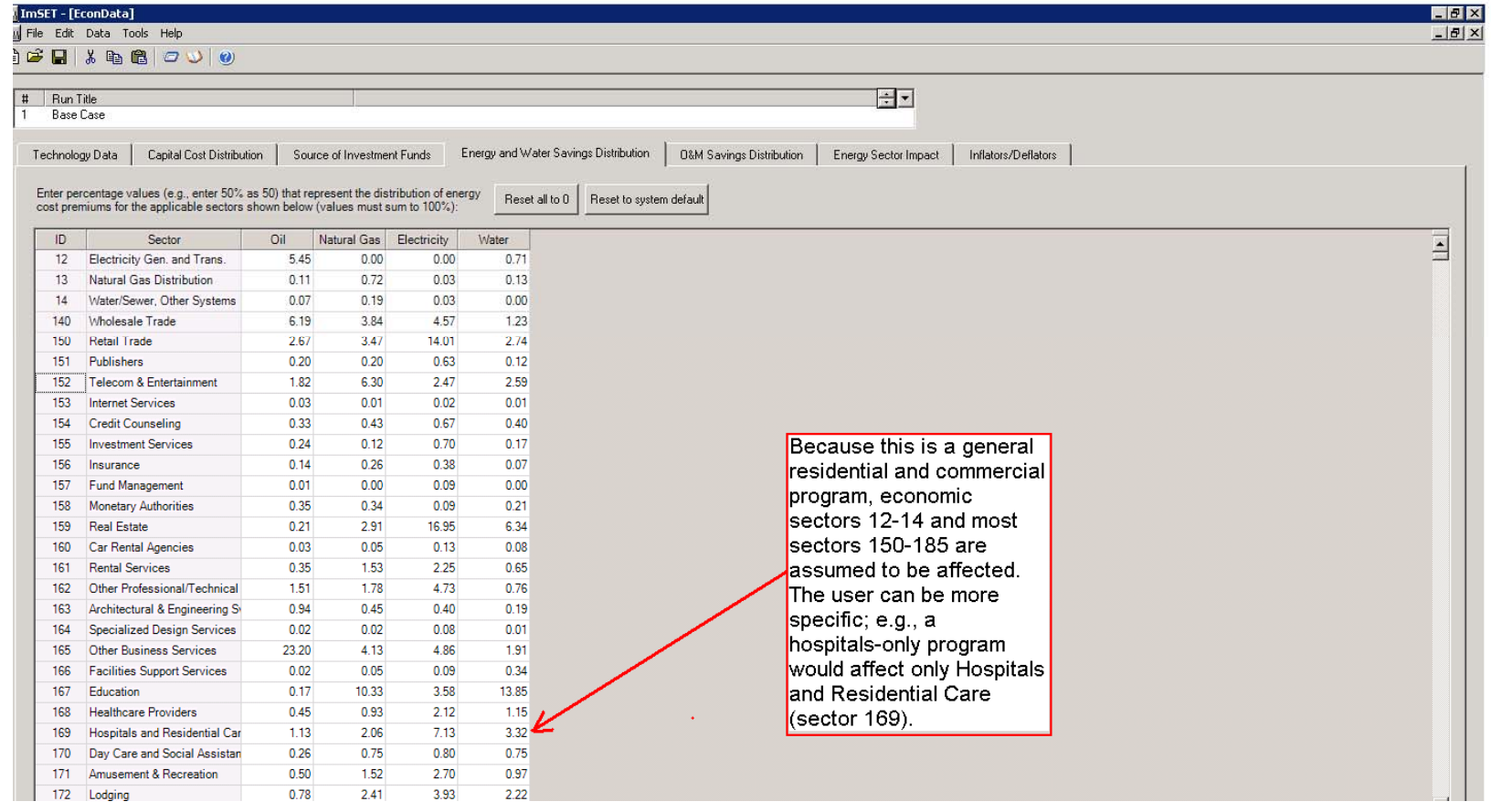

Figure 5-8. Energy/Water Cost Savings Distribution Among Sectors

\subsubsection{Tab 5: Operating and Maintenance Savings Distribution}

Default allocations for each of the end-use sectors are currently shown in Figure 5-9, but these can be modified to suit the user. Operating and maintenance (O\&M) activities, if they are purchased from one of the sectors shown, would probably all be spent on personal services. Distributions for the other end-use sectors were calculated by summing the purchases from these four sectors, then dividing each sector's sales by the total. The modest activities that transportation services sell to the commercial sector were deemed to be activities other than O\&M, so this cell is specified as zero by default. Rather than construct a distribution of O\&M expenditures for each of the end-use sectors, these changes were treated as applying to final demands.

Sensitivity tests were run with varying distributions of O\&M expenditures among the sectors shown in Figure 5-9 to determine if this would make a substantial difference in the output of the model, and the changes were found to be modest, in the extreme - in the thousandths of a percentage point for reasonable estimates of O\&M costs/savings. 


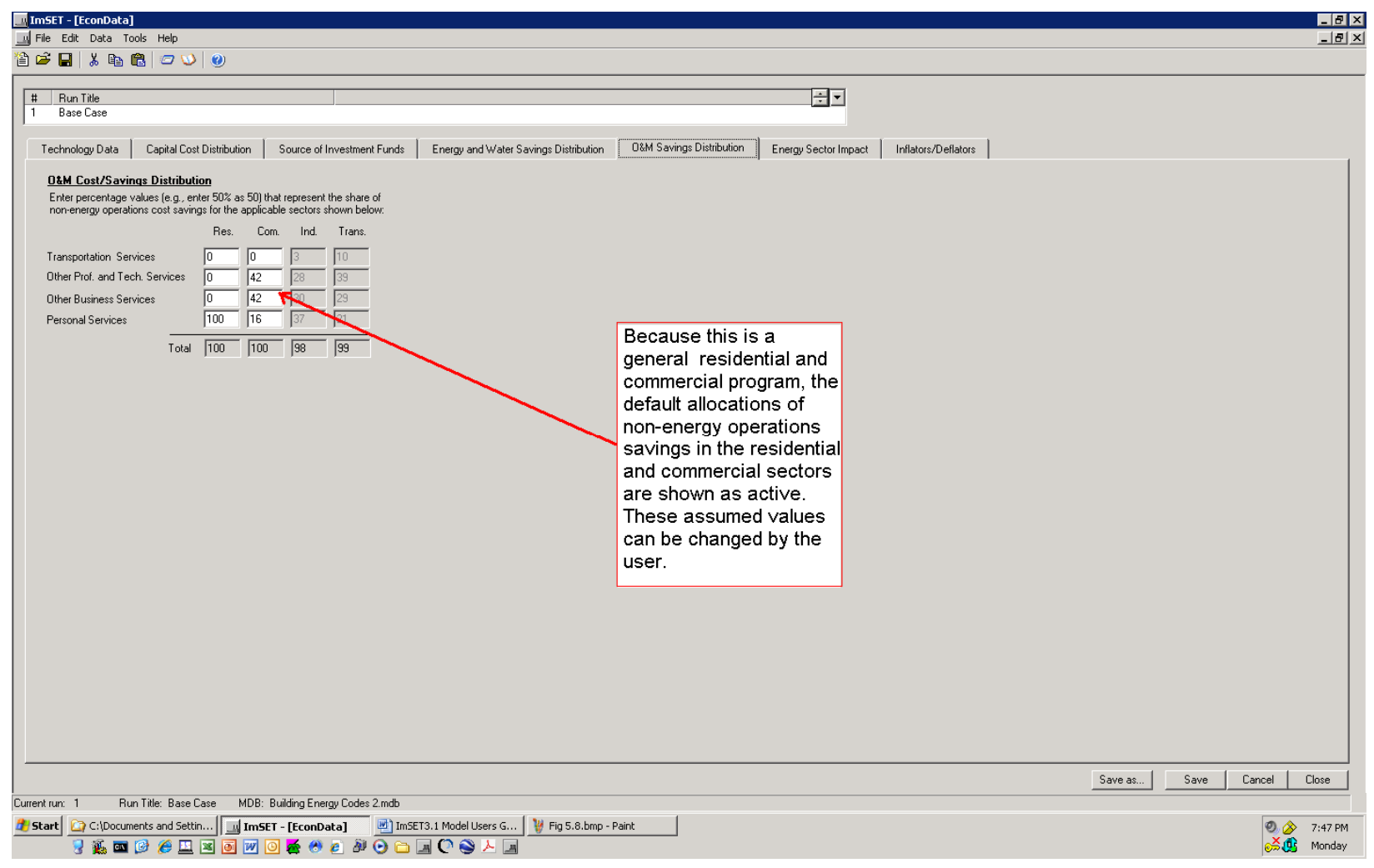

Figure 5-9. Operations and Maintenance Cost Savings for Residential and Commercial Sector

\subsubsection{Tab 6: Energy Sector Impact}

This screen allows the user to specify how the technology/program impacts will affect the investment in the energy sector, particularly the electricity and natural gas industries. Significant energy savings might allow electricity and natural gas production, transmission, and distribution companies to reduce the amount of investment they undertake, which frees up investment capital for the general economy (this is the mirror image of the "source of funds" allocation described in Tab 5). If reductions in electricity and gas investment occur because the technology/program is implemented, then enter "Yes" for the applicable question and enter any changes to load/capacity factors and costs as necessary. ${ }^{4}$ If either "Yes" is selected, then enter where (percentage shares) investment dollars would be going to (what sectors would benefit) in the right-hand box. In the example in Figure 5-10, the freed-up funds are proportionately released to the economy as a whole, which spends them on consumption, investment, etc. Note that in this case, the sum of those shares is handled the same way as the opportunity cost of invested funds (see discussion of Tab 5). The "benefit" of investment savings need not remain in the region of interest.

\footnotetext{
${ }^{4}$ Electricity generation and natural gas transmission and distribution systems do not use their full capacity at all times. Capacity is fully utilized only at peak demand (and even then, a reserve margin will be maintained). Annual load factors are used to translate between Btus of energy consumed in the course of a year and the peak demand. A 60 percent load factor means that over the course of a year, the hourly average demand is about 60 percent of peak demand. It can be computed as: annual consumption/(8760 hrs x peak demand $)$.
} 


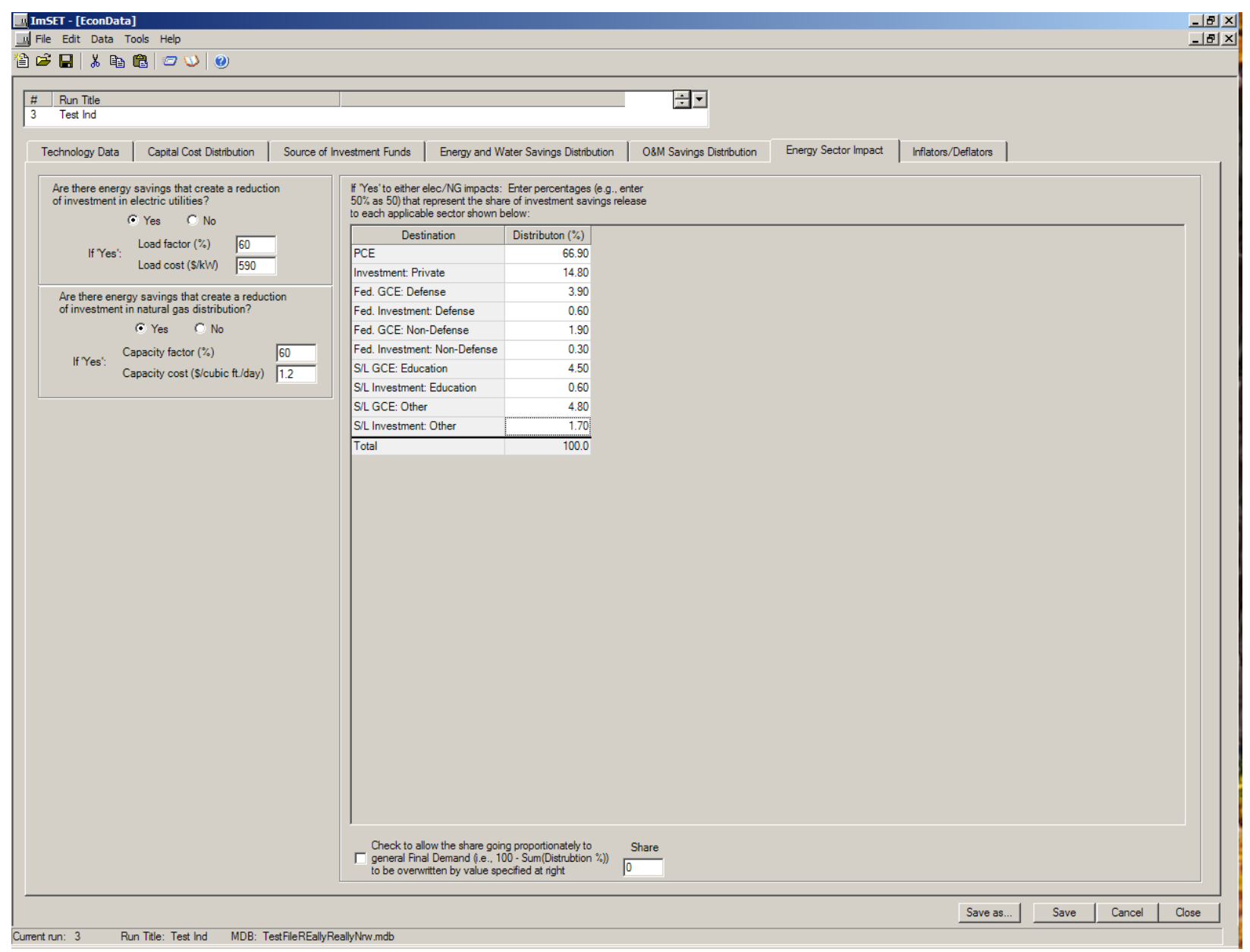

Figure 5-10. Impact of Energy Savings on Energy Sector Investments and Released Funds

\subsubsection{Tab 7: Inflators and Deflators}

The inflators/deflators page is designed to allow easy conversion of costs and savings to the appropriate year's dollars. The I-O table at the core of ImSET 3 is in 2002 dollars, so inputs to the model need to be converted to a 2002 basis. In the example shown in Figure 5-11, capital costs were expressed in 2005 dollars and savings originally available to the analysts were expressed in 2005 dollars, which needed to be converted to 2002 dollars. This is the purpose of the deflators. However, for reporting purposes, many users would like to see earnings numbers in some later year's constant dollars, not 2002. For example, in recent use of the model, some income results have been reported in 2007 dollars. This is the purpose of the inflators. To compute costs for a particular year, enter the appropriate inflators/deflators for calculation in the model (see Figure 5-11). Note that capital cost deflators are used to adjust capital cost, installation costs, and utility impact costs to the base I-O year (2002). Operations cost deflators are used to adjust energy costs and O\&M costs to the base I-O year. Both of these are based on GDP deflators. The inflator input is based on the appropriate year's Consumer Price Index and is used to adjust base I-O results for earnings to the technology database year, or to some other year for reporting purposes. 


\subsection{Computing Program Impacts}

Selecting the "Compute program impacts" will run the computations for determining the impacts of the "Run specifications." Only those records marked with "Execute run" will be processed (see Figure 5-12). Before running computations, the program checks for a common set of years between all technologies/programs. It will also test for conditions where there are no years represented.

With data integrity checks complete, the process loops through each "Run scenario" and, in turn, creates an associated file of data that will be read by the ImSET 3 model. The processing code in Appendix $\mathrm{C}$ is then called and when finished, the process retrieves the output file created by the model and parses and stores the results to the user database file. With that process complete, the ImSET 3 tool opens the results screen and presents the calculated impacts in spreadsheet form (see Figure 5-13 and Figure 5-14).

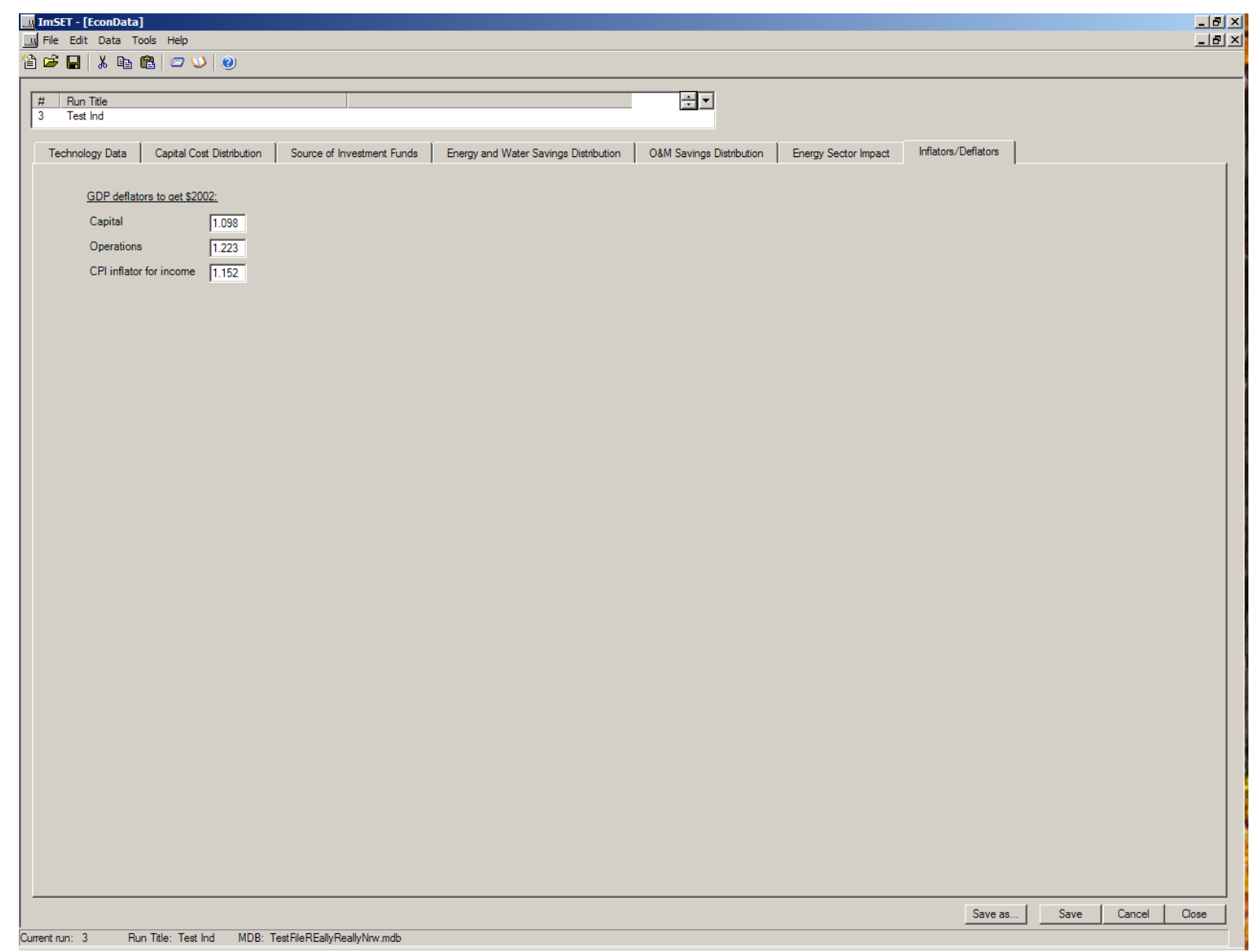

Figure 5-11. Assigning Inflators and Deflators 


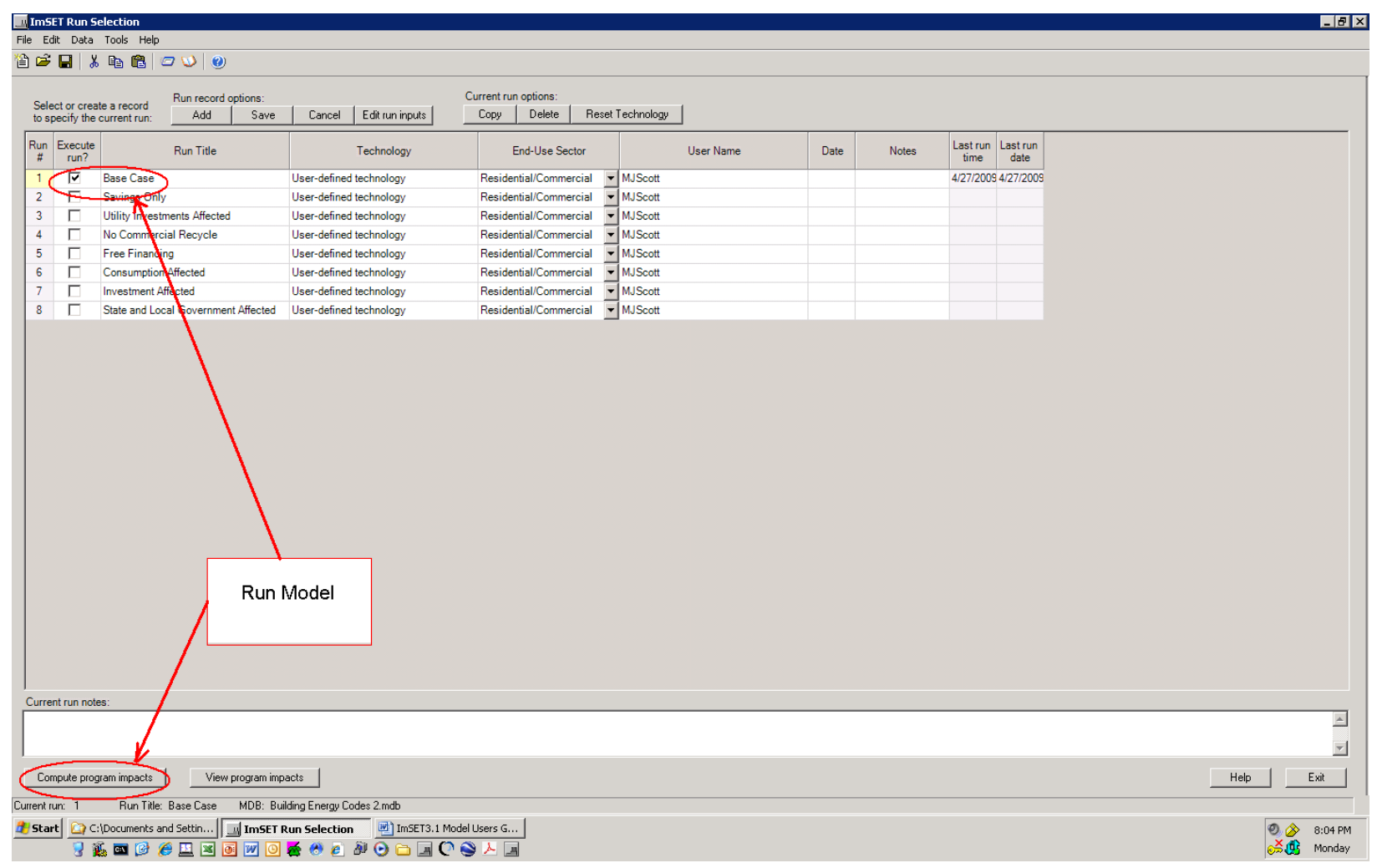

Figure 5-12. Running the ImSET Model.

Note: In this print screen, the "Buildings Energy Codes" base case is being computed using the "Compute program inputs" button. The user can also view current stored results by clicking the "View program impacts" button.

\subsection{Viewing Program Impacts}

If the user wishes to view the last computed impacts without rerunning the calculations, he/she should select the "View program impacts" button on Figure 5-12. The displayed data will depend on the "Impacts data type" choice that is available at the top of the macro outputs screen (Figure 5-13). Additional options in this screen include viewing detailed output-by-industry data and exporting all impact data types to an Excel ${ }^{\circledR}$ spreadsheet file. The name assigned to the Excel file will be the same as the user database file.

Results are presented in tabular form in individual "tab" frames. Use the "Impacts data type" drop-down list at the top of the screen to select the individual run results impact data for employment, wage income, and gross product, as well corresponding baseline values for these three variables) that are available. Data may be exported and stored in Excel spreadsheet format for additional manipulation. In the example shown in Figure 5-13, the Building Energy Codes base case produces a potential increase of 3890 net jobs in the economy in 2015. 


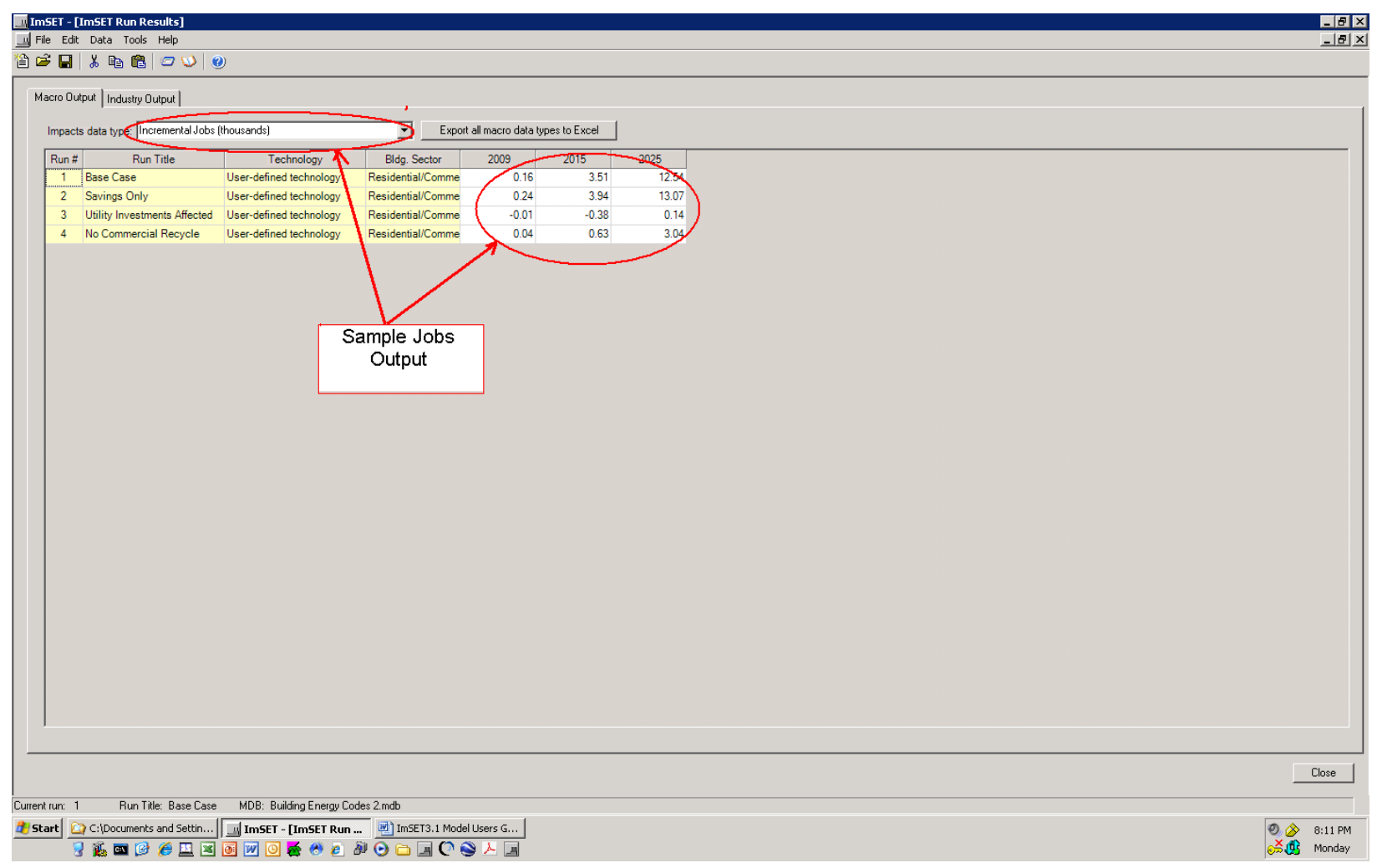

Figure 5-13. Macro Output Screen

It is often useful to have access to the impact results for individual sectors for an individual model run in order to estimate impacts such as capital flows and investment, environmental emissions, or other industry-specific outcomes. ${ }^{5}$ ImSET provides results for period-by-period changes in gross output by sector for the most recent case run by the model. Data may be exported and stored in Excel spreadsheet format for additional manipulation. In the example shown in Figure 5-14, the Building Energy Codes base case produces a variety of impacts on individual sectors, reducing gross product in sectors that sell energy services (e.g., Sector 12, Electric Generation and Transmission and Sector 13, Natural Gas Distribution) and industries that are closely related to energy services (Sector 5, Oil and Gas Extraction), but increasing output in several retail and service industries. The net impact on gross product in 2025 in Electric Generation and Transmission is a loss of $\$ 1279$ million (2002\$); however, a number of sectors such as Commercial Building Construction benefit from the Building Energy Codes. The net effect across all of the economy's economic sectors in this case is an increase of almost \$254 million.

\footnotetext{
${ }^{5}$ For example, ImSET model output of this type has been used with a supplemental spreadsheet model to estimate the impact of energy efficiency programs on reducing the need for the economy to maintain energy-related investment. See Scott et al. (2008).
} 


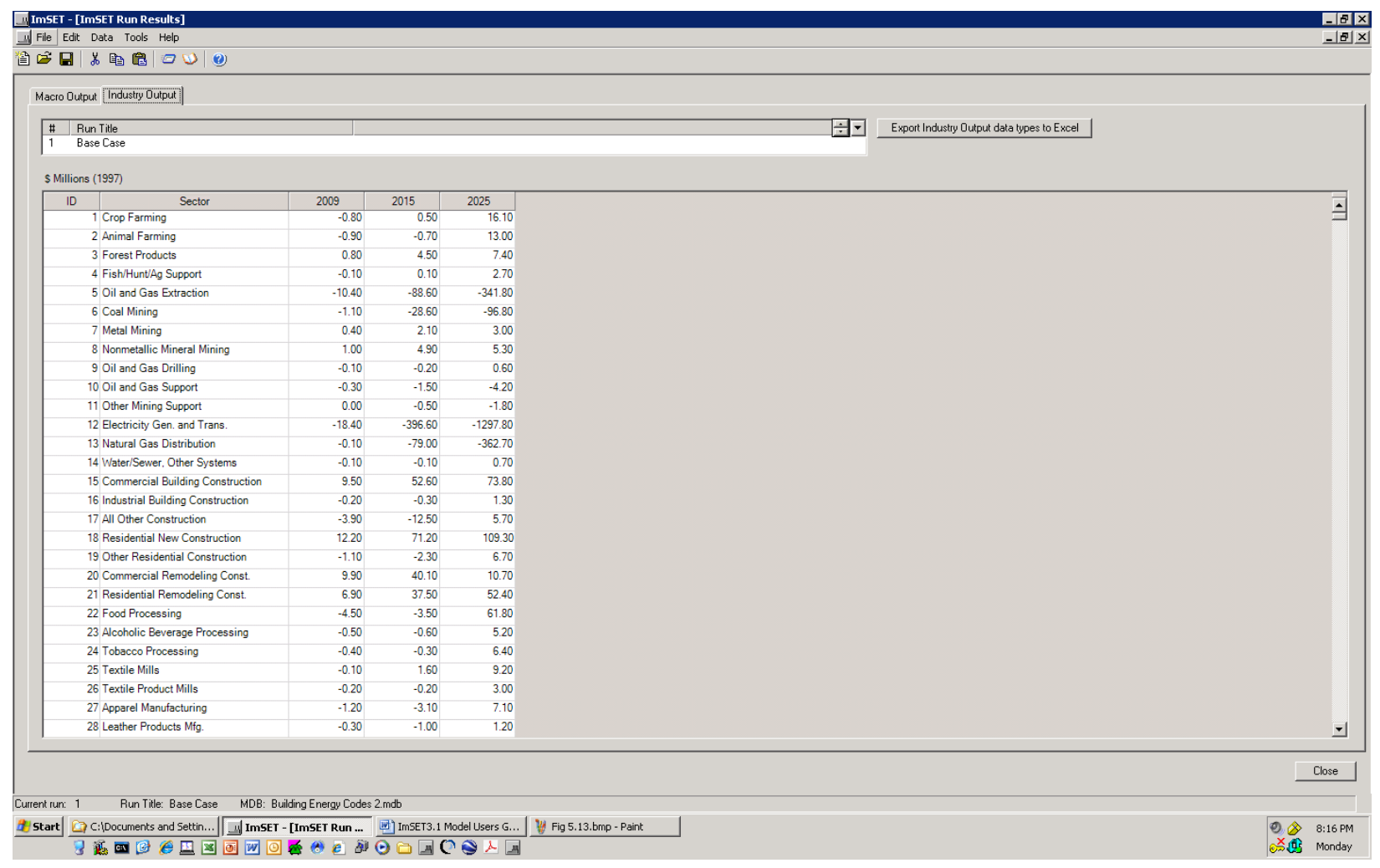

Figure 5-14. Industry Output Screen (Gross Product Impact by Sector) 


\subsection{References}

Berck P and S Hoffmann. 2002. "Assessing the Employment Impacts of Environmental and Natural Resource Policy." Environmental and Resource Economics 22:133-156.

Economic Research Associates. 2005. Modeling the Economic Impacts of National and State Energy Policy Scenarios. A Working Paper for the U.S. PIRG Education Fund.

Eldridge M, N Elliott, W Prindle, K Ackerly, S Laitner, V McKinney, S Nadel, M Neubauer, A Silverstein, B Hedman, A Hampson, and K Darrow. 2008. Energy Efficiency: The First Fuel for a Clean Energy Future. American Council for an Energy-Efficient Economy, Washington, D.C.

Elliott, D.B., D.M. Anderson, D.B. Belzer, K.A. Cort, J.A. Dirks, and D.J. Hostick. 2004. Methodological Framework for Analysis of Buildings-Related Programs: GPRA Metrics Effort. PNNL-14697. Pacific Northwest National Laboratory, Richland, Washington.

Elliott, D.B., J.A. Dirks, and D.J. Hostick. 2008. Methodological Framework for Analysis of BuildingsRelated Programs with BEAMS, 2008. PNNL-17725. Pacific Northwest National Laboratory, Richland, Washington.

Energy Information Administration (EIA). 1996. Natural Gas 1996: Issues and Trends. DOE/EIA-0560(96), U.S. Department of Energy, Washington, D.C.

Energy Information Administration (EIA). 2008. Annual Energy Outlook 2008. DOE/EIA-0383(2008), U.S. Department of Energy, Washington, D.C.

Geller H, J DeCicco, and S Laitner. 1992 . Energy Efficiency and Job Creation: The Employment and Income Benefits from Investing in Energy Conserving Technologies. American Council for an EnergyEfficient Economy, Washington, D.C.

Horowitz, KJ and MA Planting. 2006. Concepts and Methods of the Input-Output Accounts. U.S Department of Commerce, Bureau of Economic Analysis, Washington D.C., September 2006. Accessed March 11, 2009 at http://www.bea.gov/industry/index.htm\#benchmark_io.

Kaiser MJ and AG Pulsipher. 2003. "A Generalized Modeling Framework for Public Benefit Program Valuation" Energy: The International Journal 28(6):519-538.

Kaiser MJ, AG Pulsipher, and RH Baumann. 2004. "The Potential Economic and Environmental Impact of a Public Benefit Fund in Louisiana.” Energy Policy 32(2):191-206.

Kaiser MJ, WO Olatubi, and AG Pulsipher. 2005. "Economic, Energy, and Environmental Impact of the Louisiana Energy Fund.” Energy Policy 33(7):873-883.

Laitner J and V McKinney. 2008. Positive Returns: State Energy Efficiency Analyses Can Inform U.S. Energy Policy Assessments. Report E084, American Council for an Energy-Efficient Economy, Washington, D.C. 
Lawson AM, KS Bersani, M Fahim-Nader, and J Guo. 2002. "Benchmark Input-Output Accounts of the United States, 1997.” Survey of Current Business, December, pp. 19-109.

Nayak N. 2005. Redirecting America's Energy: The Economic and Consumer Benefits of Clean Energy Policies. U.S. PIRG Education Fund, Washington, D.C. Accessed March 4, 2009, at http://www.environmentamerica.org/home/reports/report-archives/new-energy-future/new-energyfuture/redirecting-americas-energy-the-economic-and-consumer-benefits-of-clean-energy-policies.

Roland-Holst D. 2008. Energy, Efficiency, Innovation, and Job Creation in California. Prepared by the Center for Energy, Resources, and Economic Sustainability, Berkeley, California.

Roop JM, MJ Scott, and RW Schultz. 2005. ImSET: Impact of Sector Energy Technologies.

PNNL-15273, Pacific Northwest National Laboratory, Richland, Washington.

Scott MJ, DJ Hostick, and DB Belzer. 1998. ImBuild: Impact of Building Energy Efficiency Programs. PNNL-11884, Pacific Northwest National Laboratory, Richland, Washington.

Scott M. J., Roop J. M., and Schultz R. W. 2002. ImBuild II: Impact of Technologies on Energy Efficiency Programs. PNNL-13926, Pacific Northwest National Laboratory, Richland, Washington.

Scott, M.J., J.M. Roop, R.W. Schultz, D.M. Anderson, K.A. Cort. 2008. "The Impact of DOE Building Technology Energy Efficiency Programs on U.S. Employment, Income, and Investment” Energy Economics 30 (5): 2283-2301.

Sedano R, C Murray, and W Steinhurst. 2005. Electric Efficiency and Renewable Energy in New England: An Assessment of Existing Policies and Prospects for the Future. The Regulatory Assistance Project, Montpelier, Vermont.

Stewart, RL, JB Stone, and ML Streitwieser. 2007. U.S. Benchmark Input-Output Accounts, 2002. Survey of Current Business October 2007. Accessed March 11, 2009 at http://www.bea.gov/industry/index.htm\#benchmark_io.

Xie J. 2000. "An Environmentally Extended Social Accounting Matrix: Conceptual Framework and Application to Environmental Policy Analysis in China." Environmental and Resource Economics $16: 391-406$. 


\section{Appendix A}

\section{Base Cases for Energy-efficiency Technologies}





\section{Appendix A}

\section{Base Cases for Energy-efficiency Technologies}

Table A.1. Integrated Heat Pump, Base Case

\begin{tabular}{lrrr}
\hline & $\mathbf{2 0 0 9}$ & $\mathbf{2 0 1 5}$ & $\mathbf{2 0 2 5}$ \\
\hline Capital Cost Increase(+) or Savings(-) & \multicolumn{2}{c}{} & \\
Millions \$ & \multicolumn{2}{c}{29.88} & 1059.37 \\
\hline Energy/Resource Cost Increase (+) or Savings (-) Million \$ & & \\
Residential -- Oil & 0 & -0.35 & -39.38 \\
Residential -- Natural gas & 0 & -10.36 & -1356.72 \\
Residential -- Electricity & 0 & 3.09 & 349.39 \\
Residential -- Water & 0 & 0 & 0 \\
\hline O\&M Cost Increase(+) or Savings(-) & & & \\
Residential (Millions \$) & 0 & 0 & 0 \\
Commercial (Millions \$) & 0 & 0 & 0 \\
Industrial (Millions \$) & 0 & 0 & 0 \\
Transportation (Millions \$) & 0 & & \\
\hline Energy/Resource units Saved(-) or Used (For System Investment) & 0 & -2.9 \\
Oil (10^12 Btu) & 0 & -0.03 & -123.68 \\
Natural gas (10^12 Btu) & 0 & -1.01 & 13.13 \\
Electricity (10^12 Btu) & 0 & 0.12 & 0 \\
Water (10^9 Gallons) & 0 & 0 & \\
\hline
\end{tabular}


Table A-2. TVMI: Building Energy Codes, Base Case

\begin{tabular}{lrrr}
\hline & $\mathbf{2 0 0 9}$ & $\mathbf{2 0 1 5}$ & $\mathbf{2 0 2 5}$ \\
\hline Capital Cost Increase(+) or Savings(-) & \multicolumn{3}{c}{} \\
Millions \$ & \multicolumn{1}{c}{826.45} & 1014.23 \\
\hline Energy/Resource Cost Increase (+) or Savings (-) Million \$ \\
Residential -- Oil & -1.62 & -42.49 & -151.9 \\
Residential -- Natural gas & -4.52 & -173.13 & -653.34 \\
Residential -- Electricity & -7.33 & -104.11 & -324.15 \\
Residential -- Water & 0 & 0 & 0 \\
Commercial -- Oil & 0 & 0 & 0 \\
Commercial -- Natural gas & 3.83 & 49.1 & 93.91 \\
Commercial -- Electricity & -22.36 & -526.07 & -1723.94 \\
Commercial -- Water & 0 & 0 & 0 \\
\hline O\&M Cost Increase(+) or Savings(-) & \multicolumn{4}{c}{} \\
Residential (Millions \$) & 0 & 0 & 0 \\
Commercial (Millions \$) & 0 & 0 & 0 \\
Industrial (Millions \$) & 0 & 0 & 0 \\
Transportation (Millions \$) & 0 & 0 & 0 \\
\hline Energy/Resource units Saved(-) or Used (For System Investment) \\
Oil (10^12 Btu) & -0.1 & -3.37 & -11.2 \\
Natural gas (10^12 Btu) & 0 & -11.12 & -49.08 \\
Electricity (10^12 Btu) & -1.17 & -26.56 & -83.33 \\
Water (10^9 Gallons) & 0 & 0 & 0 \\
\hline
\end{tabular}


Appendix B

Sectoral Detail 



\section{Appendix B}

\section{Sectoral Detail}

Table B.1. Cross Reference between ImSET 3 Sectors and 2002 U.S. Input-Output Table Sectors

\begin{tabular}{|c|c|c|c|c|}
\hline Sector & IOcode & 2002 Benchmark I-O Industry & ImS & Industry \\
\hline 1 & $1111 \mathrm{~A} 0$ & Oilseed farming & S001 & Crop Farming \\
\hline 2 & 1111B0 & Grain farming & S001 & Crop Farming \\
\hline 3 & 111200 & Vegetable and melon farming & S001 & Crop Farming \\
\hline 4 & 111335 & Tree nut farming & S001 & Crop Farming \\
\hline 5 & $1113 \mathrm{~A} 0$ & Fruit farming & S001 & Crop Farming \\
\hline 6 & 111400 & Greenhouse, nursery, and floriculture production & S001 & Crop Farming \\
\hline 7 & 111910 & Tobacco farming & S001 & Crop Farming \\
\hline 8 & 111920 & Cotton farming & S001 & Crop Farming \\
\hline 9 & 1119A0 & Sugarcane and sugar beet farming & S001 & Crop Farming \\
\hline 10 & 1119B0 & All other crop farming & S001 & Crop Farming \\
\hline 11 & 112120 & Dairy cattle and milk production & S002 & Animal Farming \\
\hline 12 & $1121 \mathrm{~A} 0$ & Cattle ranching and farming & S002 & Animal Farming \\
\hline 13 & 112300 & Poultry and egg production & S002 & Animal Farming \\
\hline 14 & $112 \mathrm{~A} 00$ & Animal production, except cattle and poultry and eggs & S002 & Animal Farming \\
\hline 15 & 113300 & Logging & S003 & Forest Products \\
\hline 16 & $113 \mathrm{~A} 00$ & Forest nurseries, forest products, and timber tracts & S003 & Forest Products \\
\hline 17 & 114100 & Fishing & S004 & Fish/Hunt/Ag Support \\
\hline 18 & 114200 & Hunting and trapping & S004 & Fish/Hunt/Ag Support \\
\hline 19 & 115000 & Support activities for agriculture and forestry & S004 & Fish/Hunt/Ag Support \\
\hline 20 & 211000 & Oil and gas extraction & S005 & Oil and Gas Extraction \\
\hline
\end{tabular}


Table B.1. Cont'd

\begin{tabular}{|c|c|c|c|c|}
\hline Sector & IOcode & 2002 Benchmark I-O Industry & ImSET 3 & Industry \\
\hline 21 & 212100 & Coal mining & S006 & Coal Mining \\
\hline 22 & 212210 & Iron ore mining & S007 & Metal Mining \\
\hline 23 & 212230 & Copper, nickel, lead, and zinc mining & S007 & Metal Mining \\
\hline 24 & $2122 \mathrm{~A} 0$ & Gold, silver, and other metal ore mining & S007 & Metal Mining \\
\hline 25 & 212310 & Stone mining and quarrying & S008 & Nonmetallic Mineral Mining \\
\hline 26 & 212320 & $\begin{array}{l}\text { Sand, gravel, clay, and ceramic and refractory minerals mining } \\
\text { and quarrying }\end{array}$ & S008 & Nonmetallic Mineral Mining \\
\hline 27 & 212390 & Other nonmetallic mineral mining and quarrying & S008 & Nonmetallic Mineral Mining \\
\hline 28 & 213111 & Drilling oil and gas wells & S009 & Oil and Gas Drilling \\
\hline 29 & 213112 & Support activities for oil and gas operations & S010 & Oil and Gas Support \\
\hline 30 & $21311 \mathrm{~A}$ & Support activities for other mining & S011 & Other Mining Support \\
\hline 31 & 221100 & Electric power generation, transmission, and distribution & S012 & Electricity Gen. and Trans. \\
\hline 32 & 221200 & Natural gas distribution & S013 & Natural Gas Distribution \\
\hline 33 & 221300 & Water, sewage and other systems & S014 & $\begin{array}{l}\text { Water/Sewer, Other Systems } \\
\text { Commercial Building }\end{array}$ \\
\hline 34 & 230101 & Nonresidential commercial and health care structures & S015 & Construction \\
\hline 35 & 230102 & Nonresidential manufacturing structures & S016 & Industrial Building Construction \\
\hline 36 & 230103 & Other nonresidential structures & S017 & All Other Construction \\
\hline 37 & 230201 & Residential permanent site single- and multi-family structures & S018 & Residential New Construction \\
\hline 38 & 230202 & Other residential structures & S019 & Other Residential Construction \\
\hline 39 & 230301 & Nonresidential maintenance and repair & S020 & Commercial Remodeling Const. \\
\hline 40 & 230302 & Residential maintenance and repair & S021 & Residential Remodeling Const. \\
\hline 41 & 311111 & Dog and cat food manufacturing & S022 & Food Processing \\
\hline 42 & 311119 & Other animal food manufacturing & S022 & Food Processing \\
\hline 43 & 311210 & Flour milling and malt manufacturing & S022 & Food Processing \\
\hline 44 & 311221 & Wet corn milling & S022 & Food Processing \\
\hline 45 & 311225 & Fats and oils refining and blending & S022 & Food Processing \\
\hline 46 & $31122 \mathrm{~A}$ & Soybean and other oilseed processing & S022 & Food Processing \\
\hline
\end{tabular}


Table B.1. Cont'd

\begin{tabular}{|c|c|c|c|c|}
\hline Sector & IOcode & 2002 Benchmark I-O Industry & ImSET 3 & Industry \\
\hline 47 & 311230 & Breakfast cereal manufacturing & S022 & Food Processing \\
\hline 48 & 311313 & Beet sugar manufacturing & S022 & Food Processing \\
\hline 49 & $31131 \mathrm{~A}$ & Sugar cane mills and refining & S022 & Food Processing \\
\hline 50 & 311320 & Chocolate and confectionery manufacturing from cacao beans & S022 & Food Processing \\
\hline 51 & 311330 & Confectionery manufacturing from purchased chocolate & S022 & Food Processing \\
\hline 52 & 311340 & Nonchocolate confectionery manufacturing & S022 & Food Processing \\
\hline 53 & 311410 & Frozen food manufacturing & S022 & Food Processing \\
\hline 54 & 311420 & Fruit and vegetable canning, pickling, and drying & S022 & Food Processing \\
\hline 55 & 311513 & Cheese manufacturing & S022 & Food Processing \\
\hline 56 & 311514 & Dry, condensed, and evaporated dairy product manufacturing & S022 & Food Processing \\
\hline 57 & $31151 \mathrm{~A}$ & Fluid milk and butter manufacturing & S022 & Food Processing \\
\hline 58 & 311520 & Ice cream and frozen dessert manufacturing & S022 & Food Processing \\
\hline 59 & 311615 & Poultry processing & S022 & Food Processing \\
\hline 60 & $31161 \mathrm{~A}$ & $\begin{array}{l}\text { Animal (except poultry) slaughtering, rendering, and } \\
\text { processing }\end{array}$ & S022 & Food Processing \\
\hline 61 & 311700 & Seafood product preparation and packaging & S022 & Food Processing \\
\hline 62 & 311810 & Bread and bakery product manufacturing & S022 & Food Processing \\
\hline 63 & 311820 & Cookie, cracker, and pasta manufacturing & S022 & Food Processing \\
\hline 64 & 311830 & Tortilla manufacturing & S022 & Food Processing \\
\hline 65 & 311910 & Snack food manufacturing & S022 & Food Processing \\
\hline 66 & 311920 & Coffee and tea manufacturing & S022 & Food Processing \\
\hline 67 & 311930 & Flavoring syrup and concentrate manufacturing & S022 & Food Processing \\
\hline 68 & 311940 & Seasoning and dressing manufacturing & S022 & Food Processing \\
\hline 69 & 311990 & All other food manufacturing & S022 & Food Processing \\
\hline 70 & 312110 & Soft drink and ice manufacturing & S022 & Food Processing \\
\hline 71 & 312120 & Breweries & S023 & Alcoholic Beverage Processing \\
\hline 72 & 312130 & Wineries & S023 & Alcoholic Beverage Processing \\
\hline
\end{tabular}


Table B.1. Cont'd

\begin{tabular}{|c|c|c|c|c|}
\hline Sector & IOcode & 2002 Benchmark I-O Industry & ImSET 3 & Industry \\
\hline 73 & 312140 & Distilleries & S023 & Alcoholic Beverage Processing \\
\hline 74 & $3122 \mathrm{~A} 0$ & Tobacco product manufacturing & S024 & Tobacco Processing \\
\hline 75 & 313100 & Fiber, yarn, and thread mills & S025 & Textile Mills \\
\hline 76 & 313210 & Broad woven fabric mills & S025 & Textile Mills \\
\hline 77 & 313220 & Narrow fabric mills and schiffli machine embroidery & S025 & Textile Mills \\
\hline 78 & 313230 & Nonwoven fabric mills & S025 & Textile Mills \\
\hline 79 & 313240 & Knit fabric mills & S025 & Textile Mills \\
\hline 80 & 313310 & Textile and fabric finishing mills & S025 & Textile Mills \\
\hline 81 & 313320 & Fabric coating mills & S025 & Textile Mills \\
\hline 82 & 314110 & Carpet and rug mills & S026 & Textile Product Mills \\
\hline 83 & 314120 & Curtain and linen mills & S026 & Textile Product Mills \\
\hline 84 & 314910 & Textile bag and canvas mills & S026 & Textile Product Mills \\
\hline 85 & 314990 & All other textile product mills & S027 & Apparel Manufacturing \\
\hline 86 & 315100 & Apparel knitting mills & S027 & Apparel Manufacturing \\
\hline 87 & 315210 & Cut and sew apparel contractors & S027 & Apparel Manufacturing \\
\hline 88 & 315220 & Men's and boys' cut and sew apparel manufacturing & S027 & Apparel Manufacturing \\
\hline 89 & 315230 & Women's and girls' cut and sew apparel manufacturing & S027 & Apparel Manufacturing \\
\hline 90 & 315290 & Other cut and sew apparel manufacturing & S027 & Apparel Manufacturing \\
\hline 91 & 315900 & Apparel accessories and other apparel manufacturing & S027 & Apparel Manufacturing \\
\hline 92 & 316100 & Leather and hide tanning and finishing & S028 & Leather Products Mfg. \\
\hline 93 & 316200 & Footwear manufacturing & S028 & Leather Products Mfg. \\
\hline 94 & 316900 & Other leather and allied product manufacturing & S028 & Leather Products Mfg. \\
\hline 95 & 321100 & Sawmills and wood preservation & S029 & Lumber Mills \\
\hline 96 & 321219 & Reconstituted wood product manufacturing & S029 & Lumber Mills \\
\hline 97 & $32121 \mathrm{~A}$ & Veneer and plywood manufacturing & S029 & Lumber Mills \\
\hline 98 & $32121 \mathrm{~B}$ & Engineered wood member and truss manufacturing & S029 & Lumber Mills \\
\hline 99 & 321910 & Wood windows and doors and millwork & S030 & Specialized Wood Product Mfg. \\
\hline
\end{tabular}


Table B.1. Cont'd

\begin{tabular}{|c|c|c|c|c|}
\hline Sector & IOcode & 2002 Benchmark I-O Industry & ImSET 3 & Industry \\
\hline 100 & 321920 & Wood container and pallet manufacturing & S030 & Specialized Wood Product Mfg. \\
\hline 101 & 321991 & Manufactured home (mobile home) manufacturing & S031 & Manufactured Buildings \\
\hline 103 & 321999 & All other miscellaneous wood product manufacturing & S032 & Misc. Wood Product Mfg. \\
\hline 104 & 322110 & Pulp mills & S033 & Pulp Mills \\
\hline 105 & 322120 & Paper mills & $\mathrm{S} 034$ & Paper And Paperboard Mills \\
\hline 106 & 322130 & Paperboard Mills & S034 & Paper And Paperboard Mills \\
\hline 107 & 322210 & Paperboard container manufacturing & S035 & Paperboard Container Mfg. \\
\hline 108 & $32222 \mathrm{~A}$ & $\begin{array}{l}\text { Coated and laminated paper, packaging paper and plastics film } \\
\text { manufacturing } \\
\text { All other paper bag and coated and treated paper }\end{array}$ & S036 & Converted Paper Product Mfg. \\
\hline 109 & $32222 \mathrm{~B}$ & manufacturing & S036 & Converted Paper Product Mfg. \\
\hline 110 & 322230 & Stationery product manufacturing & S036 & Converted Paper Product Mfg. \\
\hline 112 & 322299 & All other converted paper product manufacturing & S036 & Converted Paper Product Mfg. \\
\hline 113 & 323110 & Printing & S037 & Commercial Printing \\
\hline 114 & 323120 & Support activities for printing & S037 & Commercial Printing \\
\hline 115 & 324110 & Petroleum refineries & S038 & Petroleum Refineries \\
\hline 116 & 324121 & Asphalt paving mixture and block manufacturing & S039 & Oth. Petroleum/Coal Prod. Mfg. \\
\hline 117 & 324122 & Asphalt shingle and coating materials manufacturing & S039 & Oth. Petroleum/Coal Prod. Mfg. \\
\hline 118 & 324191 & Petroleum lubricating oil and grease manufacturing & S039 & Oth. Petroleum/Coal Prod. Mfg. \\
\hline 119 & 324199 & All other petroleum and coal products manufacturing & S039 & Oth. Petroleum/Coal Prod. Mfg. \\
\hline 120 & 325110 & Petrochemical manufacturing & S040 & Inorganic Chemical Mfg. \\
\hline 121 & 325120 & Industrial gas manufacturing & S040 & Inorganic Chemical Mfg. \\
\hline 122 & 325130 & Synthetic dye and pigment manufacturing & S040 & Inorganic Chemical Mfg. \\
\hline 123 & 325181 & Alkalies and chlorine manufacturing & S040 & Inorganic Chemical Mfg. \\
\hline
\end{tabular}


Table B.1. Cont'd

\begin{tabular}{|c|c|c|c|c|}
\hline Sector & IOcode & 2002 Benchmark I-O Industry & ImSET 3 & Industry \\
\hline 126 & 325190 & Other basic organic chemical manufacturing & S041 & Organic Chemical Mfg. \\
\hline 127 & 325211 & Plastics material and resin manufacturing & S042 & Plastics Material \& Resin Mfg. \\
\hline 128 & 325212 & Synthetic rubber manufacturing & S043 & Synthetic Rubber Mfg. \\
\hline 129 & 325220 & Artificial and synthetic fibers and filaments manufacturing & S044 & Artificial Fiber Mfg. \\
\hline 130 & 325310 & Fertilizer manufacturing & S045 & Fertilizer \& Pesticide Mfg. \\
\hline 131 & 325320 & Pesticide and other agricultural chemical manufacturing & S045 & Fertilizer \& Pesticide Mfg. \\
\hline 132 & 325411 & Medicinal and botanical manufacturing & S046 & Pharmaceutical \& Medicine Mfg. \\
\hline 133 & 325412 & Pharmaceutical preparation manufacturing & S046 & Pharmaceutical \& Medicine Mfg. \\
\hline 134 & 325413 & In-vitro diagnostic substance manufacturing & S046 & Pharmaceutical \& Medicine Mfg. \\
\hline 135 & 325414 & Biological product (except diagnostic) manufacturing & S046 & Pharmaceutical \& Medicine Mfg. \\
\hline 136 & 325510 & Paint and coating manufacturing & S047 & Paint \& Coatings Mfg. \\
\hline 137 & 325520 & Adhesive manufacturing & S048 & Misc. Chemical Prod. Mfg. \\
\hline 138 & 325610 & Soap and cleaning compound manufacturing & S048 & Misc. Chemical Prod. Mfg. \\
\hline 139 & 325620 & Toilet preparation manufacturing & S048 & Misc. Chemical Prod. Mfg. \\
\hline 140 & 325910 & Printing ink manufacturing & S048 & Misc. Chemical Prod. Mfg. \\
\hline 141 & $3259 \mathrm{~A} 0$ & $\begin{array}{l}\text { All other chemical product and preparation manufacturing } \\
\text { Plastics packaging materials and unlaminated film and sheet }\end{array}$ & S048 & Misc. Chemical Prod. Mfg. \\
\hline 142 & 326110 & manufacturing & S049 & Plastics \& Related Prod. Mfg. \\
\hline 143 & 326121 & Unlaminated plastics profile shape manufacturing & S049 & Plastics \& Related Prod. Mfg. \\
\hline 144 & 326122 & $\begin{array}{l}\text { Plastics pipe and pipe fitting manufacturing } \\
\text { Laminated plastics plate, sheet (except packaging), and shape }\end{array}$ & S049 & Plastics \& Related Prod. Mfg. \\
\hline 145 & 326130 & manufacturing & S049 & Plastics \& Related Prod. Mfg. \\
\hline 146 & 326140 & $\begin{array}{l}\text { Polystyrene foam product manufacturing } \\
\text { Urethane and other foam product (except polystyrene) }\end{array}$ & S049 & Plastics \& Related Prod. Mfg. \\
\hline 147 & 326150 & manufacturing & S049 & Plastics \& Related Prod. Mfg. \\
\hline 148 & 326160 & Plastics bottle manufacturing & S049 & Plastics \& Related Prod. Mfg. \\
\hline 149 & $32619 \mathrm{~A}$ & Other plastics product manufacturing & S049 & Plastics \& Related Prod. Mfg. \\
\hline 150 & 326210 & Tire manufacturing & S050 & Rubber Products Mfg. \\
\hline
\end{tabular}


Table B.1. Cont'd

\begin{tabular}{|c|c|c|c|c|}
\hline Sector & IOcode & 2002 Benchmark I-O Industry & ImSET 3 & Industry \\
\hline 151 & 326220 & Rubber and plastics hoses and belting manufacturing & S050 & Rubber Products Mfg. \\
\hline 152 & 326290 & Other rubber product manufacturing & S050 & Rubber Products Mfg. \\
\hline 153 & $32711 \mathrm{~A}$ & Pottery, ceramics, and plumbing fixture manufacturing & S051 & Ceramic Fixture Mfg. \\
\hline 154 & $32712 \mathrm{~A}$ & Brick, tile, and other structural clay product manufacturing & S052 & Clay Products Mfg. \\
\hline 155 & $32712 \mathrm{~B}$ & Clay and nonclay refractory manufacturing & S052 & Clay Products Mfg. \\
\hline 156 & 327211 & Flat glass manufacturing & S053 & Flat Glass Mfg. \\
\hline 157 & 327212 & Other pressed and blown glass and glassware manufacturing & S054 & Glass and Glass Products Mfg. \\
\hline 158 & 327213 & Glass container manufacturing & S055 & Glass Container Mfg. \\
\hline 159 & 327215 & Glass product manufacturing made of purchased glass & S054 & Glass and Glass Products Mfg. \\
\hline 160 & 327310 & Cement manufacturing & S056 & Cement Manufacturing \\
\hline 161 & 327320 & Ready-mix concrete manufacturing & S057 & Ready-mix Concrete Mfg. \\
\hline 162 & 327330 & Concrete pipe, brick, and block manufacturing & S058 & Concrete Products Mfg. \\
\hline 163 & 327390 & Other concrete product manufacturing & S058 & Concrete Products Mfg. \\
\hline 164 & $3274 \mathrm{~A} 0$ & Lime and gypsum product manufacturing & S059 & Lime \& Gypsum Manufacturing \\
\hline 165 & 327910 & Abrasive product manufacturing & S060 & Oth. Nonmetallic Mineral Prod. \\
\hline 166 & 327991 & Cut stone and stone product manufacturing & S060 & Oth. Nonmetallic Mineral Prod. \\
\hline 167 & 327992 & Ground or treated mineral and earth manufacturing & S060 & Oth. Nonmetallic Mineral Prod. \\
\hline 168 & 327993 & Mineral wool manufacturing & S061 & Mineral Wool Manufacturing \\
\hline 169 & 327999 & Miscellaneous nonmetallic mineral products & S060 & Oth. Nonmetallic Mineral Prod. \\
\hline 170 & 331110 & Iron and steel mills and ferroalloy manufacturing & S062 & Iron And Steel Mills \\
\hline 171 & 331200 & Steel product manufacturing from purchased steel & S063 & Steel Products Mfg. \\
\hline 172 & 331314 & Secondary smelting and alloying of aluminum & S064 & Aluminum Mills \\
\hline 173 & $33131 \mathrm{~A}$ & Alumina refining and primary aluminum production & S064 & Aluminum Mills \\
\hline 174 & $33131 \mathrm{~B}$ & Aluminum product manufacturing from purchased aluminum & S065 & Aluminum Product Mfg. \\
\hline 175 & 331411 & $\begin{array}{l}\text { Primary smelting and refining of copper } \\
\text { Primary smelting and refining of nonferrous metal (except }\end{array}$ & S066 & Nonferrous Metals Mfg. \\
\hline 176 & 331419 & copper and aluminum) & S066 & Nonferrous Metals Mfg. \\
\hline
\end{tabular}


Table B.1. Cont'd

\begin{tabular}{|c|c|c|c|c|}
\hline Sector & IOcode & 2002 Benchmark I-O Industry & ImSET 3 & Industry \\
\hline 177 & 331420 & \multirow{2}{*}{$\begin{array}{l}\text { Copper rolling, drawing, extruding and alloying } \\
\text { Nonferrous metal (except copper and aluminum) rolling, } \\
\text { drawing, extruding and alloying }\end{array}$} & S066 & Nonferrous Metals Mfg. \\
\hline 178 & 331490 & & S066 & Nonferrous Metals Mfg. \\
\hline 179 & 331510 & Ferrous metal foundries & S067 & Ferrous Metal Foundries \\
\hline 180 & 331520 & Nonferrous metal foundries & S068 & Nonferrous Metal Foundries \\
\hline 181 & 332114 & Custom roll forming & S069 & Other Forging and Stamping \\
\hline 182 & $33211 \mathrm{~A}$ & All other forging, stamping, and sintering & S069 & Other Forging and Stamping \\
\hline 183 & $33211 \mathrm{~B}$ & Crown and closure manufacturing and metal stamping & S069 & Other Forging and Stamping \\
\hline 184 & $33221 \mathrm{~A}$ & Cutlery, utensil, pot, and pan manufacturing & S071 & Tool and Utensil Mfg. \\
\hline 185 & $33221 \mathrm{~B}$ & Hand tool manufacturing & S071 & Tool and Utensil Mfg. \\
\hline 186 & 332310 & Plate work and fabricated structural product manufacturing & S070 & Fabricated Structural Metal Mfg. \\
\hline 187 & 332320 & Ornamental and architectural metal products manufacturing & S072 & Metal Architectural Product Mfg. \\
\hline 188 & 332410 & Power boiler and heat exchanger manufacturing & S073 & Power Boilers \& Heat Exchangers \\
\hline 189 & 332420 & Metal tank (heavy gauge) manufacturing & S074 & Metal Tank Manufacturing \\
\hline 190 & 332430 & $\begin{array}{l}\text { Metal can, box, and other metal container (light gauge) } \\
\text { manufacturing }\end{array}$ & S077 & Other Fabricated Metal Mfg. \\
\hline 191 & 332500 & Hardware manufacturing & S075 & Hardware Manufacturing \\
\hline 192 & 332600 & Spring and wire product manufacturing & S077 & Other Fabricated Metal Mfg. \\
\hline 193 & 332710 & Machine shops & S076 & Machine Shops \\
\hline 194 & 332720 & Turned product and screw, nut, and bolt manufacturing & S077 & Other Fabricated Metal Mfg. \\
\hline 195 & 332800 & Coating, engraving, heat treating and allied activities & S077 & Other Fabricated Metal Mfg. \\
\hline 196 & 332913 & Plumbing fixture fitting and trim manufacturing & S077 & Other Fabricated Metal Mfg. \\
\hline 197 & $33291 \mathrm{~A}$ & Valve and fittings other than plumbing & S077 & Other Fabricated Metal Mfg. \\
\hline 198 & 332991 & Ball and roller bearing manufacturing & S077 & Other Fabricated Metal Mfg. \\
\hline 199 & 332996 & Fabricated pipe and pipe fitting manufacturing & S077 & Other Fabricated Metal Mfg. \\
\hline 200 & $33299 \mathrm{~A}$ & Ammunition manufacturing & S078 & Ordinance and Ammunition Mfg. \\
\hline 201 & 33299B & Arms, ordnance, and accessories manufacturing & S078 & Ordinance and Ammunition Mfg. \\
\hline 202 & $33299 \mathrm{C}$ & Other fabricated metal manufacturing & S077 & Other Fabricated Metal Mfg. \\
\hline
\end{tabular}


Table B.1. Cont'd

\begin{tabular}{|c|c|c|c|c|}
\hline Sector & IOcode & 2002 Benchmark I-O Industry & ImSET 3 & Industry \\
\hline 203 & 333111 & Farm machinery and equipment manufacturing & S079 & Agriculture Machinery Mfg. \\
\hline 204 & 333112 & Lawn and garden equipment manufacturing & S080 & Lawn \& Garden Eq. Mfg. \\
\hline 205 & 333120 & Construction machinery manufacturing & S081 & $\begin{array}{l}\text { Construction Machinery Mfg. } \\
\text { Mining \& Exploration Machinery }\end{array}$ \\
\hline 206 & 333130 & Mining and oil and gas field machinery manufacturing & S082 & $\begin{array}{l}\text { Mfg. } \\
\text { Plastics \& Rubber Machinery }\end{array}$ \\
\hline 207 & 333220 & Plastics and rubber industry machinery manufacturing & S083 & Mfg. \\
\hline 208 & 333295 & Semiconductor machinery manufacturing & S084 & Semiconductor Machinery Mfg. \\
\hline 209 & $33329 \mathrm{~A}$ & Other industrial machinery manufacturing & S085 & $\begin{array}{l}\text { Other Industrial Machinery Mfg. } \\
\text { Commercial Service Machinery }\end{array}$ \\
\hline 210 & 333314 & Optical instrument and lens manufacturing & S086 & $\begin{array}{l}\text { Mfg. } \\
\text { Commercial Service Machinery }\end{array}$ \\
\hline 211 & 333315 & $\begin{array}{l}\text { Photographic and photocopying equipment manufacturing } \\
\text { Other commercial and service industry machinery }\end{array}$ & S086 & $\begin{array}{l}\text { Mfg. } \\
\text { Commercial Service Machinery }\end{array}$ \\
\hline 212 & 333319 & manufacturing & S086 & Mfg. \\
\hline 213 & $33331 \mathrm{~A}$ & $\begin{array}{l}\text { Vending, commercial, industrial, and office machinery } \\
\text { manufacturing }\end{array}$ & S086 & $\begin{array}{l}\text { Commercial Service Machinery } \\
\text { Mfg. }\end{array}$ \\
\hline 214 & 333414 & $\begin{array}{l}\text { Heating equipment (except warm air furnaces) manufacturing } \\
\text { Air conditioning, refrigeration, and warm air heating }\end{array}$ & S087 & Nonfurnace Heating Eq. Mfg. \\
\hline 215 & 333415 & equipment manufacturing & S088 & AC, Ref. \& Forced Air Heating \\
\hline 216 & $33341 \mathrm{~A}$ & Air purification and ventilation equipment manufacturing & S089 & Air Purification Eq. Mfg. \\
\hline 217 & 333511 & Industrial mold manufacturing & S090 & Industrial Mold Manufacturing \\
\hline 218 & 333514 & Special tool, die, jig, and fixture manufacturing & S090 & Industrial Mold Manufacturing \\
\hline 219 & 333515 & Cutting tool and machine tool accessory manufacturing & S090 & Industrial Mold Manufacturing \\
\hline 220 & $33351 \mathrm{~A}$ & $\begin{array}{l}\text { Metal cutting and forming machine tool manufacturing } \\
\text { Rolling mill and other metalworking machinery }\end{array}$ & S091 & Metalworking Machinery Mfg. \\
\hline 221 & $33351 \mathrm{~B}$ & manufacturing & S091 & Metalworking Machinery Mfg. \\
\hline 222 & 333611 & $\begin{array}{l}\text { Turbine and turbine generator set units manufacturing } \\
\text { Speed changer, industrial high-speed drive, and gear }\end{array}$ & S092 & Turbines and Related Mfg. \\
\hline 223 & 333612 & manufacturing & S093 & $\begin{array}{l}\text { Other Engine Eq. Manufacturing } \\
\text { Power Transmission Equipment }\end{array}$ \\
\hline 224 & 333613 & Mechanical power transmission equipment manufacturing & S094 & Mfg. \\
\hline
\end{tabular}


Table B.1. Cont'd

\begin{tabular}{|c|c|c|c|c|}
\hline Sector & IOcode & 2002 Benchmark I-O Industry & ImSET 3 & Industry \\
\hline 225 & 333618 & Other engine equipment manufacturing & S093 & Other Engine Eq. Manufacturing \\
\hline 226 & 333911 & Pump and pumping equipment manufacturing & S095 & Pumps and Related Eq. Mfg. \\
\hline 228 & 333920 & Material handling equipment manufacturing & S095 & Pumps and Related Eq. Mfg. \\
\hline 229 & 333991 & Power-driven hand tool manufacturing & S097 & Other Electric Machinery Mfg. \\
\hline 231 & 333994 & Industrial process furnace and oven manufacturing & S098 & Ind. Process Furnace \& Oven Mfg. \\
\hline 232 & 33399A & Other general purpose machinery manufacturing & S099 & Misc. Machinery Mfg. \\
\hline 233 & 33399B & Fluid power process machinery & S099 & Misc. Machinery Mfg. \\
\hline 234 & 334111 & Electronic computer manufacturing & S100 & Computer Products Mfg. \\
\hline 235 & 334112 & $\begin{array}{l}\text { Computer storage device manufacturing } \\
\text { Computer terminals and other computer peripheral equipment }\end{array}$ & $\mathrm{S} 100$ & Computer Products Mfg. \\
\hline 237 & 334210 & Telephone apparatus manufacturing & $\mathrm{S} 101$ & Communications Eq. Mfg. \\
\hline 238 & 334220 & Broadcast and wireless communications equipment & $\mathrm{S} 101$ & Communications Eq. Mfg. \\
\hline 239 & 334290 & Other communications equipment manufacturing & $\mathrm{S} 101$ & Communications Eq. Mfg. \\
\hline 240 & 334300 & Audio and video equipment manufacturing & S102 & Electronic Components Mfg. \\
\hline 241 & 334411 & Electron tube manufacturing & $\mathrm{S} 102$ & Electronic Components Mfg. \\
\hline 242 & 334412 & Bare printed circuit board manufacturing & $\mathrm{S} 102$ & Electronic Components Mfg. \\
\hline 243 & 334413 & Semiconductor and related device manufacturing & $\mathrm{S} 102$ & Electronic Components Mfg. \\
\hline 244 & 334417 & Electronic connector manufacturing & $\mathrm{S} 102$ & Electronic Components Mfg. \\
\hline 245 & 334418 & Printed circuit assembly (electronic assembly) manufacturing & $\mathrm{S} 102$ & Electronic Components Mfg. \\
\hline 246 & 334419 & $\begin{array}{l}\text { Other electronic component manufacturing } \\
\text { Electronic capacitor, resistor, coil, transformer, and other }\end{array}$ & S102 & Electronic Components Mfg. \\
\hline 247 & $33441 \mathrm{~A}$ & $\begin{array}{l}\text { inductor manufacturing } \\
\text { Electromedical and electrotherapeutic apparatus }\end{array}$ & S102 & Electronic Components Mfg. \\
\hline
\end{tabular}


Table B.1. Cont'd

\begin{tabular}{|c|c|c|c|c|}
\hline Sector & IOcode & 2002 Benchmark I-O Industry & ImSET 3 & Industry \\
\hline 250 & 334512 & Automatic environmental control manufacturing & S104 & $\begin{array}{l}\text { Automatic Environmental } \\
\text { Controls }\end{array}$ \\
\hline 251 & 334513 & Industrial process variable instruments manufacturing & S105 & Ind. Process Variable Instruments \\
\hline 252 & 334514 & Totalizing fluid meters and counting devices manufacturing & S106 & Fluid Meters \& Counting Devices \\
\hline 253 & 334515 & Electricity and signal testing instruments manufacturing & S107 & Electricity \& Signal Testing Inst. \\
\hline 254 & 334516 & Analytical laboratory instrument manufacturing & S108 & Other Lab \& Related Instruments \\
\hline 255 & 334517 & Irradiation apparatus manufacturing & S108 & Other Lab \& Related Instruments \\
\hline 256 & $33451 \mathrm{~A}$ & $\begin{array}{l}\text { Watch, clock, and other measuring and controlling device } \\
\text { manufacturing }\end{array}$ & S108 & Other Lab \& Related Instruments \\
\hline 257 & 334613 & Magnetic and optical recording media manufacturing & S109 & Electronic Media Processing \\
\hline 258 & $33461 \mathrm{~A}$ & Software, audio, and video media reproducing & S109 & Electronic Media Processing \\
\hline 259 & 335110 & Electric lamp bulb and part manufacturing & S110 & Electric Lamp Bulb And Part Mfg. \\
\hline 260 & 335120 & Lighting fixture manufacturing & S111 & Lighting Fixture Manufacturing \\
\hline 261 & 335210 & Small electrical appliance manufacturing & S112 & $\begin{array}{l}\text { Household Eq. Mfg. } \\
\text { Household Cooking Appliance }\end{array}$ \\
\hline 262 & 335221 & Household cooking appliance manufacturing & S113 & Mfg. \\
\hline 263 & 335222 & Household refrigerator and home freezer manufacturing & S114 & $\begin{array}{l}\text { HH Refrigerator \& Freezer Mfg. } \\
\text { Household Laundry Equipment }\end{array}$ \\
\hline 264 & 335224 & Household laundry equipment manufacturing & S115 & Mfg. \\
\hline 265 & 335228 & Other major household appliance manufacturing & S116 & Other Major HH Appliance Mfg. \\
\hline 266 & 335311 & Power, distribution, and specialty transformer manufacturing & S117 & $\begin{array}{l}\text { Electric Power, Etc. Transformers } \\
\text { Motor And Generator }\end{array}$ \\
\hline 267 & 335312 & Motor and generator manufacturing & S118 & Manufacturing \\
\hline 268 & 335313 & Switchgear and switchboard apparatus manufacturing & S119 & Industrial Controls \\
\hline 269 & 335314 & Relay and industrial control manufacturing & S119 & Industrial Controls \\
\hline 270 & 335911 & Storage battery manufacturing & S120 & Storage Battery Manufacturing \\
\hline 271 & 335912 & Primary battery manufacturing & S121 & Primary Battery Manufacturing \\
\hline 272 & 335920 & Communication and energy wire and cable manufacturing & S122 & Com/Energy Wires \& Cables Mfg. \\
\hline
\end{tabular}


Table B.1. Cont'd

\begin{tabular}{|c|c|c|c|c|}
\hline Sector & IOcode & 2002 Benchmark I-O Industry & ImSET 3 & Industry \\
\hline 273 & 335930 & Wiring device manufacturing & S123 & Misc. Electric Eq. Mfg. \\
\hline 274 & 335991 & Carbon and graphite product manufacturing & $\mathrm{S} 123$ & Misc. Electric Eq. Mfg. \\
\hline 275 & 335999 & manufacturing & $\mathrm{S} 123$ & Misc. Electric Eq. Mfg. \\
\hline 276 & 336111 & Automobile manufacturing & S124 & Car and Light Truck Mfg. \\
\hline 277 & 336112 & Light truck and utility vehicle manufacturing & S124 & Car and Light Truck Mfg. \\
\hline 278 & 336120 & Heavy duty truck manufacturing & $\mathrm{S} 125$ & Truck Manufacturing \\
\hline 279 & 336211 & Motor vehicle body manufacturing & $\mathrm{S} 124$ & Car and Light Truck Mfg. \\
\hline 280 & 336212 & Truck trailer manufacturing & S125 & Truck Manufacturing \\
\hline 281 & 336213 & Motor home manufacturing & S126 & RV Manufacturing \\
\hline 282 & 336214 & Travel trailer and camper manufacturing & S126 & $\begin{array}{l}\text { RV Manufacturing } \\
\text { Motor Vehicle Parts }\end{array}$ \\
\hline 283 & 336300 & Motor vehicle parts manufacturing & S127 & Manufacturing \\
\hline 285 & 336412 & Aircraft engine and engine parts manufacturing & $\mathrm{S} 128$ & Aerospace Product Manufacturing \\
\hline 286 & 336413 & Other aircraft parts and auxiliary equipment manufacturing & $\mathrm{S} 128$ & Aerospace Product Manufacturing \\
\hline 287 & 336414 & Guided missile and space vehicle manufacturing & S128 & Aerospace Product Manufacturing \\
\hline 288 & $33641 \mathrm{~A}$ & missiles & $\mathrm{S} 128$ & Aerospace Product Manufacturing \\
\hline 289 & 336500 & Railroad rolling stock manufacturing & S129 & Railroad Rolling Stock Mfg. \\
\hline 290 & 336611 & Ship building and repairing & S130 & Ship Building And Repairing \\
\hline 291 & 336612 & Boat building & S131 & Boat/Cycle \& Parts Mfg. \\
\hline 292 & 336991 & $\begin{array}{l}\text { Motorcycle, bicycle, and parts manufacturing } \\
\text { Military armored vehicle, tank, and tank component }\end{array}$ & S131 & Boat/Cycle \& Parts Mfg. \\
\hline 293 & 336992 & manufacturing & S132 & Other Transportation Eq. \\
\hline 294 & 336999 & All other transportation equipment manufacturing & $\mathrm{S} 132$ & Other Transportation Eq. \\
\hline 295 & 337110 & Wood kitchen cabinet and countertop manufacturing & S133 & Household Furniture \\
\hline
\end{tabular}


Table B.1. Cont'd

\begin{tabular}{|c|c|c|c|c|}
\hline Sector & IOcode & 2002 Benchmark I-O Industry & ImSET 3 & Industry \\
\hline 297 & 337122 & Nonupholstered wood household furniture manufacturing & S133 & Household Furniture \\
\hline 298 & 337127 & Institutional furniture manufacturing & S134 & Institutional Furniture \\
\hline 299 & $33712 \mathrm{~A}$ & Metal and other household furniture manufacturing & S133 & Household Furniture \\
\hline 300 & 337212 & Custom architectural woodwork and millwork manufacturing & S135 & Custom Woodwork And Millwork \\
\hline 301 & 337215 & Showcase, partition, shelving, and locker manufacturing & S136 & Office Furniture Mfg. \\
\hline 302 & $33721 \mathrm{~A}$ & Office furniture manufacturing & S136 & Office Furniture Mfg. \\
\hline 303 & 337910 & Mattress manufacturing & S137 & Misc. Furniture Mfg. \\
\hline 304 & 337920 & Blind and shade manufacturing & S137 & Misc. Furniture Mfg. \\
\hline 305 & 339111 & Laboratory apparatus and furniture manufacturing & S138 & Laboratory Instruments \& Eq. \\
\hline 306 & 339112 & Surgical and medical instrument manufacturing & S138 & Laboratory Instruments \& Eq. \\
\hline 307 & 339113 & Surgical appliance and supplies manufacturing & S138 & Laboratory Instruments \& Eq. \\
\hline 308 & 339114 & Dental equipment and supplies manufacturing & S138 & Laboratory Instruments \& Eq. \\
\hline 309 & 339115 & Ophthalmic goods manufacturing & S138 & Laboratory Instruments \& Eq. \\
\hline 310 & 339116 & Dental laboratories & $\mathrm{S} 138$ & Laboratory Instruments \& Eq. \\
\hline 311 & 339910 & Jewelry and silverware manufacturing & S138 & Laboratory Instruments \& Eq. \\
\hline 312 & 339920 & Sporting and athletic goods manufacturing & S139 & Misc. Manufacturing \\
\hline 313 & 339930 & Doll, toy, and game manufacturing & S139 & Misc. Manufacturing \\
\hline 314 & 339940 & Office supplies (except paper) manufacturing & S139 & Misc. Manufacturing \\
\hline 315 & 339950 & Sign manufacturing & S139 & Misc. Manufacturing \\
\hline 316 & 339991 & Gasket, packing, and sealing device manufacturing & S139 & Misc. Manufacturing \\
\hline 317 & 339992 & Musical instrument manufacturing & S139 & Misc. Manufacturing \\
\hline 318 & 339994 & Broom, brush, and mop manufacturing & S139 & Misc. Manufacturing \\
\hline 319 & $33999 \mathrm{~A}$ & All other miscellaneous manufacturing & S139 & Misc. Manufacturing \\
\hline 320 & 420000 & Wholesale trade & S140 & Wholesale Trade \\
\hline 321 & 481000 & Air transportation & S141 & Air Transportation \\
\hline 322 & 482000 & Rail transportation & S142 & Rail Transportation \\
\hline 323 & 483000 & Water transportation & S143 & Water Transportation \\
\hline
\end{tabular}


Table B.1. Cont'd

\begin{tabular}{|c|c|c|c|c|}
\hline Sector & IOcode & 2002 Benchmark I-O Industry & ImSET 3 & Industry \\
\hline 324 & 484000 & Truck transportation & S144 & Truck Transportation \\
\hline 325 & 485000 & Transit and ground passenger transportation & S145 & Transit \& Related Services \\
\hline 326 & 486000 & Pipeline transportation & S146 & Pipeline Transportation \\
\hline 327 & $48 \mathrm{~A} 000$ & $\begin{array}{l}\text { transportation } \\
\text { the }\end{array}$ & S147 & Sightseeing Transportation \\
\hline 328 & 491000 & Postal service & S148 & Postal and Courier Services \\
\hline 329 & 492000 & Couriers and messengers & S148 & Postal and Courier Services \\
\hline 330 & 493000 & Warehousing and storage & S149 & Warehousing And Storage \\
\hline 331 & $4 \mathrm{~A} 0000$ & Retail trade & S150 & Retail Trade \\
\hline 332 & 511110 & Newspaper publishers & S151 & Publishers \\
\hline 333 & 511120 & Periodical publishers & S151 & Publishers \\
\hline 334 & 511130 & Book publishers & S151 & Publishers \\
\hline 335 & $5111 \mathrm{~A} 0$ & Directory, mailing list, and other publishers & S151 & Publishers \\
\hline 336 & 511200 & Software publishers & S151 & Publishers \\
\hline 337 & 512100 & Motion picture and video industries & S152 & Telecom \& Entertainment \\
\hline 338 & 512200 & Sound recording industries & S152 & Telecom \& Entertainment \\
\hline 339 & 515100 & Radio and television broadcasting & S152 & Telecom \& Entertainment \\
\hline 340 & 515200 & Cable and other subscription programming & S152 & Telecom \& Entertainment \\
\hline 341 & 516110 & Internet publishing and broadcasting & S153 & Internet Services \\
\hline 342 & 517000 & Telecommunications & S152 & Telecom \& Entertainment \\
\hline 343 & 518100 & Internet service providers and web search portals & S153 & Internet Services \\
\hline 344 & 518200 & Data processing, hosting, and related services & S152 & Telecom \& Entertainment \\
\hline 345 & 519100 & Other information services & S152 & Telecom \& Entertainment \\
\hline 346 & $522 \mathrm{~A} 00$ & $\begin{array}{l}\text { Nondepository credit intermediation and related activities } \\
\text { Securities, commodity contracts, investments, and related }\end{array}$ & S154 & Credit Counseling \\
\hline 347 & 523000 & activities & S155 & Investment Services \\
\hline 348 & 524100 & Insurance carriers & S156 & Insurance \\
\hline 349 & 524200 & Insurance agencies, brokerages, and related activities & S156 & Insurance \\
\hline
\end{tabular}


Table B.1. Cont'd

\begin{tabular}{|c|c|c|c|c|}
\hline Sector & IOcode & 2002 Benchmark I-O Industry & ImSET 3 & Industry \\
\hline 350 & 525000 & Funds, trusts, and other financial vehicles & S157 & Fund Management \\
\hline 351 & $52 \mathrm{~A} 000$ & Monetary authorities and depository credit intermediation & S158 & Monetary Authorities \\
\hline 352 & 531000 & Real estate & S159 & Real Estate \\
\hline 353 & 532100 & Automotive equipment rental and leasing & S160 & Car Rental Agencies \\
\hline 354 & 532230 & Video tape and disc rental & S161 & Rental Services \\
\hline 355 & 532400 & $\begin{array}{l}\text { Commercial and industrial machinery and equipment rental } \\
\text { and leasing } \\
\text { General and consumer goods rental except video tapes and }\end{array}$ & S161 & Rental Services \\
\hline 356 & 532A00 & discs & S161 & Rental Services \\
\hline 357 & 533000 & Lessors of nonfinancial intangible assets & S161 & Rental Services \\
\hline 358 & 541100 & Legal services & S162 & Other Professional/Technical Svc. \\
\hline 359 & 541200 & $\begin{array}{l}\text { Accounting, tax preparation, bookkeeping, and payroll } \\
\text { services }\end{array}$ & S162 & Other Professional/Technical Svc. \\
\hline 360 & 541300 & Architectural, engineering, and related services & S163 & Architectural \& Engineering Svc. \\
\hline 361 & 541400 & Specialized design services & S164 & Specialized Design Services \\
\hline 362 & 541511 & Custom computer programming services & S162 & Other Professional/Technical Svc. \\
\hline 363 & 541512 & Computer systems design services & S162 & Other Professional/Technical Svc. \\
\hline 364 & $54151 \mathrm{~A}$ & $\begin{array}{l}\text { Other computer related services, including facilities } \\
\text { management }\end{array}$ & S162 & Other Professional/Technical Svc. \\
\hline 365 & 541610 & Management, scientific, and technical consulting services & S162 & Other Professional/Technical Svc. \\
\hline 366 & $5416 \mathrm{~A} 0$ & Environmental and other technical consulting services & S162 & Other Professional/Technical Svc. \\
\hline 367 & 541700 & Scientific research and development services & S162 & Other Professional/Technical Svc. \\
\hline 368 & 541800 & Advertising and related services & S162 & Other Professional/Technical Svc. \\
\hline 369 & 541920 & Photographic services & S162 & Other Professional/Technical Svc. \\
\hline 370 & 541940 & $\begin{array}{l}\text { Veterinary services } \\
\text { All ther miscellanous nrofessional scientific and technical }\end{array}$ & S162 & Other Professional/Technical Svc. \\
\hline 371 & 5419A0 & services & S162 & Other Professional/Technical Svc. \\
\hline 372 & 550000 & Management of companies and enterprises & S165 & Other Business Services \\
\hline 373 & 561100 & Office administrative services & S165 & Other Business Services \\
\hline 374 & 561200 & Facilities support services & S166 & Facilities Support Services \\
\hline
\end{tabular}


Table B.1. Cont'd

\begin{tabular}{|c|c|c|c|c|}
\hline Sector & IOcode & 2002 Benchmark I-O Industry & ImSET 3 & Industry \\
\hline 375 & 561300 & Employment services & S165 & Other Business Services \\
\hline 376 & 561400 & Business support services & S165 & Other Business Services \\
\hline 377 & 561500 & Travel arrangement and reservation services & S165 & Other Business Services \\
\hline 378 & 561600 & Investigation and security services & S165 & Other Business Services \\
\hline 379 & 561700 & Services to buildings and dwellings & S165 & Other Business Services \\
\hline 380 & 561900 & Other support services & S165 & Other Business Services \\
\hline 381 & 562000 & Waste management and remediation services & S165 & Other Business Services \\
\hline 382 & 611100 & Elementary and secondary schools & S167 & Education \\
\hline 383 & $611 \mathrm{~A} 00$ & $\begin{array}{l}\text { Junior colleges, colleges, universities, and professional } \\
\text { schools }\end{array}$ & S167 & Education \\
\hline 384 & $611 \mathrm{~B} 00$ & Other educational services & S167 & Education \\
\hline 385 & 621600 & Home health care services & S168 & Healthcare Providers \\
\hline 386 & $621 \mathrm{~A} 00$ & Offices of physicians, dentists, and other health practitioners & S168 & Healthcare Providers \\
\hline 387 & $621 \mathrm{~B} 00$ & $\begin{array}{l}\text { Medical and diagnostic labs and outpatient and other } \\
\text { ambulatory care services }\end{array}$ & S168 & Healthcare Providers \\
\hline 388 & 622000 & Hospitals & S169 & Hospitals and Residential Care \\
\hline 389 & 623000 & Nursing and residential care facilities & S169 & Hospitals and Residential Care \\
\hline 390 & 624200 & $\begin{array}{l}\text { Community food, housing, and other relief services, including } \\
\text { rehabilitation services }\end{array}$ & S170 & Day Care and Social Assistance \\
\hline 391 & 624400 & Child day care services & S170 & Day Care and Social Assistance \\
\hline 392 & $624 \mathrm{~A} 00$ & Individual and family services & S170 & Day Care and Social Assistance \\
\hline 393 & 711100 & Performing arts companies & S171 & Amusement \& Recreation \\
\hline 394 & 711200 & Spectator sports & S171 & Amusement \& Recreation \\
\hline 395 & 711500 & $\begin{array}{l}\text { Independent artists, writers, and performers } \\
\text { Promoters of performing arts and sports and agents for public }\end{array}$ & S171 & Amusement \& Recreation \\
\hline 396 & $711 \mathrm{~A} 00$ & Figures & S171 & Amusement \& Recreation \\
\hline 397 & 712000 & Museums, historical sites, zoos, and parks & S171 & Amusement \& Recreation \\
\hline 398 & 713940 & Fitness and recreational sports centers & S171 & Amusement \& Recreation \\
\hline 399 & 713950 & Bowling centers & S171 & Amusement \& Recreation \\
\hline
\end{tabular}


Table B.1. Cont'd

\begin{tabular}{|c|c|c|c|c|}
\hline Sector & IOcode & 2002 Benchmark I-O Industry & ImSET 3 & Industry \\
\hline 400 & 713A00 & Amusement parks, arcades, and gambling industries & S171 & Amusement \& Recreation \\
\hline 401 & 713B00 & Other amusement and recreation industries & S171 & Amusement \& Recreation \\
\hline 402 & $7211 \mathrm{~A} 0$ & Hotels and motels, including casino hotels & S172 & Lodging \\
\hline 403 & $721 \mathrm{~A} 00$ & Other accommodations & S172 & Lodging \\
\hline 404 & 722000 & Food services and drinking places & S173 & Food \& Beverage Services \\
\hline 405 & 811192 & Car washes & S174 & Personal Services \\
\hline 406 & $8111 \mathrm{~A} 0$ & Automotive repair and maintenance, except car washes & S174 & Personal Services \\
\hline 407 & 811200 & $\begin{array}{l}\text { Electronic and precision equipment repair and maintenance } \\
\text { Commercial and industrial machinery and equipment repair }\end{array}$ & S174 & Personal Services \\
\hline 408 & 811300 & and maintenance & S174 & Personal Services \\
\hline 409 & 811400 & Personal and household goods repair and maintenance & S174 & Personal Services \\
\hline 410 & 812100 & Personal care services & S174 & Personal Services \\
\hline 411 & 812200 & Death care services & S174 & Personal Services \\
\hline 412 & 812300 & Dry-cleaning and laundry services & S174 & Personal Services \\
\hline 413 & 812900 & Other personal services & S174 & Personal Services \\
\hline 414 & 813100 & Religious organizations & S175 & Other Services \\
\hline 415 & $813 \mathrm{~A} 00$ & Grantmaking, giving, and social advocacy organizations & S175 & Other Services \\
\hline 416 & 813B00 & Civic, social, professional, and similar organizations & S175 & Other Services \\
\hline 417 & 814000 & Private households & S176 & Households \\
\hline 418 & S00101 & Federal electric utilities & S177 & Federal Electric Utilities \\
\hline 419 & S00102 & Other Federal Government enterprises & S178 & Other Fed. Gov. Enterprises \\
\hline 420 & S00201 & State and local government passenger transit & S179 & $\mathrm{S} / \mathrm{L}$ Government Passenger Transit \\
\hline 421 & S00202 & State and local government electric utilities & S180 & $\mathrm{S} / \mathrm{L}$ Government Electric Utilities \\
\hline 422 & S00203 & Other state and local government enterprises & S181 & Other S/L Government Enterprises \\
\hline 423 & S00300 & Noncomparable imports & S182 & Miscellaneous Goods \\
\hline 424 & S00401 & Scrap & S182 & Miscellaneous Goods \\
\hline 425 & S00402 & Used and secondhand goods & S182 & Miscellaneous Goods \\
\hline
\end{tabular}


Table B.1. Cont'd

\begin{tabular}{cclll}
\hline Sector & IOcode & 2002 Benchmark I-O Industry & ImSET 3 & Industry \\
\hline 426 & S00500 & General Federal defense government services & S183 & General Fed. Defense Services \\
427 & S00600 & General Federal nondefense government services & S184 & $\begin{array}{l}\text { General Fed. Nondefense Services } \\
\text { General State \& Local Gov. }\end{array}$ \\
428 & S00700 & General state and local government services & S185 & Services \\
429 & S00800 & Owner-occupied dwellings & S186 & Owner-Occupied Dwellings \\
430 & S00900 & Rest of the world adjustment & S187 & RTW Adjustment
\end{tabular}


Appendix C

\section{The C++ Calculator}





\section{Appendix C}

\section{The C++ Calculator}

This appendix describes the input file generated by the Visual Basic program ImSET 3, three C++ routines used to the calculations, and the output file that returns the calculations to ImSET 3.

\section{C.1 The Input File}

The $\mathrm{C}++$ calculator is designed to process a data stream generated by the program ImSET 3. Such a file (named "qminput.txt") is shown in the box below (line numbers have been added for readability):

(1) QMIO INPUT FILE. Data provided by ImSET 3

(2) Run number: 1

(3) Run title: Demo

(4) Technology: Sample Technology

(5) End-use sector: Residential

(6) User name:

(7) $50,50,0,0,0,0,0,0,0,0,0$

(8) $70,5,4,3,3,2,1,1,1,1,9$

(9) 10,6

(10) $1,2,3,4,5,10,15,20,25,30$

(11) $12,188,32.899,65.799,98.698,0.000,0.000,0.000,0.000,0.000,0.000,0.000$

(12) $13,188,0.000,0.000,0.000,0.000,0.000,0.000,0.000,0.000,0.000,0.000$

(13) $22,189,1.866,2.799,3.731,4.664,0.000,0.000,0.000,0.000,0.000,0.000$

(14) $12,22,-1.867,-1.867,-1.867,0.000,0.000,0.000,0.000,0.000,0.000,0.000$

(15) $147,190,-0.014,-0.014,-0.014,0.000,0.000,0.000,0.000,0.000,0.000,0.000$

(16) $162,190,-0.131,-0.131,-0.131,0.000,0.000,0.000,0.000,0.000,0.000,0.000$

(17) $163,190,-0.140,-0.140,-0.140,0.000,0.000,0.000,0.000,0.000,0.000,0.000$

(18) $174,190,-0.173,-0.173,-0.173,0.000,0.000,0.000,0.000,0.000,0.000,0.000$

The first six lines describe the project. Line 7 represents seven weights for the various sources of funds. Line 8 represents seven weights for the various shares of investment funding provided for reduction of investment in electric and natural gas utilities. Line 9 provides the calculator how many years of data are included (i.e., 10) and the number of sector changes to read (6). Line 10 lists the abbreviated years to consider (i.e., 2, 3, etc.). The year numbers are added to 2000 so the results are reported as 2001, 2002, etc. Lines 11 and 12 report the capacity adjustments as a result of energy savings, one for electricity and one for gas utilities, both as applied to final demand. Following these capacity changes are six sets of changes to the sector data, one for each of the sectors 22, 12,147, 162, 163, and 174. Cross referencing these sectors (see Appendix B) reveals that line 13 represents the capital changes for food processing (sector 22), line 14 represents electricity generation and transmission (sector 12) and final demand (matrix row 190). The second index number, for capital expenditures 190, indicates that these changes are to be 
made to the final demand vector, specifically to investment. If residential equipment was considered rather than commercial equipment, there would be changes to other industry sectors. For fuel savings, the second index number is 188 , indicating the savings occurs in the consumption vector.

\section{C.2 C++ Calculator Program}

The "C++" Calculator program is named IMSETEngine.exe. This program begins in the "main" function and in turn calls functions QM3 and DEMAND. The main program reads the data file described above and transfers the data to the calculating subroutine QM3, which returns the results to the main function and writes the data file that is then read by the Visual Basic (VB) program. The function QM3 first reads the core data from a comma separated value file that holds the 2002 Benchmark I-O data, then calculates the base period employment, earnings, and output. It then loops through each of the years to be processed, changing the "Use" matrix data or the final demand data, then recalculates the employment, earnings, and output. When all years are processed, the function transfers the results back to the main function. In the course of this processing, QM3 calls the DEMAND subroutine to make adjustments to final demands and assure that the final demand vector is appropriately rescaled. In addition, there are five other routines that multiply, add, and invert matrices, which are briefly described but not shown here.

\section{ImSET Engine}

The main body of the calculator program (ImSETEngine) is shown in the text boxes below. While comments in the code explain most of the operations, this explanation will be cued to the input file, shown above. After a number of parameter and variable definitions, the program opens two files, the input file above, and the file to which the results will be printed, QM-CHG.DAT. The program then skips over the six lines of documentation text that are not used by the calculator. The next read statements put the first set of 11 weights into the variable iwgt, and the second set of weights into the variable jwgt. Because the final demand vectors include both exports and imports, two additional weights (both 0 ) are added to be consistent with the structure of final demand. The next two read statements (in the continuation text box) assign the number of years processed to JYR and the number of changes to be made to N. The next two read statements read the capacity changes into the variable "y." Each of the remaining input file line reads initialize two variables, inx and indx, that hold the set of industry or final demand indexes, along with all the associated I-O changes into X.

The program then has input the data stream and turns over processing to QM3. When the results are returned from QM3, they are contained in six variables: SUMJ, SUMH, and SUMQ contain the base period jobs, earnings, and total output. Vectors SJ, SH, and SQ contain the calculated model results, one for each year, of which there are JYR years. The program next prints the base period values to the output file, then calculates and prints out the difference between subsequent years calculated values and the base period values to this same file. The final output is the industry output sector-by-sector. A rounding adjustment factor is applied both this output and to the yearly differences output to account for rounding errors associated with the $\mathrm{I} / 0$ binary input and $\mathrm{C}++$ math rounding process.

At this point, all processing has been completed so control is transferred back to the VB user interface program.

The "main" function of ImSETEngine.exe 
// This program will read in data, make a few calculations, then

// transfer operation to QMIOS, which does the work: Changes the

// Use matrix, then calculate output then multiply the outputs by

// the employment intensities, after adjusting final demands by iwgt.

// JYR is the number of years. jwgt is used for capital distribution.

// The years for analysis are then read in as 1, 2, etc., then

// these are added to 2000 to construct the vector of years reported.

// There are twelve categories of final demand: C, I, X, M, FI,

// for both Defense and Nondefense (D, N), FC for both D\&N, SLI

// for Education and Other (E \& 0 ) and SLC (E \& 0), but just

$/ /$ ten are read in

// - - no X or M (weights for these are set to zero.

// The thirteenth column is total final demand.

// If iwgt(11)=100 changes are just made to the total vector.

// This version allows up to 350 changes and 50 years of data.

int const $\operatorname{MP}(999)$;

int const NY( 50$)$;

int const NZ( 187 );

FArray1D_int iyr( NY );

FArray2D_int inx ( 2, 2);

FArray2D_int indx( MP, 2 );

FArray1D_int iwgt( 11$)$;

FArray1D_int jwgt( 11$)$;

FArray2D_double X( MP, NY );

FArray1D_double SH( NY);

FArray1D_double SJ( NY);

FArray1D_double SQ( NY);

FArray1D_double wgt $(13,0.0)$;

FArray1D_double wgt2 $(13,0.0)$;

FArray2D_double y( 2, NY);

FArray2D_double TA( NZ, NY );

FArray1D_double baselineI0( NZ );

FArray1D_double IORoundingAdjFactor( NZ );

std: :cout $<$ " BEGIN EXECUTION" $<$ std: :endl;

// This section reads in the input file, for one technology

// First skip the first 6 lines, then read in two sets of 7 weights

// one for final demand (wgt), one for capacity savings (wgt2)

// These integer values are divided by 100 to change to floating point

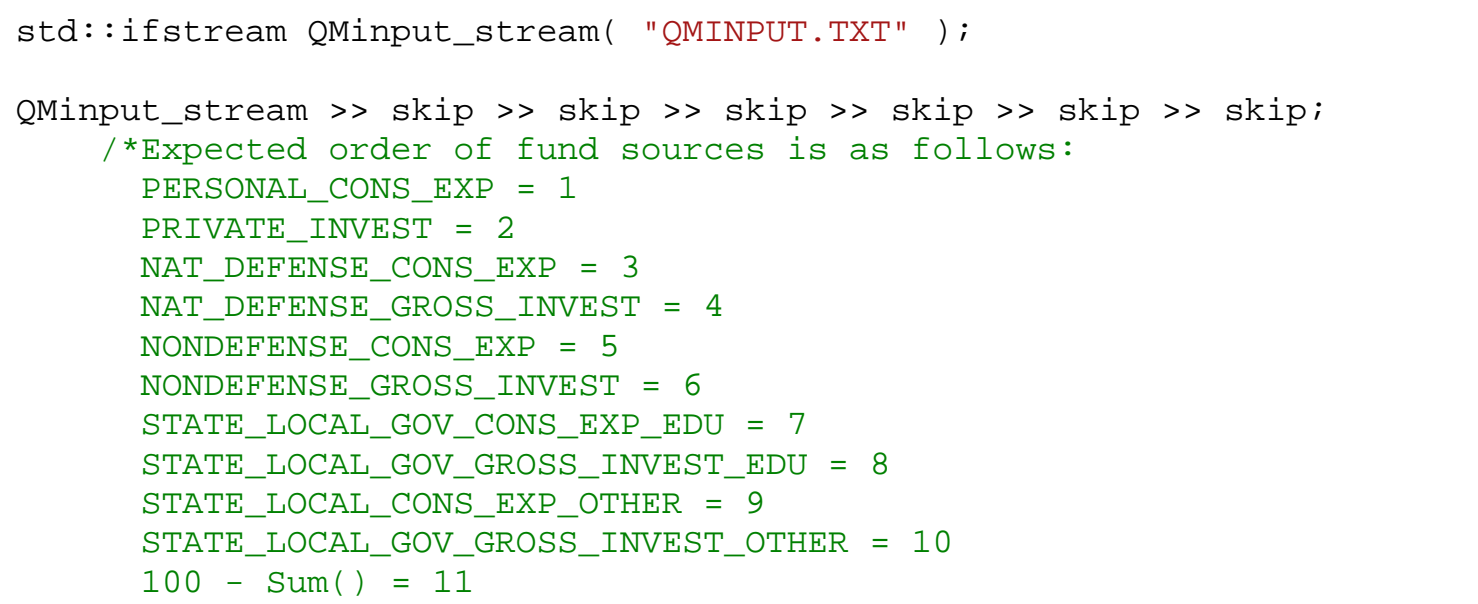




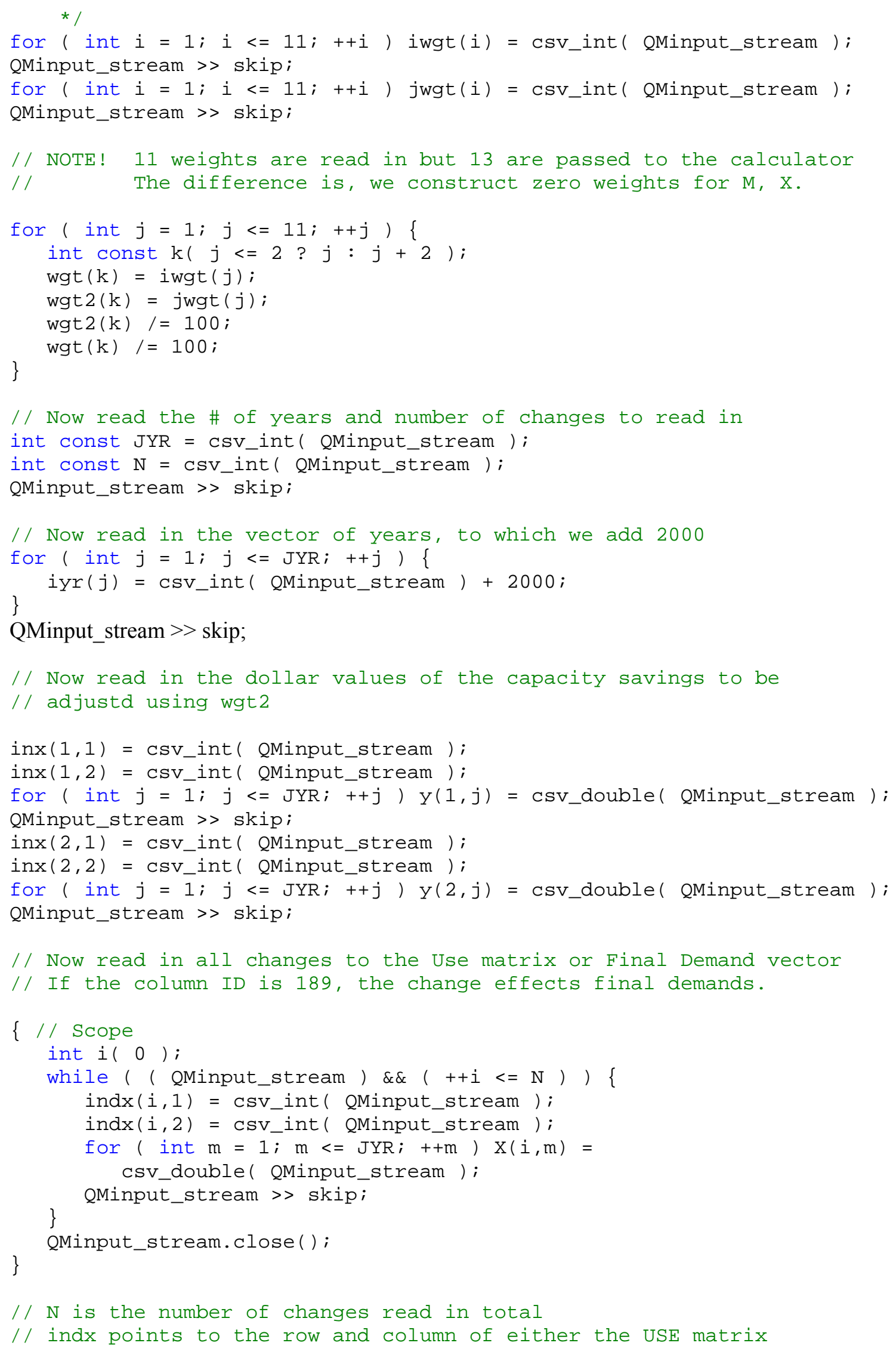


// or the final demand column to change

$/ /$ and $X$ are the change values for the JYR years

// Now do the calculations

// This version of the calculator handles capacity savings

double SUMH, SUMJ, SUMQ;

QM3(X, N , indx, inx, SUMJ, SUMH, SUMQ, SJ, SH, SQ, TA, wgt, JYR, y, wgt2, baselineI0 );

// Now write results

std: : ofstream QMchg_stream( "QM-CHG.DAT" );

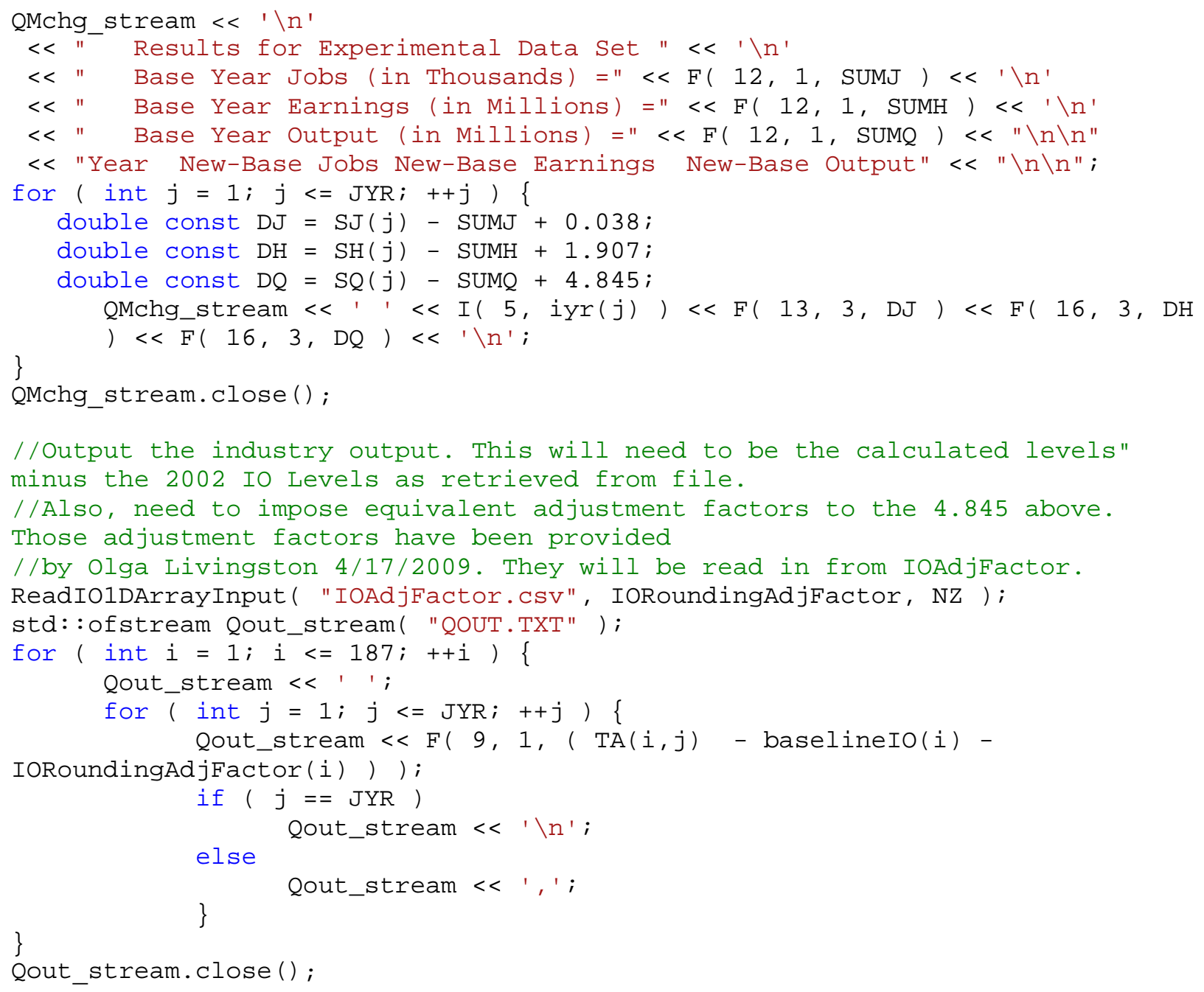

\section{The Calculator - QM3}

The lengthy code on the following pages is a listing of the calculation function, QM3. The first set of comments explains how the naming convention changes from the main program within this routine. Parameters and variables are then defined and the 2002 Benchmark I-O data is opened and read in. The data from this file are arrays $\mathrm{W}$; the market share matrix, $\mathrm{U}$; the use matrix, $\mathrm{Q}$; the vector of industry outputs, DF; the final demand matrix; and EI, the matrix of employment and earnings intensity by 
industry. The dimensionality of each of these variables can be determined from the variable definitions at the beginning of the program.

Once the I-O data is returned, the data are used to construct the base period employment, earnings and output. Base period results are constructed by multiplying industry output, the first column of Q, by two sets of industry intensities. These intensities are found in the variable EI, with the first column job intensities and the second earnings intensities. Multiplying each industry's output by these intensities yields jobs and earning, which are cumulated over all industries. Total output is also cumulated and returned in the scalar variables SUJ, SUE, and SUQ.

A looping process through each year's data is then executed. The processing of each year begins by re-reading the I-O data, to assure that any changes will be made to the original data because the changes to this data will be different for each year. The next set of statements zero out the set of variables used to differentiate between changes to capital purchases, changes to fuel use, changes in water use, and changes in O\&M expenses. Then, vectors are defined that allow the program to identify which changes fall into each of these categories. These are the vectors FL, KL, WL, and OM, consisting of zeros and ones, where the units identify the change as falling into the specific categories, with F, K, W, and OM referencing fuel, capital water and O\&M changes, respectively.

After these assignments, QM3 begins processing each year's data. After zeroing out two variables to hold the sum of final demand and the sum of changes to value added, identified by fuel type, the total capacity adjustment is calculated for this year. That is stored in the variable ADJK. Then, the changes to final demand and the use matrix are made, identifying the capital and O\&M, fuel, and water final demand changes separately. The value-added changes to the use matrix are made to each of the appropriate columns, which are then cumulated into SVA. O\&M changes are cumulated into OAM. While specific industries have their use of the fuels adjusted within the use matrix, the impact on the fuel supplying industry is applied to the final demand vector.

After these changes are made and results for this year have been zeroed out, I-O data are processed to create a total requirements matrix. ${ }^{1}$ This is done by creating a matrix, $\mathrm{B}$, which is derived from the use matrix by dividing each element in the columns by that industry's output. This loop is also used to create the identity matrix ai. First, $\mathrm{W}$ is constructed by multiplying PH by D the market share matrix - this is derived from the make matrix. Then, $\mathrm{W}$ is multiplied by $\mathrm{B}$. These matrix multiplications rely on calls to a matrix multiply function, MMULT, which multiplies a matrix of dimension ( $\mathrm{k} \times \mathrm{n})$ by a second ( $\mathrm{n} \times \mathrm{m})$ matrix and returns a $(\mathrm{k} \mathrm{x}$ m) matrix. A similar routine, MMULT1, multiplies a ( $\mathrm{k} \times \mathrm{n})$ matrix by an ( $\mathrm{n} \times 1)$ vector to create a ( $\mathrm{k}$ x 1$)$ vector. This $\mathrm{B}^{*} \mathrm{~W}$ matrix (called "a" in the program) is then subtracted from the identity matrix, ai, using the subroutine MADD (which adds or subtracts, depending on the value of $\mathrm{j},-1$ in this case for subtraction). The result, which replaces the "Use" matrix, is then inverted using two subroutines from numerical recipes. ${ }^{2}$

\section{QM3 Function:}

// In this function, j1=n, 11=INDX, and X1 is $X$ in ImSET.for

// This program will change the Use matrix, then calculate output

\footnotetext{
${ }^{1}$ See Lawson et al. 2002 in references list.

2 Press WH, WT Vetterling, SA Teukolsky, and BP Flannery. 1986. Numerical Recipes: The Art of Scientific Computing. Cambridge University Press, New York. For matrix inversion, see p. 38.
} 
// then multiply the outputs by the employment intensities

// X1 contains j1 rows and up to 100 columns of changes to the

// Final Demand vectors and/or the Use Matrix.

// 11 is j1x2: first element is the row ID, second is the column ID

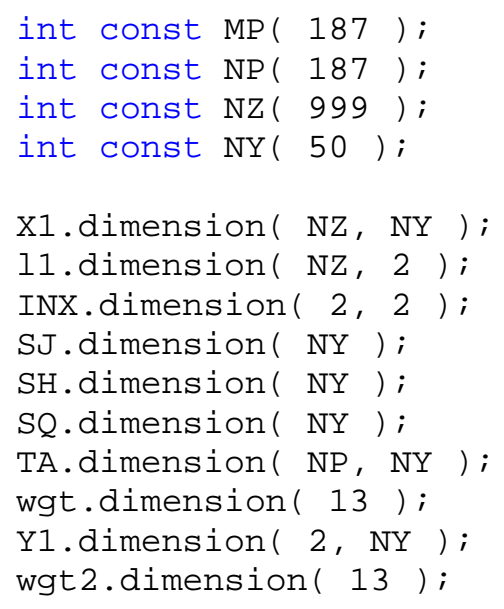


// Zero out results to be returned

SuJ $=0.0$;

SuH $=0.0 ;$

SUQ $=0.0 ;$

// Now calculate employment and hours with output, Q

TMP $=0.0$;

for ( int $1=1 ; 1<=M P ;++1)\{$

SuJ $+=Q(1,1){ }^{*} \mathrm{EI}(1,1)$;

$\mathrm{SuH}+=\mathrm{Q}(1,1){ }^{\star} \mathrm{EI}(1,2)$;

SuQ $+=Q(1,1)$;

for ( int $\mathrm{k}=1 ; \mathrm{k}<=12 ;++\mathrm{k})\{$

\}

\}

$\mathrm{TMP}+=\operatorname{DF}(1, \mathrm{k})$;

// SU"J,H.Q" are all base case numbers (jobs, earning, and output)

// Identify Fuel and water changes so each can be added to consumption

// Capital and 0\&M are added to investment

// Now process changes

// BIG LOOP: EACH YEAR FROM 2001 TO whenever

for ( int $\mathrm{m}=1 ; \mathrm{m}<=$ JYR; $++\mathrm{m}$ ) \{

ReadI02DArrayInput ( "W.csv", W, NP, NP );

ReadI02DArrayInput ( "U.csV", U, NP, NP));

ReadI02DArrayInput ( "GQ.csv", Q, NP, 2 );

ReadI02DArrayInput ( "DF.csv", DF, NP, 13);

ReadI02DArrayInput ( "EI.csv", EI, NP, EICols);

// Zero out vectors -- Final Demand changes from $\mathrm{x} 1$

// TFD is the sum of all of final demand

// sva is the sum of the value added changes

for ( int $i=1 ; i<=M P ;++i)\{$

$\mathrm{CV}(\mathrm{i})=0.0$;

$\mathrm{CW}(\mathrm{i})=0.0$;

$\operatorname{CK}(i)=0.0$;

\}

$C F(i)=0.0$;

$\mathrm{TFD}=0.0 ;$

$\mathrm{sva}=0.0 ;$

$\mathrm{OAM}=0.0 ;$

// Zero out then identify fuel, water, services, and capital changes

for ( int $i=1 ; i<=j 1 ;++i)\{$

int $k=11(i, 1)$;

int $1=11(i, 2)$;

$F L(i)=0.0$;

$\mathrm{KL}(\mathrm{i})=0.0$;

$W L(i)=0.0$;

$O M(i)=0.0$;

if $(\mathrm{k}==38|| \mathrm{k}==12|| \mathrm{k}==13$ \&\& $1==188)$

$\mathrm{FL}(\mathrm{i})=1.0$;

if $(k==14$ \&\& $l==188) W L(i)=1.0$;

if $(1==189) \mathrm{KL}(\mathrm{i})=1.0$;

\}

if $(1==190)$ OM(i) $=1.0$; 
// First construct ADJK, capacity adjustments for this period

// Capacity savings are negative, so change sign

$\operatorname{ADJK}=-1 \cdot 0 \mathrm{E} \odot *(\mathrm{Y} 1(1, \mathrm{~m})+\mathrm{Y} 1(2, \mathrm{~m}))$;

// Make the changes to the use matrix first, $\mathrm{J} 1=\mathrm{N}$.

// Aggregate all final demand changes into CV

// Partition CV into Fuel, Capital (and O\&M) and Water Changes (for

// future use). Value added total is also calculated as is total O\&M.

for ( int $1=1 ; 1<=j 1 ;++1)\{$

int $i=11(1,1)$;

int $j=11(1,2)$;

if $(j>=188 \& \& j<=190) \mathrm{CV}(i)+=\times 1(1, m)$;

if $(j==188) \operatorname{CF}(i)+=X 1(1, m)$ * $F L(1)$;

if $(\mathrm{j}==189) \mathrm{CK}(\mathrm{i})+=\mathrm{X} 1(1, \mathrm{~m})$ * $\mathrm{KL}(1)$;

if $(j==190) \operatorname{CK}(i)+=X 1(1, m)$ * OM $(1)$;

if $(\mathrm{j}==188) \mathrm{CW}(\mathrm{i})+=\mathrm{X} 1(1, \mathrm{~m})$ * WL $(1)$;

if $(\mathrm{j}==190) \mathrm{OAM}+=\mathrm{X} 1(1, \mathrm{~m})$ * OM(1);

if $(j<188) U(i, j)+=X 1(1, m)$;

\}

if $(j<188)$ sva $-=X 1(1, m)$;

// Zero out results to be returned

$\mathrm{SJ}(\mathrm{m})=0.0$;

$\mathrm{SH}(\mathrm{m})=0.0$;

$\mathrm{SQ}(\mathrm{m})=0.0$;

// Construct the $\mathrm{PH}$, the scrap matrix Inverse (I-Phat)

// and B, based on modified Use matrix, a vector with all ones,

// and the identity matrix, ai

TMP $=0.0$;

for ( int $1=1 ; 1<=M P ;++1)\{$

for ( int $\mathrm{k}=1 ; \mathrm{k}<=\mathrm{MP} ;++\mathrm{k}$ ) \{

$\operatorname{ai}(1, k)=0.0$;

if $(Q(1,1)==0.0) b(k, 1)=0.0$;

\}

if $(Q(1,1) !=0.0) b(k, l)=U(k, 1) / Q(1,1)$;

\}

$\operatorname{ai}(1,1)=1.0$;

// create $a=B^{*} W$ and subtract from ai

mmult ( $b, M P, M P, W, N P, a)$;

$\operatorname{madd}(\mathrm{ai}, \mathrm{MP}, \mathrm{MP}, \mathrm{a}, \mathrm{U}, \mathrm{false})$;

// Now invert I-BW

// perform decomposition

$\operatorname{ludcmp}(\mathrm{U}, \mathrm{MP}, \mathrm{MP}$, indx, z ) ;

// now invert by columns

for ( int $\mathrm{k}=1 ; \mathrm{k}<=\mathrm{MP} ;++\mathrm{k}$ ) \{

\}

lubksb(U, MP, MP, indx, ai $(1, k))$;

// Check ai

$/ /$ construct $t=W(I-B W)^{\wedge-1}$

mmult (W, MP, MP, ai, MP, t ) ;

// Now construct final demand vector $x(1)$

$\operatorname{DEMAND}(\mathrm{x}, \mathrm{CV}, \mathrm{CF}, \mathrm{CK}, \mathrm{CW}, \mathrm{DF}$, wgt, wgt2, ADJK, sva, OAM) ; 


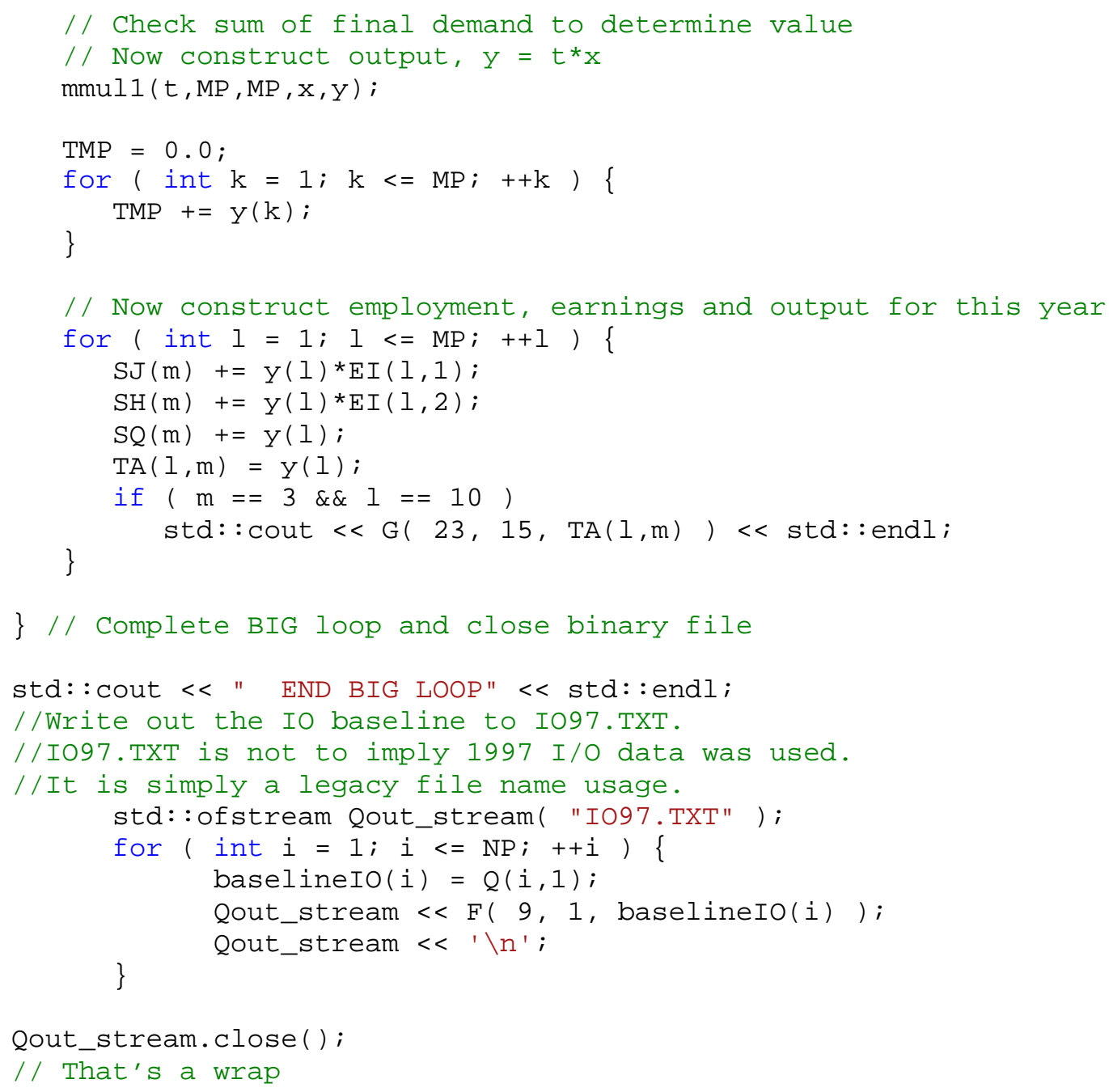

The resulting inverse (replacing ai) is then multiplied by the modified market share matrix, $\mathrm{W}$, to yield the total requirements matrix, labeled t. At this point, we are ready to create the final demand vector, so a call is made to the DEMAND function. This returns the final demand vector $\mathrm{x}$, which is then multiplied by the total requirements matrix, $t$, to yield the output vector, $y$. Output then is multiplied by each column of the intensity matrix to yield this year's jobs and earnings. This period's output is then just the sum of all of the industry outputs. When each of the JYRs of data has been processed, the big loop is complete and the results are returned to the main function.

\section{Changing Final Demands - DEMAND}

The call to this subroutine transfers the changes to final demand read in by the main function, contained in the vectors $\mathrm{CV}, \mathrm{CF}, \mathrm{CK}$, and $\mathrm{CW}$, and the array of final demands, DF, read in from the binary file. In addition, the weights to distribute the financing charges and the weights to allocate the capacity changes are transferred in the wgt and WGT2, along with the value of the capacity changes, contained in ADJK. Finally, all the value-added variables, a total and a variable for each of the fuel changes, and the total value of O\&M changes contained in OAM are transferred. The first set of 
statements below the initial comments zero out accumulator variables, aggregate the finance and capacity weights, and sum each of the components of final demand. The 13th column in this array is the total final demand vector, with the other columns corresponding to consumption, investment, exports, imports, various federal government investment and consumption and various state and local investment and consumption components. The next block of calculations zero out the vector of final demands to be returned and cumulates the changes to final demand partitioning these changes into capital and O\&M purchases, which affect investment, and fuel and water purchases, which affect consumption.

The capital and O\&M changes (all those changes to final demand except for changes to the fuel vectors) are added to the investment vector, just as the fuel savings are subtracted from the consumption vector. These investments need to be financed by "taxing" some component of final demand, after adjusting for O\&M expenses, which are not "financed". The strategy with this version of the model is to first determine how the different components of final demand are to be taxed; then adjust components of final demand for the tax, carrying along all changes to the twelve vectors that constitute the components of final demand. In the event that all the "tax" applies to the aggregated component (the $13^{\text {th }}$ column), then these weights for the various components are zero and no adjustment occurs to them. From a computational point of view, this simply means that the components are not modified when adjustments are made. Once the aggregation occurs, if a portion of the "tax" is to be applied to the aggregate component, then that is processed. A similar scheme is used if the "savings" achieved by a reduction in the building of energy capacity is distributed back to final demand or are simply applied to the aggregate final demand.

Accordingly, the first step is to adjust the consumption vector for the fuel savings and redistribute these savings back to other consumption. Similarly, adjustments to the investment vector are made according to the distribution of capital expenditures after adjusting for O\&M changes, then each of the vectors of final demand are "taxed" my multiplying the weight associated with this component of GDP (which in our example, is line 7) by the total capital expense and rescaling each component of GDP to reflect the cost of financing the investment. (Note, that if the investment costs are nil, then no scaling occurs, but the adjustment proceeds as if the weights were there.) Then if there are capacity adjustments to be made, these are subtracted from the applicable sector activity row of the final demand vector. The scalars provided by the user to make these adjustments are used to expand (or contract) the vector of final demand so it is scaled appropriately. Note also that if the capital costs are not financed, then the total of final demand will expand by that capital expense just as if the capacity savings are not redistributed to other sectors, then these savings are "lost" and the total of final demand is reduced.

Capital costs and capacity adjustments might not be fully added back in, depending on sum of the weights provided in wgt and WGT2.

Before final adjustments are made, the 12 components of final demand are aggregated to a single vector. Then the program branches to the concluding section that makes adjustments if there is a non-zero weight in component 13 of the two weighting vectors. The next step adjusts this aggregate vector for the changes either to the financing of capital expenditures or for the distribution of capacity savings changes. As with each component of final demand, we construct a scalar that integrates the financing proportion or the capacity adjustment used to scale the total final demand vector. The 13th weight in each case is used to construct a scalar, Z1, which is the total of final demand minus the 13th weight times the capital change divided by the total of final demand. In symbols, as in the code, z1=(ztot-WGT(13)*SCK)/ztot (note that this is one if WGT(13) is zero). The remaining task is the adjustment for changes in value- 
added if changes were made to the use matrix. (The continuation statement 45 shows the entry point from the section where final demand is treated as a single vector; recall that the same variable, SCV, was used to sum total final demand.) A scaling multiplier, z1, is constructed by adding the sum of value added, SVA, to SCV, then dividing by SCV. Z1 is then used to multiply each element of the final demand vector $\mathrm{x}$, which is then returned to QM3.

\section{DEMAND Function:}

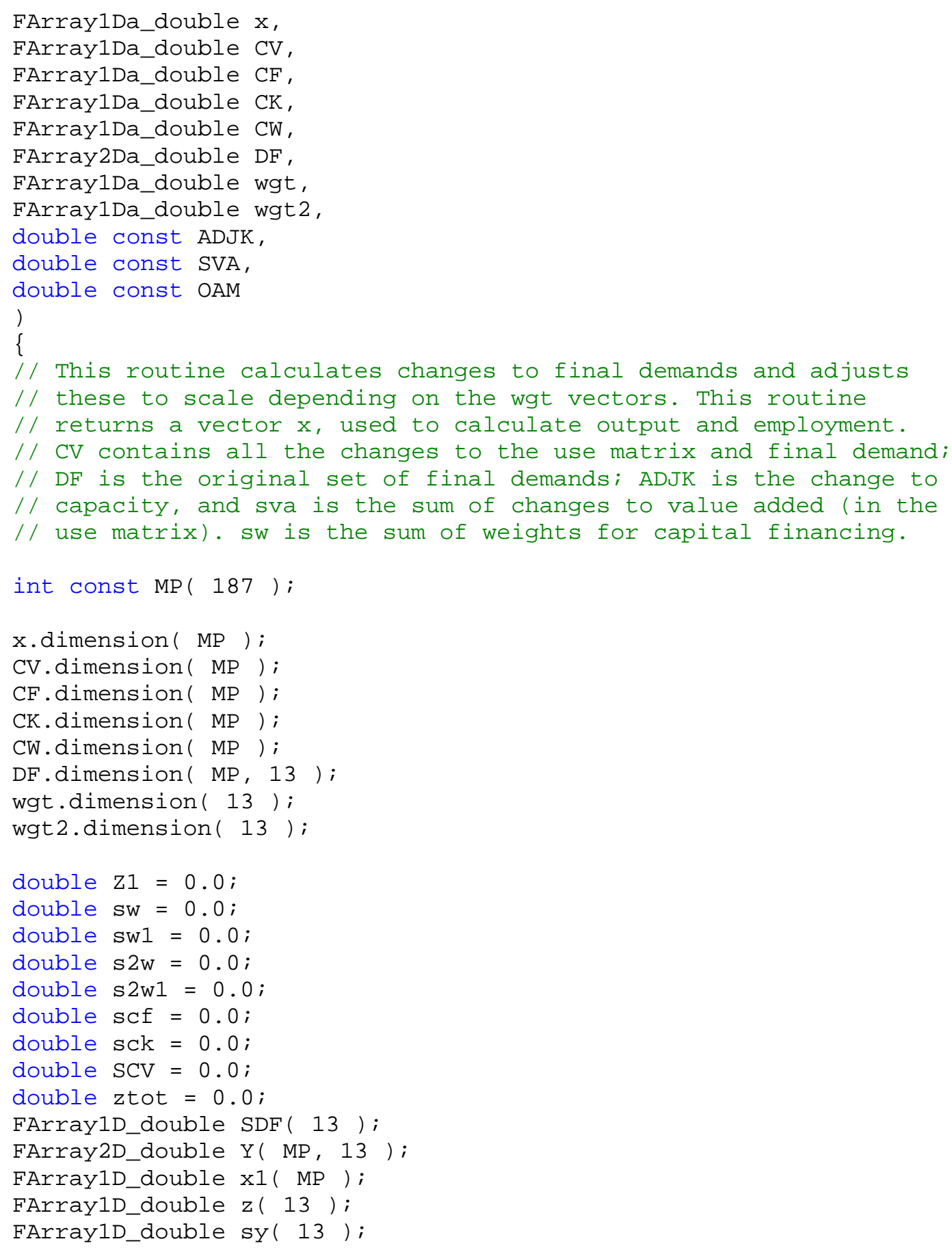




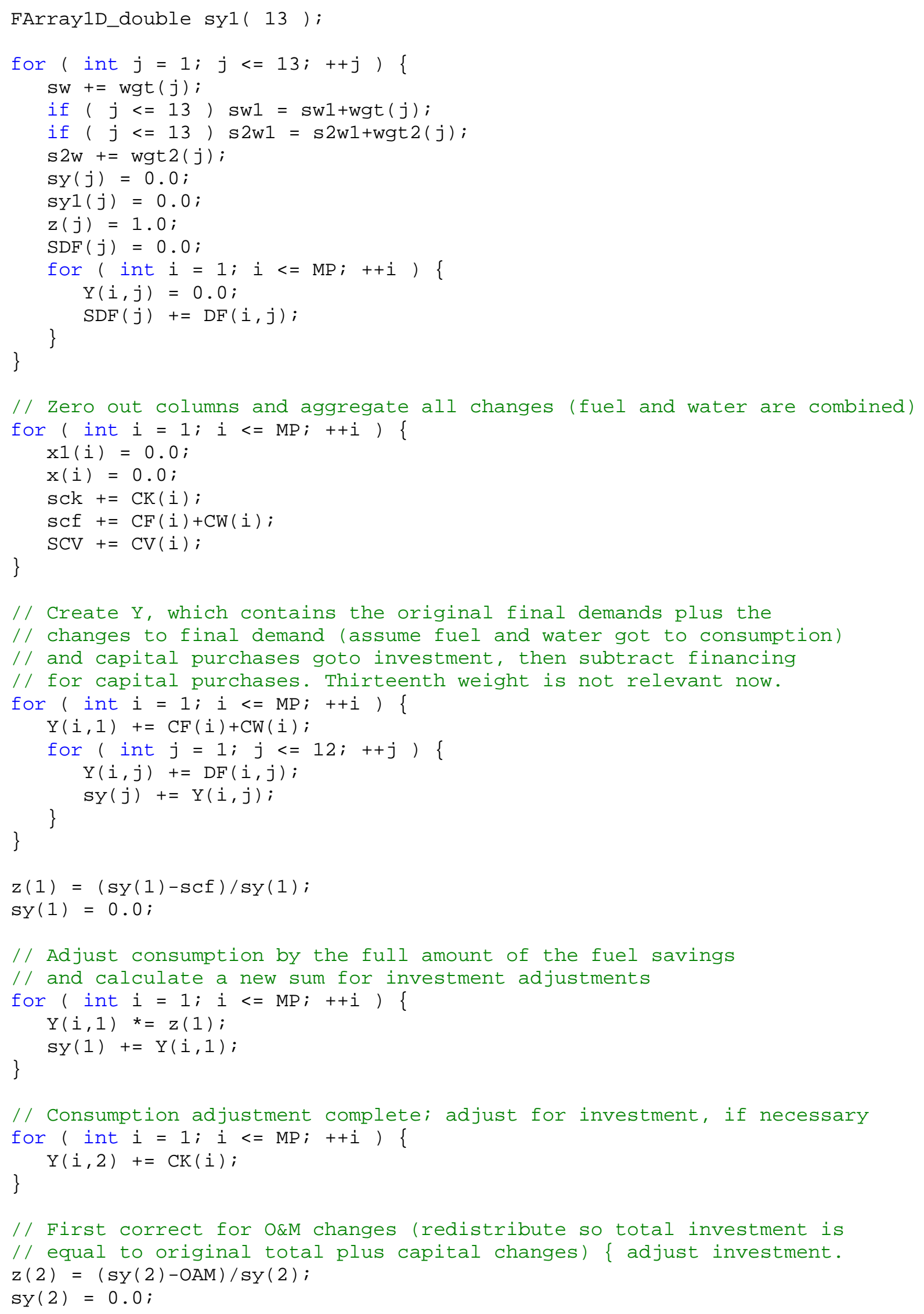




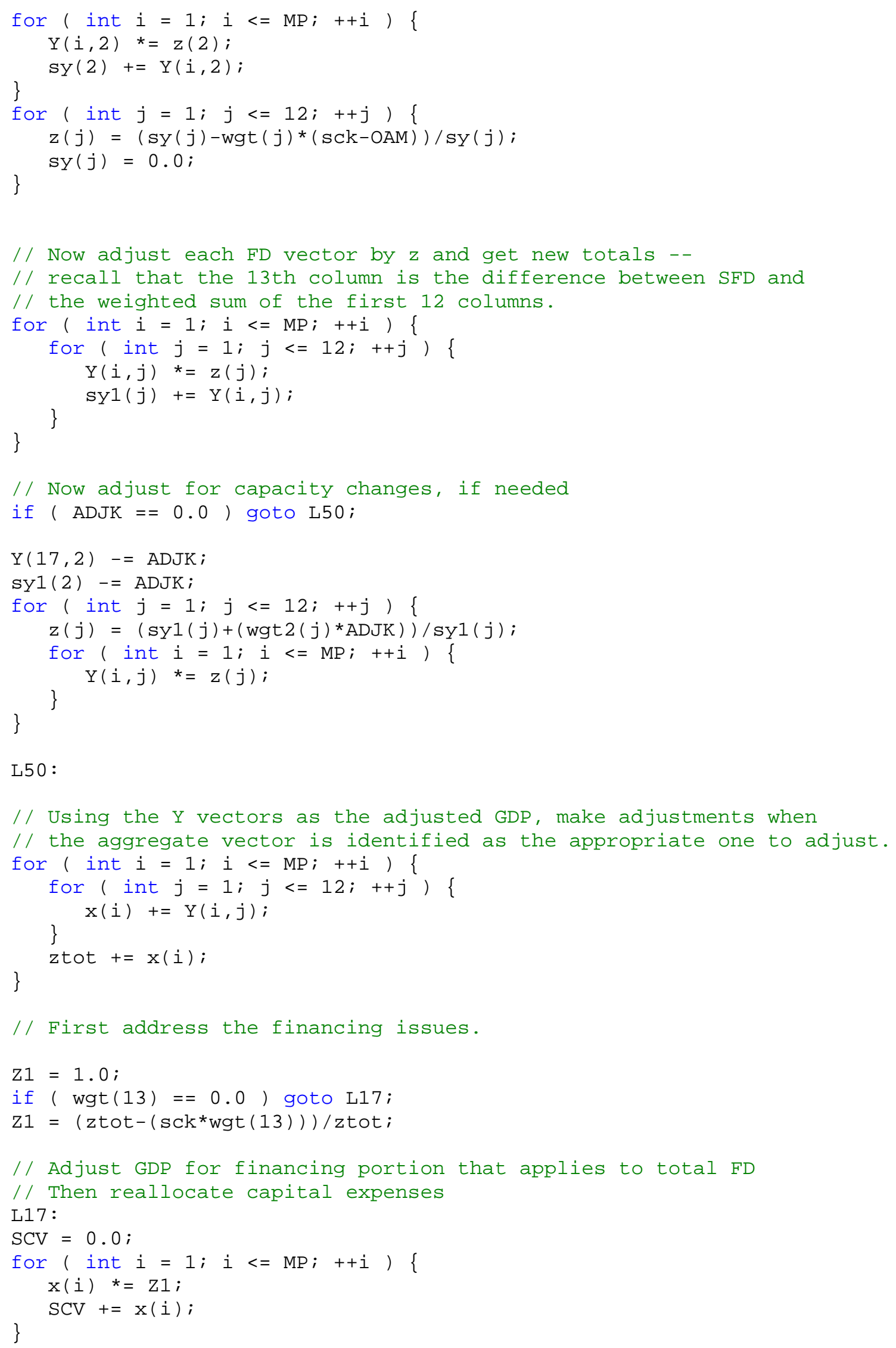




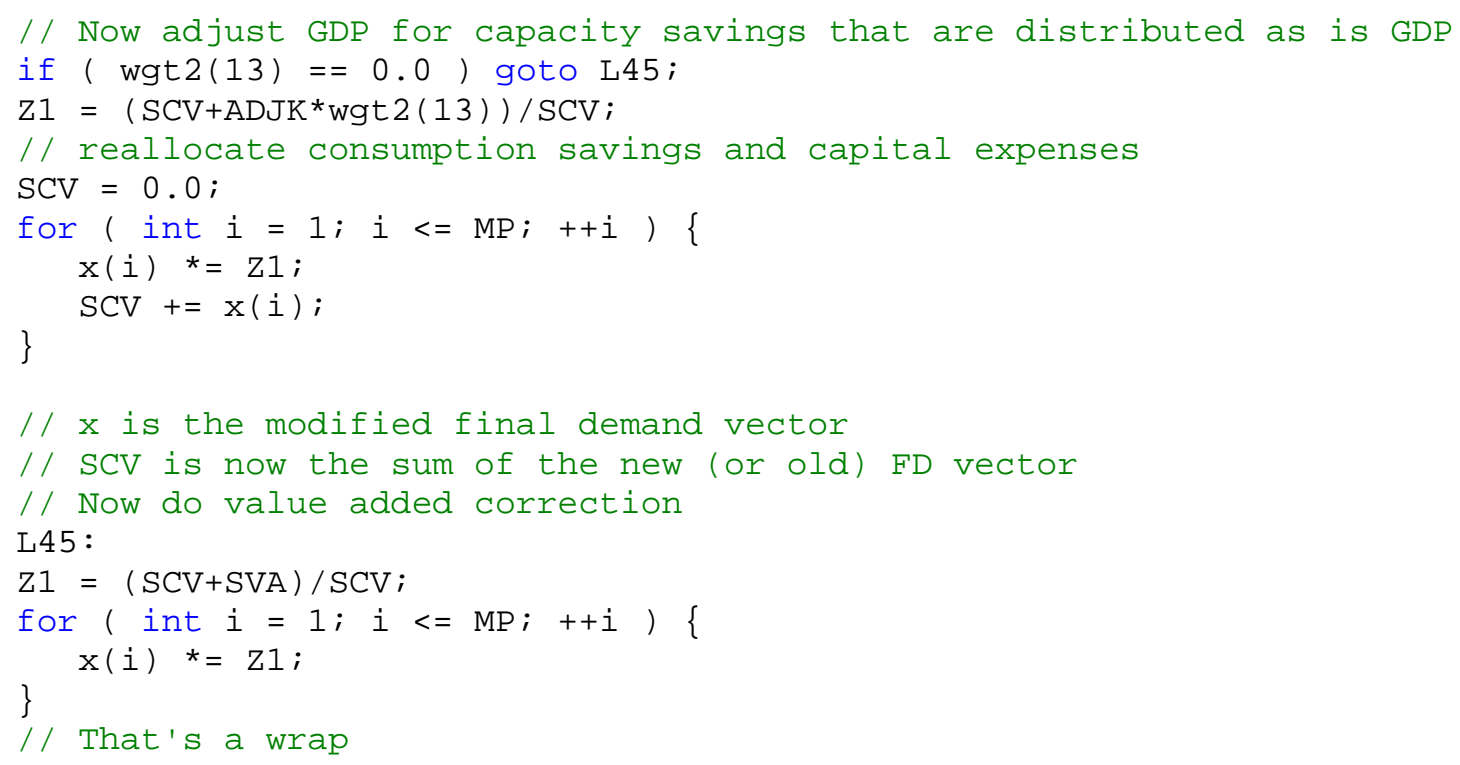

\section{C.3 The Output File}

The calculations from the ImSET Engine program generate a file called QM-CHG.DAT, which contains the results of the calculations, an example of which is shown in the text box below. This file is read back into the ImSET 3 user interface program to provide the data and graphics shown below in Figure C.1. The numbers graphed are the same as the right-hand column of outputs shown in the text box.

\section{Example of QM-CHG.DAT:}

Results for Experimental Data Set

Base Year Jobs (in Thousands) $=129174.2$

Base Year Earnings (in Millions) $=4678287.0$

Base Year Output (in Millions) $=14862876.2$

Year New-Base Jobs New-Base Earnings New-Base Output

$\begin{array}{llll}2001 & -0.972 & 34.854 & 244.522 \\ 2002 & -0.902 & 31.688 & 233.736 \\ 2003 & -0.997 & 34.494 & 265.278 \\ 2004 & -0.951 & 32.246 & 262.970 \\ 2005 & -0.855 & 28.264 & 248.447 \\ 2010 & -0.488 & 11.448 & 204.857 \\ 2015 & 1.191 & -51.792 & -188.537 \\ 2020 & 1.149 & -50.710 & -179.832 \\ 2025 & 1.200 & -52.761 & -194.602 \\ 2030 & 1.184 & -52.536 & -192.41\end{array}$


C. 16 


\section{Distribution}

No. of

Copies

9 U.S. Department of Energy

EERE-Office of Planning, Budget and

Analysis (EE-3B)

1000 Independence Avenue, S.W.

Washington, DC 20585

Darrell Beschen

David Boomsma

Pat Booher

Brian Card

Jeff Dowd

Phil Patterson

Peggy Podolak

Randy Steer

Brian Unruh

16 U.S. Department of Energy

EERE-Building Technologies

Program (EE-2J)

1000 Independence Avenue, S.W.

Washington, DC 20585

Scott Hine

Jerry Dion (5)

Jim Rannells

Ed Pollock

Tony Bouza

Michael McCabe (3)

Qonnie Laughlin

Richard Orrison

Jim Brodrick

Linda Silverman

5 Sam Baldwin

U..S. Department of Energy

EERE-Board of Directors (EE-11)

1000 Independence Avenue, S.W.

Washington, DC 20585

Mark Ginsberg

Senior Technical Advisor (Buildings

and Communities)

EERE-Board of Directors (EE-11)

U.S. Department of Energy

1000 Independence Avenue, S.W.

Washington, DC 20585
No. of

Copies

Jacques Beaudry-Losique

Acting DAS for Renewable Energy

EERE- Office of the Deputy Assistant

Secretary for Technology Development

(EE-20)

U.S. Department of Energy

1000 Independence Avenue, S.W.

Washington, DC 20585

Steve Chalk

Principal Deputy Assistant Secretary

EERE Office of Principal Deputy

Assistant Secretary (EE-10)

U.S. Department of Energy

1000 Independence Avenue, S.W.

Washington, DC 20585

David Rodgers

Director, Strategic Planning \& Analysis

EERE Office of Principal Deputy

Assistant Secretary (EE-10)

U.S. Department of Energy

EERE-Building Technologies

Program (EE-2J)

1000 Independence Avenue, S.W.

Washington, DC 20585

3 Ed Barbour (3)

Navigant Consulting

1801 K Street, NW

Suite 500

Washington, D.C. 20006

M.D. Levine

Ernest Orlando Lawrence Berkeley

National Laboratory

1 Cyclotron Road, 90-R3027D

Berkeley, CA 94720 


\section{Distribution}

No. of

Copies

T. Chan

Ernest Orlando Lawrence Berkeley

National Laboratory

1 Cyclotron Road, 90-R4000

Berkeley, CA 94720

L.L. Dale

Ernest Orlando Lawrence Berkeley

National Laboratory

1 Cyclotron Road, 90-R4000

Berkeley, CA 94720

W. Short

National Renewable Energy Laboratory

617 Cole Boulevard, Mail Stop 2721

Golden, CO 80401-3393

Harvey Sachs

American Council for an Energy-

Efficient Economy

1001 Connecticut Avenue, N.W.,

Suite 801

Washington, DC 20036

Jeff Harris

Alliance to Save Energy

$120018^{\text {th }}$ Street, N.W.

Suite 900

Washington, DC 20036

John "Skip" Laitner

Alliance to Save Energy

$120018^{\text {th }}$ Street, N.W.

Suite 900

Washington, DC 20036

William Haslebacher

National Energy Technology Laboratory

3610 Collins Ferry Road

P.O. Box 880

Morgantown, WV 26507-0880
No. of

Copies

Local Distribution

2 DOE Pacific Northwest Site Office

W. F. Edwards K9-42

38 Pacific Northwest National Laboratory

D. M. Anderson K6-05

P. J. Balducci Portland/1/OS

R. Bartlett K6-05

D. B. Belzer K6-05

K. A. Cort K6-05

J. A. Dirks K6-10

D. B. Elliott Portland/1/OS

D. J. Hostick K6-05

B. R. Kinzey BWO

O. V. Livingston K6-05

S. C. McDonald (10) BWO

A. K. Nicholls (5) BWO

L. A. Stevenson Offsite/MA/OS

J. M. Roop K6-05

T. J. Samuel K6-05

L. J. Sandahl Portland/1/OS

E.G. Baker K2-20

M. J. Scott (5) K6-05

S. A. Shankle K9-01

R.W. Schultz K6-10

T. M. Weber K6-05 


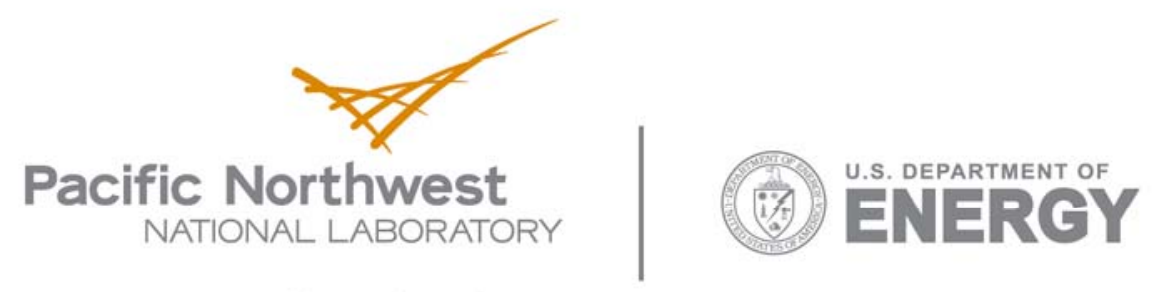

902 Battelle Boulevard

P.O. Box 999

Richland, WA 99352

1-888-375-PNNL (7665)

www.pnl.gov 